Review

\title{
Strategies and progress in synthetic textile fiber biodegradability
}

\author{
Jeannie $\operatorname{Egan}^{1}$ (1) $\cdot$ Sonja Salmon ${ }^{1}$ (])
}

Received: 4 August 2021 / Accepted: 27 October 2021

Published online: 18 December 2021

(c) The Author(s) $2021 \quad$ OPEN

\begin{abstract}
The serious issue of textile waste accumulation has raised attention on biodegradability as a possible route to support sustainable consumption of textile fibers. However, synthetic textile fibers that dominate the market, especially poly(ethylene terephthalate) (PET), resist biological degradation, creating environmental and waste management challenges. Because pure natural fibers, like cotton, both perform well for consumer textiles and generally meet certain standardized biodegradability criteria, inspiration from the mechanisms involved in natural biodegradability are leading to new discoveries and developments in biologically accelerated textile waste remediation for both natural and synthetic fibers. The objective of this review is to present a multidisciplinary perspective on the essential bio-chemo-physical requirements for textile materials to undergo biodegradation, taking into consideration the impact of environmental or waste management process conditions on biodegradability outcomes. Strategies and recent progress in enhancing synthetic textile fiber biodegradability are reviewed, with emphasis on performance and biodegradability behavior of poly(lactic acid) (PLA) as an alternative biobased, biodegradable apparel textile fiber, and on biological strategies for addressing PET waste, including industrial enzymatic hydrolysis to generate recyclable monomers. Notably, while pure PET fibers do not biodegrade within the timeline of any standardized conditions, recent developments with process intensification and engineered enzymes show that higher enzymatic recycling efficiency for PET polymer has been achieved compared to cellulosic materials. Furthermore, combined with alternative waste management practices, such as composting, anaerobic digestion and biocatalyzed industrial reprocessing, the development of synthetic/natural fiber blends and other strategies are creating opportunities for new biodegradable and recyclable textile fibers.
\end{abstract}

\section{Article Highlights}

- Poly(lactic acid) (PLA) leads other synthetic textile fibers in meeting both performance and biodegradation criteria.

- Recent research with poly(ethylene terephthalate) (PET) polymer shows potential for efficient enzyme catalyzed industrial recycling.
- Synthetic/natural fiber blends and other strategies could open opportunities for new biodegradable and recyclable textile fibers.

Keywords Biodegradable $\cdot$ Enzyme Polymer $\cdot$ Textile $\cdot$ Sustainable $\cdot$ Waste

Supplementary Information The online version contains supplementary material available at https://doi.org/10.1007/s42452-02104851-7.

Sonja Salmon, sisalmon@ncsu.edu | 'Department of Textile Engineering, Chemistry and Science, Wilson College of Textiles, North Carolina State University, Raleigh, NC 27606, USA.

SN Applied Sciences $\quad$ (2022) 4:22 $\quad$ |https://doi.org/10.1007/s42452-021-04851-7 


\section{Abbreviations}

a-AA

AdA

AATCC

AD

Ala

ASTM

BDO

BHET

BS

BTA

BTAB

CellOAc

CellOH

4CHMS

5CHMS 5-Carboxy-2-hydrocymuconate-6-

CM

CMF

DCD

DS

DSC

EC

EG

FDCA

GA

GC

$\mathrm{GL}$

GLA

Glc

GlcAc

$\Delta \mathrm{H}_{\text {melt }}$

$\mathrm{HiC}$

HMDA

HOAC

HT polyester

ISO

IsP

$k_{\text {cat }}$

LA

LCC

LDPE

MCF

MHET

MSW

PA

PAN semialdehyde

Alpha amino acid

Adipic acid

American Association of Textile Chemists and Colorists

Anaerobic Digestion

Alanine

American Society for Testing and

Materials

Butanediol

Bis-(2-hydroxyethyl) terephthalate

British Standard

1,4-Hydroxybutylene terephthalate

Bis-1,4-butylene

adipate-co-terephthalate

Cellulose acetate

Cellulose

4-Carboxy-2-hydroxymuconate

semialdehyde

3-Carboxy-cis,cis-muconate

5-(Chloromethyl)furfural

1,6-Dihydroxycyclohexa-2,4-diene-

dicarboxylate

Degree of substitution

Differential Scanning Calorimetry

Enzyme Commission

Ethylene glycol

Furandicarboxylic acid

Glycoaldehyde

Glycolate

Glycerate

Glyoxylate

Glucose

Glucose acetate

Enthalpy of fusion

Humicola insolens Cutinase

Hexamethylenediamine

Acetic acid

High tenacity polyester

International Organization for

Standardization

Ideonella sakaiensis PETase

Initial catalytic rate

Lactic acid

Leaf-branch compost cutinase

Low density poly(ethylene)

Mass conversion factor

Mono(2-hydroxyethyl) terephthalic acid

Polyamide

Poly(acrylonitrile)
Municipal Solid Waste
PBAT Poly(butylene adipate terephthalate)

PBS Poly(butylene succinate)

PBST Poly(butylene

succinate-co-terephthalate)

PBT Poly(butylene terephthalate)

PCA Protocatechuate

PCL Poly(caprolactone)

PCNR Product Compounds Not Reported

PDLA Poly(D-lactic acid)

PDLLA Poly(DL-lactic acid)

PEF Poly(ethylene furanoate)

PETase PET hydrolase

PET/PETE Poly(ethylene terephthalate)

3PG 3-Phosphoglycerate

PHA Poly(hydroxyalkanoate)

PHB Poly(hydroxybutyrate)

PHBH Poly(3-hydroxybutyrate-co-3-

hydroxyhexanoate)

P3HB4HB Poly(3-hydroxybutyrate-co-4-

hydroxybutyrate)

PHBV Poly(3-hydroxybutyrate-co-3-

hydroxyvalerate)

PLA Poly(lactic acid), polylactide

PLLA Poly(L-lactic acid)

PP Poly(propylene)

PS Poly(styrene)

PTT Poly(trimethylene terephthalate)

SA 1,4-Succinic acid

SEM Scanning Electron Microscope

Ser Serine

TA Terephthalic acid

TfCut2 Thermobifida fusca Cutinase 2

$\mathrm{T}_{\mathrm{g}} \quad$ Glass transition temperature

$T_{m}$

TS
Melting transition temperature

Tartronate semialdehyde

\section{Introduction}

Although precise global figures are not available due to incomplete reporting, within the approximately 2 billion tons of global municipal solid waste (MSW) generated annually [1], textile waste has been estimated at between 65 to 92 million tons [2, 3] (Fig. 1). Based on population and per capita disposal, Bukhari et al. reported a combined 34.6 million tons of landfilled textile waste was disposed in 2016 by the United States, China, Hong Kong, the EU-27, France and the United Kingdom [4]. At a country level, the U.S. Environmental Protection Agency reported 11 million tons of textile waste were disposed of in USA landfills in $2018[5,6]$. The average service lifetime of textile products has been estimated to be about five years [7], and another estimate predicts that a business-as-usual approach will 
Global Fiber Production (2019)

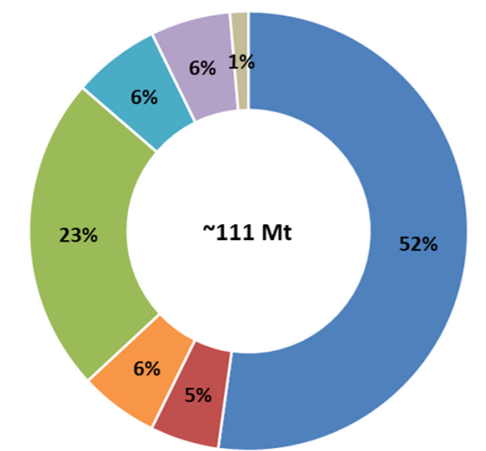

- Polyester

ather Synthetics

- Manmade Cellulosics

Wool, Silk \& Down

Polyamide
Global MSW Disposal

(data across 2000-2017)

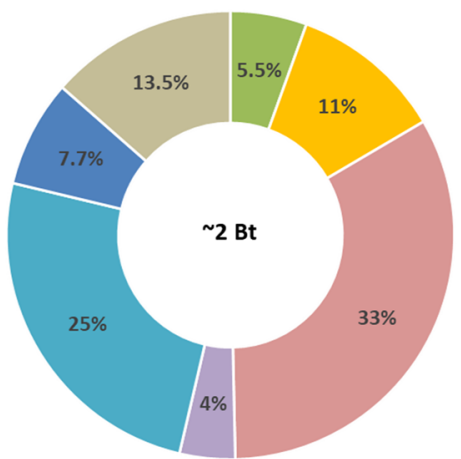

Composting

Open Dump

- Other Plant Fibers

- Landfill (unspecified)
- Incineration

- Controlled Landfil

- Sanitary Landfill
Global MSW Composition

(data across 2000-2017)

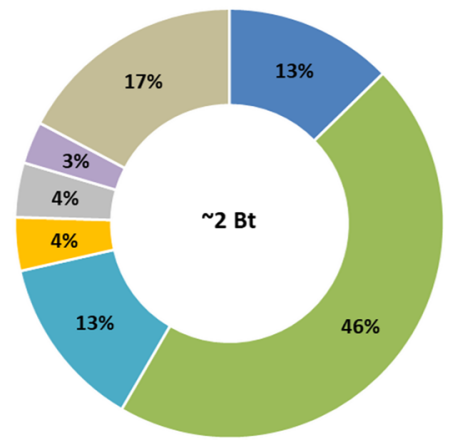

- Paper and Paperboard $\square$ Organic Material

- Plastics $=$ Glass

Metals $\quad$ Textiles

Other Inorganic

Fig. 1 Global fiber production [24] relative to global municipal solid waste (MSW) disposal methods [1] and the portion of textile waste contributing to global MSW composition [2]

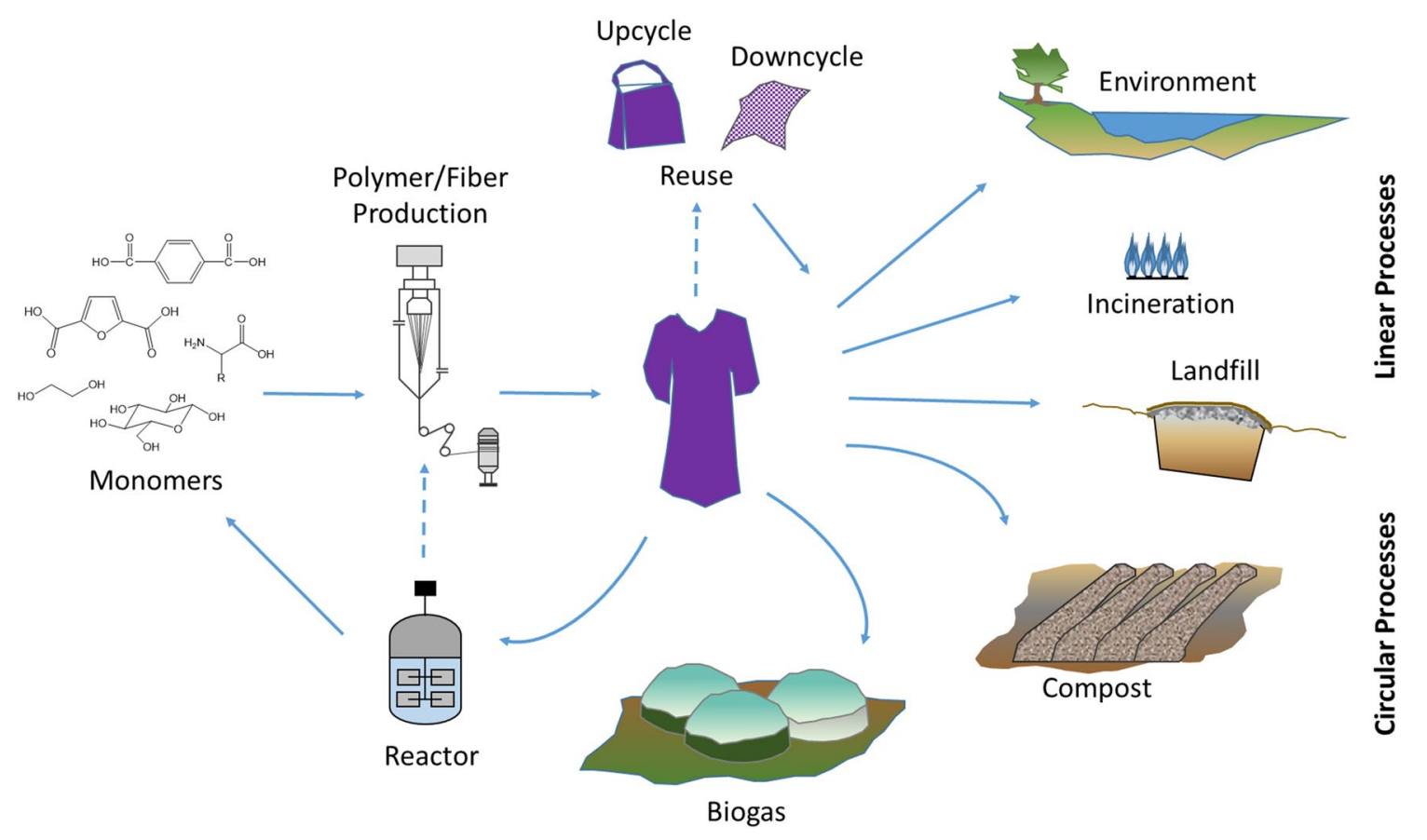

Fig. 2 Textile disposal by linear and circular processes

result in accumulation of more than $4.5 \mathrm{Gt}$ of textile waste by 2040 [8]. Therefore, strategies are needed to address this serious waste issue, reduce environmental impacts, and improve textile waste handling, while also transforming the industry from a linear to a circular economy (Fig. 2). Biodegradability attributes can help accelerate the transformation by diverting waste from landfills to existing alternatives, like composting and anaerobic digestion, or to new biocatalytically enhanced recycling processes.

In concept, biodegradation is simple-large or complex materials are biologically converted into smaller, simpler, ideally non-toxic compounds that can be recycled in the biosphere, ideally without human intervention. However, the mechanisms involved in biological degradation 
are technically complex and the conditions under which biodegradation occurs in large scale waste management environments, such as landfills, compost and anaerobic digestion, generally do not match those found in purely natural environments, such as soil and seawater. Therefore, the context in which the term "biodegradable" is used should always be specified. The term "biobased" is frequently found together with "biodegradable", but they have distinctly different meanings. Biobased materials are naturally occurring organic compounds of biological origin or are materials fully or partially derived from biologically renewable natural resources $[9,10]$. While biobased materials provided the foundation for technological developments throughout human history, the development of high performance products from petrochemicals displaced many of these materials [11]. Now, sustainability concerns are driving renewed attention on utilizing biobased materials [10,12-14], such as for the development of "bioplastic" alternatives to petrochemical plastics [15-19]. Importantly, the term "biobased" refers to the origin of a material, whereas "biodegradable" describes the response of a material to certain conditions. Absent evidence, no assumption about biodegradability should be made simply because a material is biobased, and proper disposal of biobased materials should consider broader impacts, such as potential for release of toxic catalysts that may be used in bioplastic production $[20,21]$. Nevertheless, a common chemical characteristic of biobased materials is their overall higher ratio of oxygen and nitrogen to carbon, which generally increases their chemical reactivity and hydrophilicity relative to the primarily hydrocarbon composition of petrochemical derived compounds [8]. Increased chemical reactivity and hydrophilicity contribute to increased potential for biodegradability. Conversely, high levels of crystallinity, orientation and intermolecular bonding, which are commonly found in textile fibers, cause resistance to biodegradation.

Fundamentally, textiles are composed of fibers made up of synthetic and naturally occurring polymers. Historically, textile fibers came from plants and animals. Natural fibers are renewable by virtue of their biological origins and exhibit biodegradability in their natural forms $[22,23]$ because microorganisms are evolutionarily adapted to breaking biologically-created chemical bonds and modifying the chemistry of these polymers. Now, synthetic fibers, primarily of petrochemical origin, dominate (around 64\% by volume) the global textile fiber market which produces 111 million metric tons of fiber annually [24]. The two main textile fiber types, polyester (poly(ethylene terephthalate) (PET), 52\%) and cellulosic fibers (35\%), including cotton
(23\%), manmade cellulosics (6\%) and other plant based fibers (6\%), make up the majority of fiber production [24] and ultimately textile waste. Because of their relatively hydrophobic and highly crystalline properties, most synthetic fibers, i.e. fibers produced from polymers made by industrial chemical synthesis, resist environmental degradation, which contributes to overall plastic waste accumulation [7]. This includes microfibers (fibers $<1-5 \mathrm{~mm}$ long $[25,26]$ ) that are released during laundering and reach the environment through wastewater effluents [25, 27-30]. Continuing trends in fast-fashion, fueled by growing global consumerism, wealth and population [31,32], together with the evolution of waste disposal practices from open dump to sanitary landfill [33], mean the management of post-consumer textile waste is becoming more difficult and costly $[34,35]$. Understanding textile fiber biodegradability has renewed importance as brands and producers, responding to consumer concerns about accumulating textile waste, seek to meet performance and cost requirements while improving apparel product sustainability.

In response to these challenges, three textile fiber biodegradation strategies are evolving to improve textile sustainability. One strategy is to develop textiles that can degrade efficiently in controlled microbial environments, like composting or anaerobic digestion, as alternatives to open dumping or landfilling. This strategy is supported by existing infrastructure and test methods that could be adapted to accommodate new waste streams. Another strategy is to develop biologically-based circular manufacturing technologies that depolymerize textile fibers back to their component monomers for recycling, using microorganisms, enzymes or combinations, together with process intensifications like heating and grinding. These industrial process strategies rely on controllable environments to achieve specific outcomes. The third strategy considers how to minimize the consequences of releasing textile wastes into the natural environment. Since the natural environment is essentially an uncontrollable space, if released into the environment, intentionally or unintentionally, the material itself should be capable of degrading without causing immediate or accumulated ecological damage [36]. In the following discussions, factors contributing to textile fiber biodegradation in different environments are considered and biodegradation behaviors of synthetic textile fibers compared to natural textile fibers are reviewed. Recent research leading to improvements in poly(lactic acid) (PLA) fiber as an alternative biobased synthetic textile and improvements in enzymatic PET hydrolysis is highlighted, along with suggestions for future work to advance textile sustainability. 
Fig. 3 Cascade of transformations involved in deconstruction and degradation

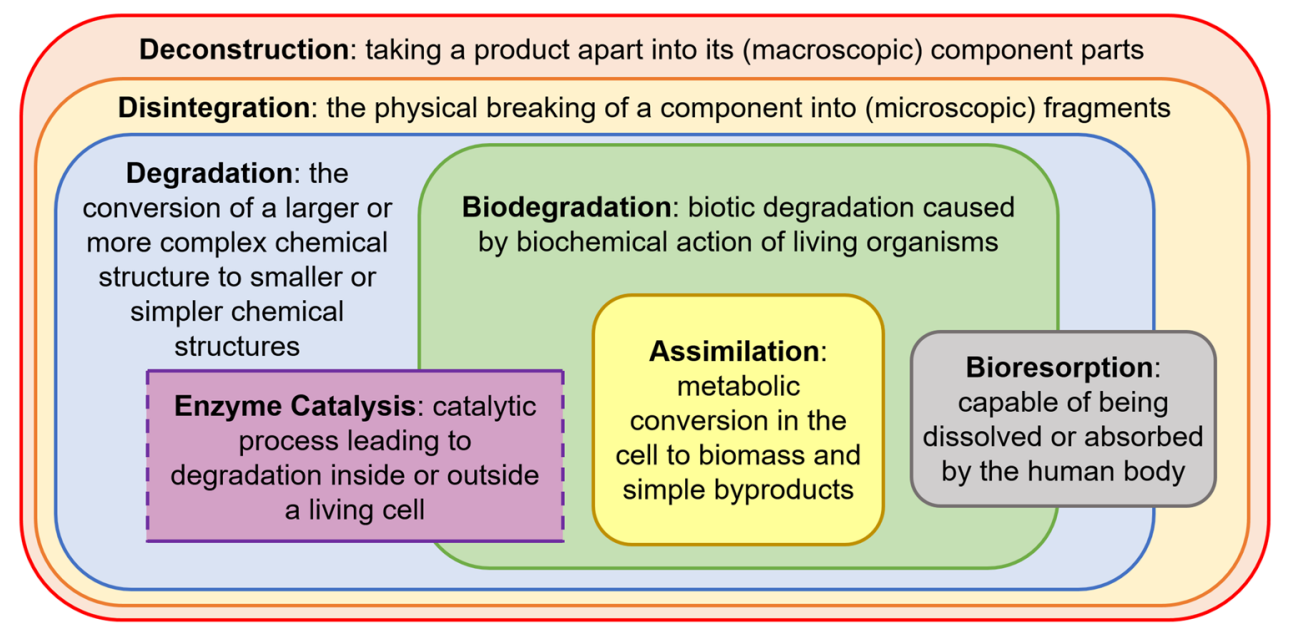

\section{Biodegradability cascade}

Biodegradation, or biological degradation, is the chemical conversion of large or complex molecules to smaller or simpler molecules caused by the biochemical action of living organisms, typically, microorganisms. Biodegradation is part of a cascade of physical and chemical phenomena by which a material is broken down into small parts and eventually converted to substances that either are reused in biological cycles or accumulate on the planet. The different transformations occurring during deconstruction and degradation and how they relate to one another are summarized in Fig. 3. These phenomena, which can occur sequentially or simultaneously, are important for polymer biodegradation [37]. Textile products, especially apparel products, have a high level of structural complexity-polymers assemble into semicrystalline substructures which form fibers that are tightly twisted into yarns, often in blends of different fiber types; yarns are interlaced to form fabrics; fabrics are sewn to make garments; and, dyes and other chemical finishes are applied throughout the processes to achieve various performance effects. Because of this, at a given set of conditions, a particular product could be completely biodegradable, partially biodegradable, or not biodegradable at all. When the conditions change, the behavior may change. Therefore, discussing product biodegradability as an attribute depends on the extent to which product disassembly and separation into its component parts is required prior to or during disposal, and depends on the treatment conditions. Furthermore, avoiding waste accumulation requires complete biological metabolic assimilation, complete recovery and recycling of deconstructed, disintegrated or degraded components by biological or other means, or combinations of these.

\subsection{Physical deconstruction}

Deconstruction is the physical disassembly of a product into its different (usually) macroscopic component parts. Within textile mechanical recycling, examples of apparel deconstruction are removing the buttons from a shirt or cutting open the seams of a garment, and further involves the disassembly of intimately mingled textile materials by mechanically pulling apart fabrics or yarns into individual fibers [38]. Disintegration occurs when material components are sufficiently reduced in physical size that they can no longer perform their original function, such as occurs when an applied mechanical force is sufficient to cut or break fibers (e.g. cotton) [39] into fragments that are too short $(<10 \mathrm{~mm})$ for spinning new yarn [40] but may be suitable for other purposes [41]. In contrast, during biodegradation, fiber disintegration results from the biochemical action of microorganisms $[42,43]$ rather than by mechanical force. Closed-loop recycling of apparel textiles is especially difficult to achieve by only mechanical means because of the difficulty in separating intimate fiber blend mixtures into pure component streams at the individual fiber level [44]. Melting and solubilization are other types of physical deconstruction that, by converting polymer molecules from solids to flowing liquids, are important, respectively, for producing recycled polyester fibers from bottles $[45,46]$ and producing manufactured cellulosics from wood pulp [47] or waste cotton $[48,49]$.

\subsection{Chemical degradation}

In contrast to physical deconstruction, chemical degradation is the conversion of larger or more complex chemical molecules to smaller or simpler molecules through 
the breaking of chemical bonds. Chemical degradation broadly includes thermal degradation like burning a fabric, which is a chemical oxidation process [50]; radiationinduced degradation, such as molecular bond cleavage caused by ultraviolet light [51]; and chemically reactive degradation like the hydrolysis of peptide bonds in wool [52]. Biodegradation occurs when the chemical changes to a molecule are caused by the action of living cells. Assimilation is the metabolic consequence of biodegradation, where the atoms of degraded molecules become part of living cells through biochemical cascade reactions or are excreted from cells as simple byproducts, such as carbon dioxide and water [53]. Bioresorption is a term primarily used to describe the disappearance of materials implanted in the human body, like sutures and stents. Bioresorbable materials are sometimes described as "biodegradable" even though bioresorption can be a physical (solubilization) as well as a (bio)chemical phenomenon [54]. While certain bioresorbable materials have characteristics that are useful for apparel textile applications, those suited exclusively for biomedical applications are beyond the scope of this discussion and further information can be found in reviews of the topic [55-58], including mathematical approaches to modeling polymer degradation phenomena [59].

\subsection{Enzyme catalysis}

Enzymes are protein-based molecules produced by living cells that catalyze chemical conversion reactions, hence are called "biocatalysts." Enzymes operate inside as well as outside living cells, such as when cells 'secrete' enzymes into their surrounding environment to degrade substances needed by the organism as food. Small molecules are easier for organisms to ingest. Therefore, enzyme catalysis is a central mechanism by which biodegradation occurs. Because enzymes can be isolated, produced at large scale, and used in consumer products or for industrial applications [60], enzymes are the biocatalytic bridge between chemical degradation and biodegradation. Within textile applications, enzymes have been used to clean and improve cotton properties during fabric and garment production, for cleaning and softening silk and wool, and for surface modification of synthetic fibers [61-63], and have been used in laundry detergents to clean and preserve garment appearance, while reducing chemical, water and energy requirements $[64,65]$. Now, as discussed below, enzymes are becoming useful biological tools for improved textile waste management.

\subsection{Biodegradation pathways}

There are two main pathways of biodegradation, aerobic and anaerobic (Fig. 4). Aerobic biodegradation requires oxygen (i.e. exposure to air) and ultimately yields carbon dioxide $\left(\mathrm{CO}_{2}\right)$, water, biomass, and oxidation products of nitrogen and sulfur. Anaerobic biodegradation occurs in an oxygen deficient environment and ultimately yields hydrocarbons, methane, carbon dioxide, biomass, and reduction products of nitrogen and sulfur $[66,67]$. Anaerobic digestion occurs in symbiotic stages requiring three types of microorganisms: 1) fermentative bacteria hydrolyze polymers to oligomers and monomers and convert these to fatty acids, alcohols, acetate, $\mathrm{CO}_{2}$ and hydrogen; 2) acetogenic bacteria convert low molecular weight compounds to acetic acid, $\mathrm{CO}_{2}$ and hydrogen; and, 3) methanogenic bacteria convert acetic acid to methane and $\mathrm{CO}_{2}$,

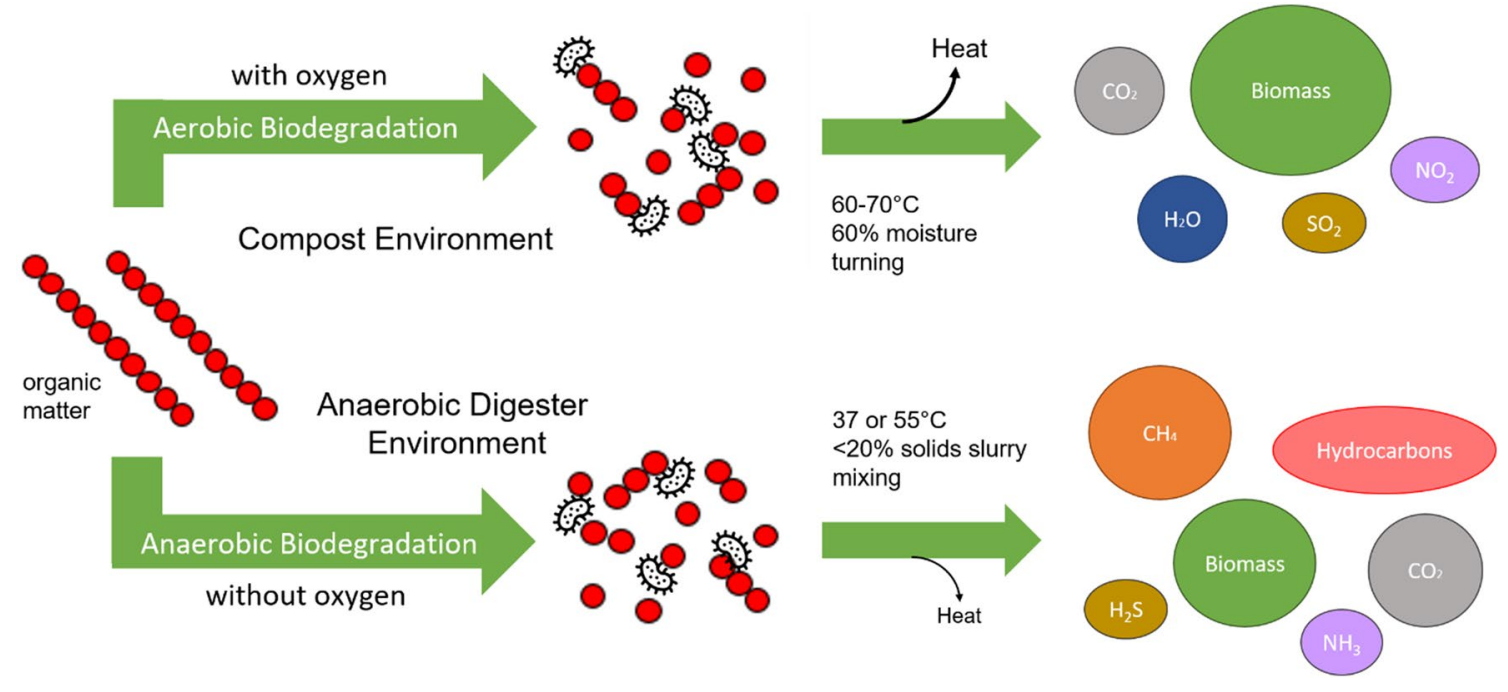

Fig. 4 Schematic aerobic versus anaerobic pathways for degradation of organic polymers $[66,67]$ 
Fig. 5 Different biodegradation scenarios

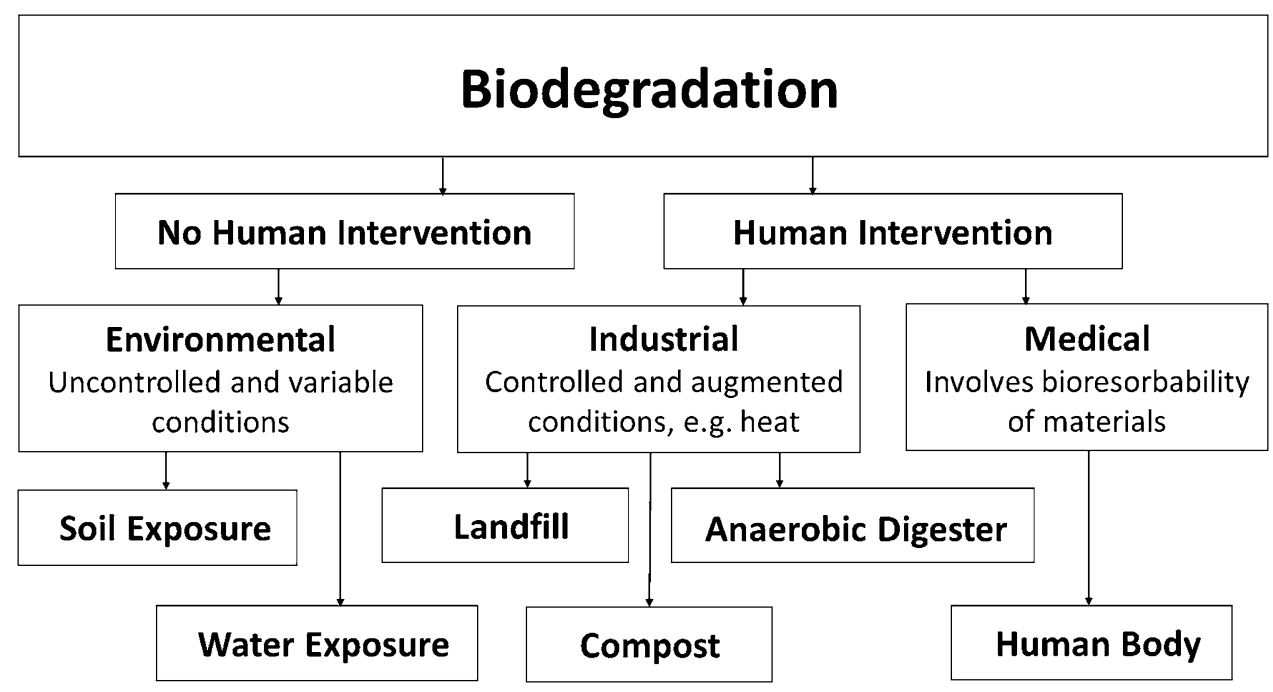

as well as use hydrogen to reduce some $\mathrm{CO}_{2}$ to methane [68]. Sulfate and nitrate reducing bacteria are also present. While non-contained anaerobic biodegradation can result in the uncontrolled release of methane (a potent greenhouse gas) $[6,69]$, properly controlled anaerobic digestion can recover methane as a useful biofuel to replace fossil-based natural gas [70]. Both aerobic and anaerobic environments require moisture. When textile materials are the source of organic matter, extracellular degradation of polymers into lower molecular weight compounds is the first critical step in both pathways.

Biodegradation occurs in response to conditions that can involve human intervention or require no intervention (Fig. 5). Environmental biodegradation refers to biotic degradation that occurs without human intervention or any control of environmental conditions. When these conditions are inadequate, waste accumulation occurs. Industrial (commercial) biodegradation involves human intervention and control of conditions like temperature, moisture, $\mathrm{pH}$, nutrients, oxygen level, presence of organisms, and composition of the waste. Medical biodegradation is concerned with the physiological bioresorbability of materials and their impact on human health rather than whether the degraded components are ultimately released into the environment.

\section{Measuring biodegradability}

Measuring biodegradability requires standard methods. Methods provide the basis for meeting regulatory requirements, for making labeling claims, and to support waste management logistics and control. No claim of biodegradability should be made without supporting evidence based on standardized testing, and must be limited to the scope of the test method. Standardized test methods simulate the conditions at which biodegradation is expected to occur. The methods have evolved over time, however, the development of test methods across all product segments is not yet mature. Notably, to date, biodegradability test methods specifically intended for textiles were developed to quantify degradation resistance rather than enhancement. For example, both British Standard BS EN 14,119:2003 and the withdrawn AATCC 30 methods measure resistance to rot, mildew, and microbiological deterioration. Therefore, with respect to waste management, test methods used to measure desired biodegradation of textile materials are currently borrowed from those intended for plastics (Table 1). The methods established for plastics $[19,71]$ are in response to regulatory requirements that do not specifically encompass textile materials. Nevertheless, these methods are used to characterize textile material biodegradability.

\subsection{Respirometric methods}

Respirometric methods are preferred for quantifying biodegradation. These methods rely on the principle of evolution of $\mathrm{CO}_{2}$ and/or consumption of oxygen to quantify biodegradation. Measuring the amount of $\mathrm{CO}_{2}$ released over time provides insight on both extent and rate of biodegradation [72]. Respirometric methods are relatively inexpensive, specifically track biodegradation and can be applied to various treatment scenarios. These methods require experiments to be conducted for the specified period of time associated with the method. For a biodegradable textile subjected to these tests, an amount of carbon dioxide would release from the textile during the test 


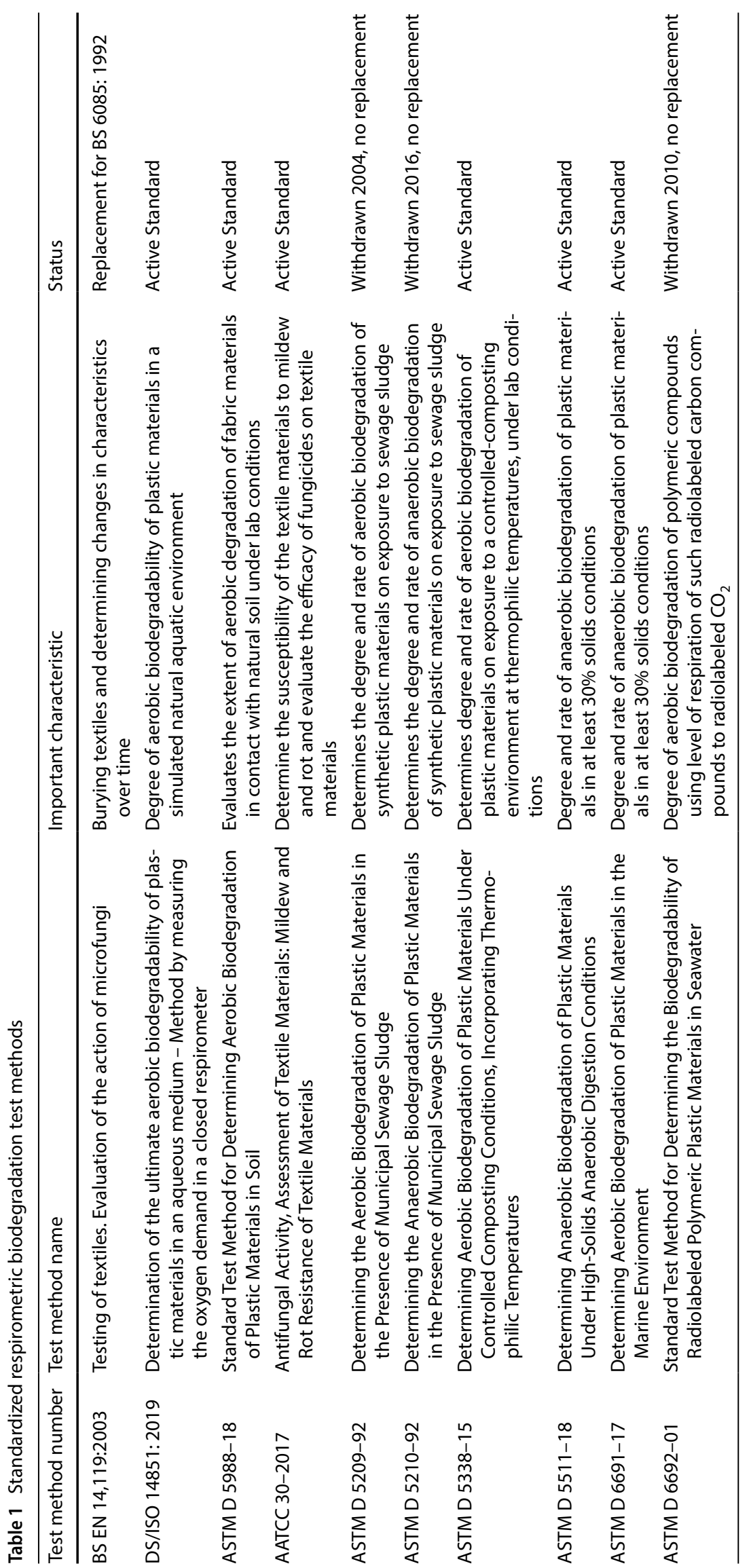


as a result of microbial metabolic processes which would not be released during non-biotic degradation. Therefore, tracking the net $\mathrm{CO}_{2}$ evolved denotes biodegradation. Respirometric methods can be applied at different conditions, including aerobic (compost and soil incubation) and anaerobic (anaerobic digestion) [73]. Examples of commonly used respirometric test methods conducted under aerobic or anaerobic conditions are shown in Table 1.

An advanced isotopic respirometric method that requires special preparation of ${ }^{13} \mathrm{C}$-labeled test samples not only measures biodegradation based on carbon conversion, but also identifies which specific carbon atoms in a chemical structure undergo chemical transformations, giving insight to the biodegradation mechanism for a given material [74]. By replacing specific carbon atoms with the isotope, the biodegradation of one monomer present in a polymer can be isolated and studied by capturing and measuring the amount of carbon dioxide containing the released isotope. In a study with poly(butylene adipate-co-terephthalate) (PBAT) polymer, this method was used to identify depolymerization as the rate-controlling step during biodegradation because more than $30 \%$ of labeled carbon atoms in monomers were "mineralized" (converted to $\mathrm{CO}_{2}$ ) within two days of adding the monomers to the soils, but less than $1 \%$ of carbon atoms in the corresponding polymer were converted to $\mathrm{CO}_{2}$ during that same incubation period [74]. Therefore, isotopic methods can establish the unambiguous fate of specific compounds and provide important mechanistic insights. A standardized method (ASTM D6692) using radiolabeled polymers was previously used to measure plastic biodegradation in seawater but was withdrawn without replacement in 2010. Due to cost and sample preparation complexity, these isotopic methods are slow to be adopted and applied in biodegradation studies.
Respirometric study of biodegradation in marine environments is different from other respirometric methods in that the measured value is not the mineralized carbon but rather the consumption of oxygen. Biodegradation is quantified by comparing measured oxygen uptake during the test to the theoretical oxygen demand [75]. Theoretical oxygen demand is a calculated value based on the total organic carbon in the substrate and predictions of oxygen consumption from other sources. For example, nitrification consumes some amount of oxygen in the marine environment. This interferes with the measurement of oxygen consumption and must be accounted for. This method of respirometric quantification is utilized in standardized methods for aerobic biodegradation in marine environments like freshwater (ISO 14851) and seawater (ASTM D6691).

\subsection{Additional methods}

Although respirometric methods give the strongest direct evidence of biodegradation, additional methods are commonly used for convenience or to build mechanistic understanding of degradation phenomena. The most prevalent technique is measurement of percent weight loss. This relatively inexpensive method requires accurate sample mass measurements before and after exposure to the degradation environment, with drying or otherwise correcting for sample moisture content, and potentially involves use of mesh bags or other containment to ensure recovery of disintegrated sample fragments. Weight loss experiments under soil burial conditions convincingly show more rapid biodegradation of cellulosic materials compared to conventional synthetic textile fibers [42, 76-79]. Also, when paired

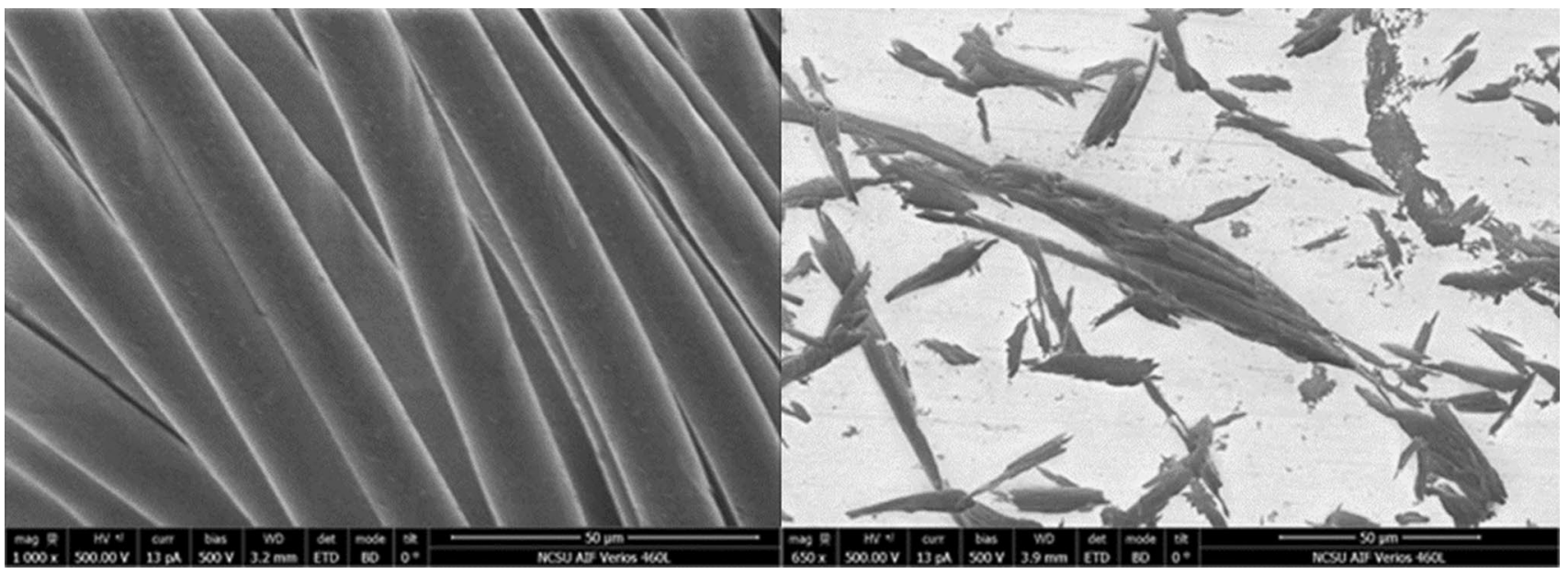

Fig. 6 SEM images of non-degraded PET fibers (left) and degraded cotton fragments (right) separated by filtration from a cellulase enzyme treated PET/cotton fabric blend [89] 
with microbial culture tests [76] or microbe-inhibited controls [80], weight loss can be attributed to the presence of microorganisms. However, depending on the polymer, other factors may also play a role. For example, even when microorganisms are not present, weight loss of sterilized PLA can be caused by hydrolysis in pure water [81]. Therefore, experimental context is essential to interpret the extent to which biodegradation is a factor. Microscopic examination by scanning electron microscopy (SEM) gives visual evidence of microbial $[42,76,78,80]$ or enzymatic [82-85] degradation, based on the experimental parameters. Images of degraded materials are compared to initial or control sample images, or relative degradation of one fiber type is compared to another (Fig. 6). Insights on degradation mechanisms are obtained by monitoring changes in polymer crystallinity and molecular weight. Crystallinity of non-thermoplastic materials, like cellulosic fibers, is measured using X-ray diffraction [79], whereas changes in enthalpy of fusion $\left(\Delta \mathrm{H}_{\text {melt }}\right)$, measured by Differential Scanning Calorimetry (DSC) relative to a standard with known crystallinity, is used to calculate crystallinity of thermoplastics, like PLA $[86,87]$ and poly(caprolactone) (PCL) [80]. Observations from these methods follow a general pattern that sample crystallinity initially increases in degradation environments because more accessible amorphous polymer regions degrade first, then crystallinity decreases as more degradation occurs over longer periods of time. Notably, in a study where lipase enzymes were dispersed and encapsulated within a PCL polymer film, the percent crystallinity remained constant at $\sim 40 \%$ even after the sample lost $80 \%$ of its initial mass, indicating that both amorphous and crystalline phases degraded in the presence of the confined enzymes [88].

\section{Textile waste management practices}

The World Bank estimates that global MSW generation will increase to 3.4 billion tons per year by 2050 without changes in behaviors, practices and policies [1]. About $37 \%$ of global MSW is disposed in landfills, $33 \%$ is openly dumped, $11 \%$ is incinerated and only $19 \%$ undergoes materials recovery through recycling and composting (Fig. 1). Textile production, use and disposal follows this primarily linear trend (Fig. 2). In the U.S., $66.4 \%$ of textile waste is disposed in landfills, $18.9 \%$ is incinerated for energy recovery, and $14.7 \%$ is recycled [5]. Recycling can involve up-cycling to value-added products [90], conversion to fiber by shredding [91], or down-cycling to wiping and polishing cloths [92], which are disposed after use. Disposed textiles that are sent to landfills represent lost value and persist there because landfills are primarily designed to contain rather than to degrade [33]. When organic matter degrades in landfills, it undergoes anaerobic decomposition to methane and carbon dioxide mediated by microorganisms [93]. The extent to which a material, such as cellulose, degrades depends on the microbial population specific to the landfill site [22]. Some textiles are incinerated for power production when the proper facilities exist [94]. Waste textiles discarded in the environment through improper disposal, or via partial disintegration (e.g. lint and microfibers released during laundering) may accumulate or degrade, depending on the conditions.

To divert solid food and paper waste from conventional landfills towards alternative biological waste treatment options, the European Commission Landfill Directive defined "biodegradable waste" as "any waste that is capable of undergoing anaerobic or aerobic decomposition, such as food and green waste, and paper and paperboard" [95]. While some textile fibers that originate from plants ("green waste") or are composed of cellulose (the same polymer as found in paper and paperboard) could fall within that definition, because the composition of textiles today is dominated by synthetic fibers and added chemistries like dyes and finishes can interfere with biodegradation, textiles overall persist significantly longer in landfills or the environment than other forms of solid waste, like food waste.

Alternative waste management strategies include composting, biogas production and reprocessing in industrial reactors. Composting is an aerobic process where organic materials, such as manure and leaves, are decomposed and transformed by microorganisms into a humus-like substance called compost, $\mathrm{CO}_{2}$, water, and minerals [78]. Composting environments have highly active microbial and enzymatic constituents that accelerate degradation processes [96]. Composting can be a low-cost (on the order of two- to six-fold lower) waste management practice for biodegradable polymers compared to landfilling, incineration or recycling petroleum-derived polymers [97, 98]. Pure natural fibers are completely degraded under microbial composting conditions [99], and certain types of plastics have been engineered to degrade by composting [72]. However, the presence of process contaminants associated with bioplastics can lead to ecotoxicity [100]. Anaerobic digestion (AD) is a waste-to-energy process that produces biogas (methane) while decomposing wastes with primarily organic content, such as manure, municipal wastewater, agricultural residues and food wastes [101]. Generally, AD processes require feedstocks to be in the form of liquid slurries ( $<20 \%$ solids), which is not the usual form for waste textiles. Processes that convert textile wastes to the required form have been proposed [102] 


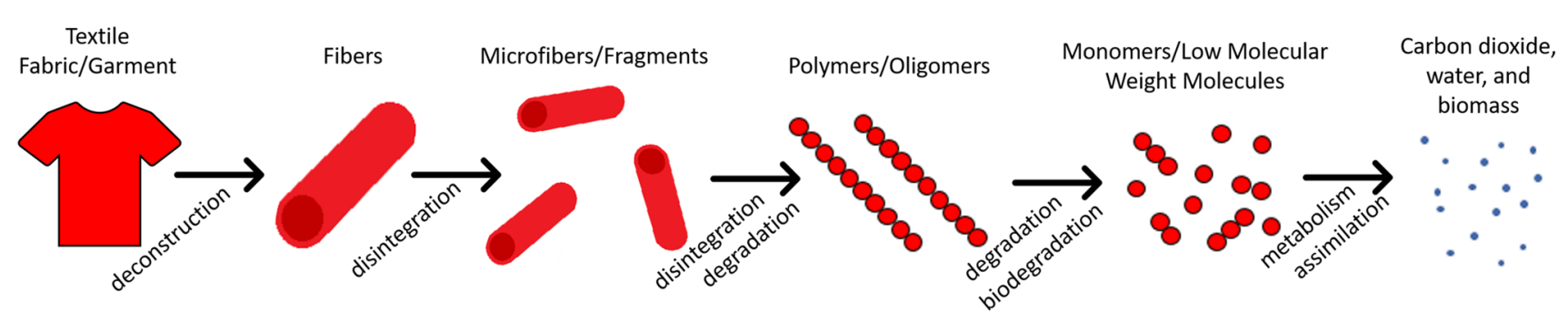

Fig. 7 Schematic pathway of deconstruction, disintegration, and degradation outcomes

and the susceptibility of various plastic wastes to digestion under AD and landfill conditions has been reviewed [103]. Industrial reprocessing includes melt reprocessing, chemical/enzymatic conversion, or biological conversion (fermentation). Circular processes recover valuable components in the waste and avoid loss of waste material to the environment [104].

\section{Textile fiber biodegradability}

Both natural and synthetic textile fibers are semi-crystalline, meaning they consist of both amorphous and crystalline regions. This important characteristic gives textile fibers a combination of toughness and strength. Initial disintegration and degradation of fibers occurs in the amorphous regions, which are more accessible to water and other compounds because of higher free volume $[16,96,105]$, causing fibers to break apart into small fragments and microfibers (Fig. 7). When materials biodegrade in the environment, the small fragments continue to depolymerize to low molecular weight molecules that ultimately are consumed by microorganisms as an energy source and metabolized to carbon dioxide and water. Some molecules will be converted to biomass that makes up the cells themselves [106]. However, the chemical structures and crystalline regions of fibers, and of plastic materials in general, can resist degradation. This interrupts the full degradation pathway and leads to accumulation in the environment.

While analysis of textile degradation has historically been relevant for archaeology and forensics [107] or for preservation [108], measuring the environmental persistence of textile materials from a sustainability perspective is relatively new because there are no specific regulatory requirements. Within the work that has been published, comparison of textile biodegradation results is hindered by variabilities in test methods, conditions, physical form of samples, and duration of testing. Many investigations are time-limited and do not provide data up to complete degradation. There is also no standard practice for the physical form (e.g. powders, films, fibers, etc.) of materials tested. Bearing these complications in mind, a schematic timeline that summarizes published biodegradation test results for textiles and related materials is shown in Fig. 8. Supporting details for the timeline are provided in Supplementary Information Table S1. Overall, results show that textiles made from natural fibers, absent of dyes and finishing treatments, persist for much shorter times than conventional synthetic fibers. In a soil burial study that measured the amount of fabric remaining over time, Warnock et al. [77] found that the degradation rates of three vat blue dyed cellulosic fabrics-rayon, cotton and lyocell-in warm $\left(25^{\circ} \mathrm{C}\right)$, moist (18\%) soil conditions largely followed zero-order (linear) kinetics in the range between around 20-90\% degraded, allowing calculation of half-life values (the time required for $50 \%$ of the fabric to decompose) of 22 , 40 and 94 days, respectively. This trend was attributed to increasing crystallinity and longer cellulose polymer chains for cotton and lyocell compared to rayon. The half-lives increased when soil moisture decreased, and decreased when soil temperature increased. Vat Blue 20 (C.I. 59,800) was chosen as an experimental marker because it remained as a visible blue residue on soil particles after fabrics degraded. While this illustrates that some categories of colorants (in this case, a physically entrapped organic pigment) do not interfere with fiber degradation, it also illustrates that the colorant can have different (lower) biodegradability than the fiber, and emphasizes the importance of developing techniques to detect residual dyestuffs in biodegradation environments [109]. Regarding the impact of textile finishing chemicals, in compost and aquatic textile degradation studies, the presence of silicone softener was found to increase extent of degradation while durable press crosslinking chemicals hindered degradation $[78,110]$. Given the large diversity of textile dyes and chemical finishes currently in use, more work is needed to measure their degradation products and impacts [111].

Natural fibers including cotton, flax, and wool exhibit substantial weight loss within one year when buried in soil, whereas synthetic materials, including poly(ethylene terephthalate) (PET), polypropylene (PP), 


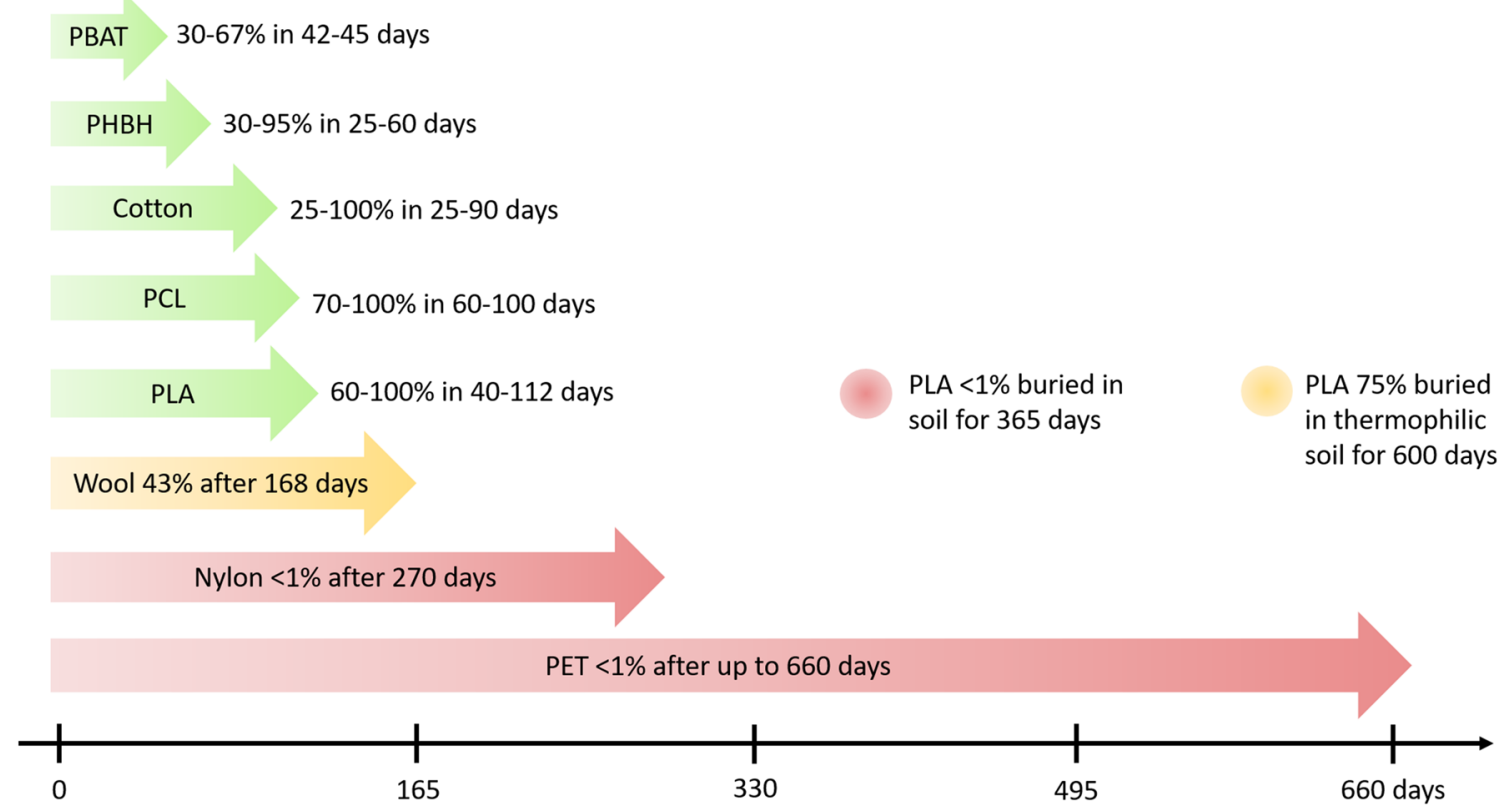

Fig. 8 Consolidated schematic timeline showing percent biodegradation of textile fibers and related polymer materials, based on published studies in various biodegradation environments including soil $[23,66,73,74,77,99,107]$, aerobic sludge [99], seawater $[29,112,113]$, compost $[66,73,78,96,114,115]$, and anaerobic conditions [73, 116, 117]; arrow colors give relative indication of rate and extent of biodegradation, where green indicates fast and complete, yellow indicates slower and eventually complete, and red indicates negligible biodegradation over long time periods; refer to Supplementary Information Table S1 for supporting details

\begin{tabular}{|c|c|c|c|c|c|}
\hline $\begin{array}{c}\text { Common Test } \\
\text { Method }\end{array}$ & Time & $\begin{array}{l}\text { Biodegradable } \\
>70 \% \text { biodegradation }\end{array}$ & Gray Zone & $\begin{array}{l}\text { Semi-Biodegradable } \\
\text { Moderate biodegradation }\end{array}$ & $\begin{array}{l}\text { Nonbiodegradable } \\
<10 \% \text { biodegradation }\end{array}$ \\
\hline $\begin{array}{c}\text { SOIL } \\
\text { ASTM D5988-18 }\end{array}$ & $\begin{array}{l}6 \text { months } \\
(\sim 180 \text { days })\end{array}$ & $\begin{array}{l}\text { Cotton } \\
\text { Flax }\end{array}$ & $\begin{array}{c}\text { PBAT } \\
30 \% \\
\text { degradation } \\
\text { in } 42 \text { days } \\
\end{array}$ & $\begin{array}{l}\text { Wool } \\
\text { Ramie }\end{array}$ & $\begin{array}{l}\text { PET } \\
\text { PLA }\end{array}$ \\
\hline $\begin{array}{c}\text { COMPOST } \\
\text { ASTM D5338-18 }\end{array}$ & 45 days & $\begin{array}{l}\text { PCL } \\
\text { PLA }\end{array}$ & & $\begin{array}{l}\text { Cotton } \\
\text { PBAT }\end{array}$ & PET \\
\hline $\begin{array}{c}\text { ANAEROBIC } \\
\text { DIGESTION } \\
\text { ASTM D5511-18 } \\
\end{array}$ & 30 days & Cotton & & $\begin{array}{l}\text { PCL } \\
\text { PLA }\end{array}$ & PET \\
\hline $\begin{array}{c}\text { SEAWATER } \\
\text { ASTM D6691-17 }\end{array}$ & 90 days & $\mathrm{PHBH}$ & $\begin{array}{c}\text { Cotton } \\
49 \% \\
\text { degradation } \\
\text { in } 38 \text { days } \\
\end{array}$ & $\begin{array}{l}\text { PCL } \\
\text { PLA }\end{array}$ & PET \\
\hline
\end{tabular}

Fig. 9 Extent of textile fiber biodegradability, guided by standard test criteria for plastics; refer to Supplementary Information Table S1 for supporting details

and polystyrene (PS), exhibit negligible weight loss even after almost two years. Some synthetic polyesters, such as poly(butylene adipate-co- terephthalate) (PBAT) and poly(3-hydroxybutyrate-co-3-hydroxyhexanoate) (PHBH) can degrade relatively rapidly at environmental conditions because their copolymer aliphatic ester linkages are more accessible for degradation than those in
PET. Compared to the low temperatures encountered at ambient environments, waste treatment practices including composting and anaerobic digestion occur at sufficiently high temperatures for biodegradation of aliphatic polyesters, like PCL and PLA.

For biodegradability to be relevant in waste management, material biodegradation must occur within an 
acceptable timeframe. For regulated materials, such as biodegradable plastics, timeframe guidance is incorporated in standard test methods developed at specific biodegradation conditions [71]. Figure 9 summarizes four standard methods representing four different biodegradation environments. Each method provides criteria for a material to be considered biodegradable at that condition. For example, a material exposed to seawater that degrades by $>70 \%$ in 90 days is considered biodegradable according to ASTM D6691-17. Materials that do not meet all the criteria cannot be considered biodegradable by that method.

Based on the studies summarized in Fig. 8, Fig. 9 groups textile fibers according to whether the material exhibited "biodegradable," "semi-biodegradable" or "nonbiodegradable" behavior at the specific test conditions. From a practical perspective, a material that degrades $<10 \%$ under the test conditions is considered nonbiodegradable, because its shape and physical properties remain largely intact. This implies that a material exhibiting between 10 and $70 \%$ biodegradation might be considered semi-biodegradable, not as a formal designation, but as a way to help understand the factors impacting the behavior at those conditions. For example, a material that is blended from different components might exhibit semi-biodegradable behavior if one component biodegrades and the other does not. The term "semi-biodegradable" is only used here as a relative descriptor to recognize materials that do not fully meet the defined method criteria but do exhibit significant changes in physical form and properties at the test conditions. A "Gray Zone" designation is included to recognize materials that show potential to meet the formal test method criteria, but where the published studies were stopped before completing the full testing time requirement. For example, cotton was shown to reach $49 \%$ biodegradation in seawater after 38 days [75]. Therefore, while cotton is predicted to reach $70 \%$ biodegradation by the 90 -day mark specified in ASTM D6691-17, here it is assigned to the "Gray Zone"for the seawater condition due to incomplete evidence. Such mapping can help inform what additional testing is needed. In general, whereas pure cotton is biodegradable under most conditions, PLA shows differing levels of biodegradability depending on the conditions, and PET is not biodegradable under any standardized conditions.

\subsection{Balancing performance and biodegradability}

A biodegradable textile fiber must fulfill both mechanical and aesthetic standards for apparel while also having properties that make it favorable to be broken down by microorganisms. Many factors can contribute to a textile's ability to biodegrade, such as chemical composition, fiber crystallinity, degree of orientation, degree of polymerization, hydrophilicity or hydrophobicity, and presence of dyes and other chemicals $[73,79]$. Desirable physical properties for apparel fibers span ranges that align with different apparel applications. Tenacity, elongation at break, and modulus are considered the primary mechanical properties of textile fibers, with typical associated ranges of 1-7 g/denier, 5-45\%, and $25-120 \mathrm{~g} /$ denier, respectively [118]. Given that textile fiber densities are in the range $1-1.5 \mathrm{~g} / \mathrm{cm}^{3}$ [119], the typical tenacity and modulus ranges expressed in $\mathrm{SI}$ units are 90-900 MPa and 2-16 GPa, respectively. End use determines which properties are most essential. For example, fibers used in workwear may have high tenacity and low elongation, whereas fibers in casual or athletic wear may have relatively higher elongation, and lower tenacity could be acceptable. Mechanical properties of common apparel fibers are shown in the Supplementary Information (Table S2).

In addition to mechanical properties, chemical properties, especially moisture absorbency, are important for comfort and are critical factors in biodegradability. Increased biodegradability generally correlates with increased hydrophilicity $[23,79]$. Traditional textile fibers have moisture absorption regain values on the low end for PET ( 0.4\%), acrylic and nylon (1-4\%), in the mid-range of $7 \%$ for cotton and cellulose acetate, and at the high end of $10-18 \%$ for mercerized cotton, rayon, silk and wool [120]. Most natural fibers, notably cotton and wool, have much higher absorbance capabilities whereas commonly used synthetic fibers, like nylon and polyester, have moisture absorbance in the lower range. The ability of fibers to absorb moisture is related to their chemical structures, shown in Table 2. Fiber compositions with high percentages of oxygen and nitrogen are generally more hydrophilic than fibers with a high hydrocarbon percentage.

For both manufacturing and end-use considerations, the thermal stability of fibers is important, especially the melting temperature, when the fiber loses its solid shape and changes phase to a liquid state. The ability of fibers to melt depends on their thermal degradation temperature being higher than the melting temperature. As shown in Table S2 (Supplementary Information), textile fibers based on cellulose (e.g. cotton, rayon) and protein (e.g. wool, silk) do not melt due to extensive hydrogen bonding at the molecular level that prevents the polymers from moving and flowing in response to heat. For these fibers, hydrogen bonding preserves the solid fiber structure until it thermally degrades. In contrast, synthetic fibers generally melt at useful temperatures, meaning temperatures that are higher than typical use conditions and lower than the thermal degradation temperature. This "thermoplastic" behavior allows synthetic fibers to be melt-processed into different fiber shapes and sizes. Thermoplastic materials are also characterized by their glass transition temperature $(\mathrm{Tg})$, which is a temperature below the melting temperature at which polymer chains within the material can undergo 
Table 2 Expected primary degradation products of common apparel and polyester polymers, with examples of enzymes capable of catalyzing the depolymerization step, and reported extents of degradation at indicated conditions

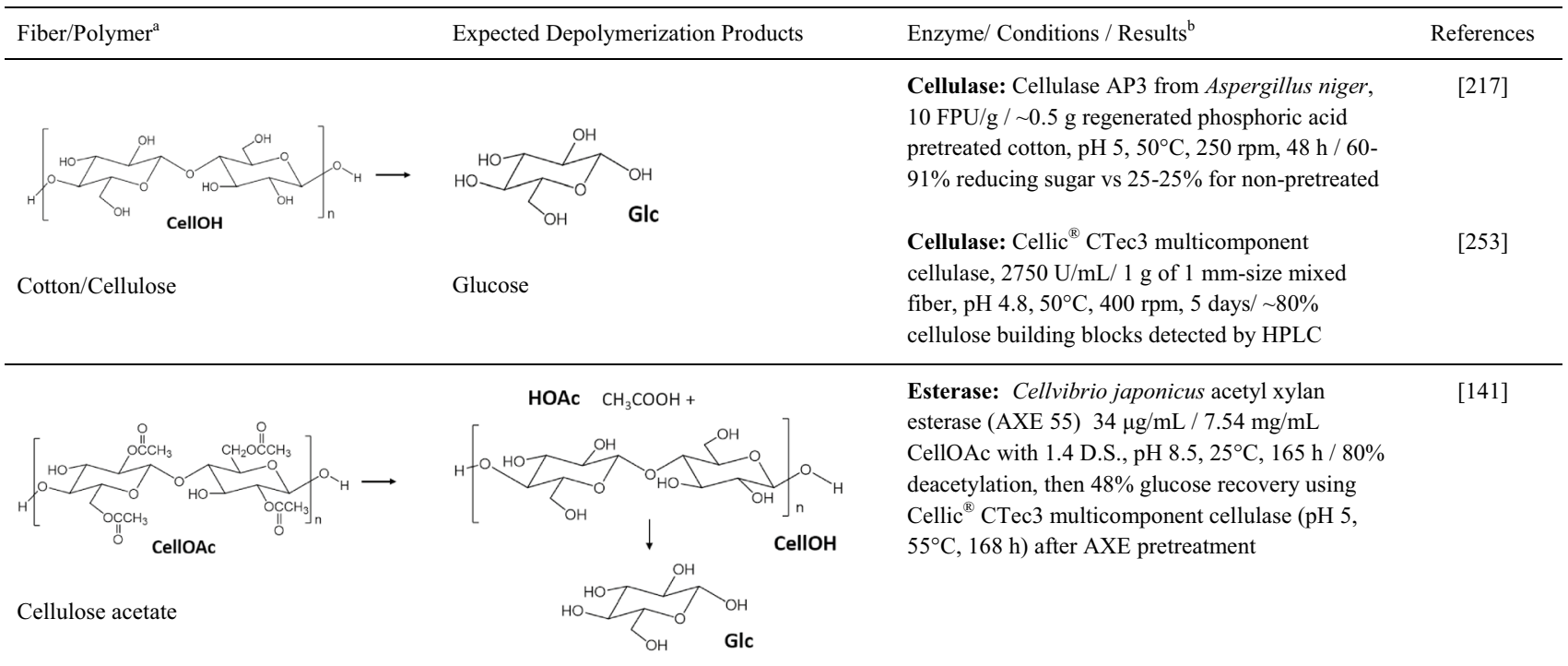

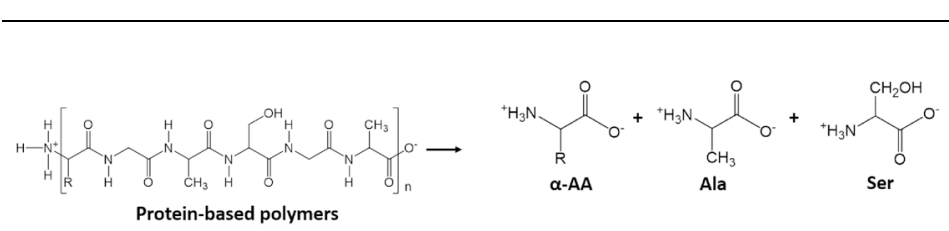

Silk and Wool
Protease: Protease XIV, $1 \mathrm{U} / \mathrm{mL} / 9 \mathrm{~cm}^{2}$ freeze dried silk fibroin sheet, $\mathrm{pH} 7,37^{\circ} \mathrm{C}, 15$ days $/ 70 \%$ weight loss (protease XIV), $52 \%$ collagenase IA, with released amino acids

Protease: Ronozyme ${ }^{\circledR}$ ProAct (serine protease) 2 $\mathrm{KU} / \mathrm{mL} / 0.1 \mathrm{~g}$ wool fabric ground to $\leq 0.6 \mathrm{~mm}, \mathrm{pH}$ $10,50^{\circ} \mathrm{C}, 200 \mathrm{rpm}, 16 \mathrm{~h}$ with reducing agent / $>95 \%$ weight loss (PCNR)

Nylon hydrolase: 6 -aminohexanoate oligomer<smiles>CCC(=O)CCCCC(=O)NCCCCCCN(C)C(=O)c1ccccc1</smiles>

PA

Nylon 6,6/Polyamide

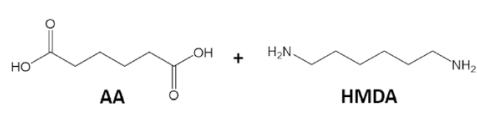

HMDA drolase (NylC), $0.1 \mathrm{mg} / \mathrm{mL} / 5 \mathrm{mg} / \mathrm{mL}$ nylon 6 or nylon 6,6 powders, $\mathrm{pH} 7.3,60^{\circ} \mathrm{C}, 5 \mathrm{~h} / \leq 1 \%$ free amine released (PCNR)

Protease: Protex ${ }^{\circledR}$ modified subtilisin, Lipase: Lipe ${ }^{\circledR}$ serine hydrolase, and mixtures $6-9 \%$ o.w.f. products / nylon 6,6 woven fabric, $\mathrm{pH} 6.5,30^{\circ} \mathrm{C}$, $80 \mathrm{~min} /<5 \%$ weight loss (PCNR)

Cutinase: Thermobifida fusca KW3 cutinase (TfCut2) $50 \mu \mathrm{g} / \mathrm{mL} / 0.5 \mathrm{mg}$ PET fiber nanoparticles, $\mathrm{pH} 8.5,60^{\circ} \mathrm{C}, 1000 \mathrm{rpm}, 40 \mathrm{~min} /$ $>97 \%$ turbidity reduction (PCNR)

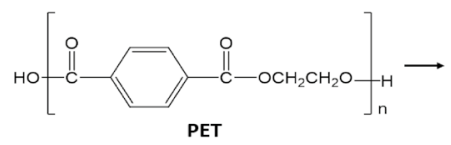

HO-

TA $\stackrel{\mathrm{O}}{\mathrm{C}}-\mathrm{OH}+\mathrm{HOCH}_{2} \mathrm{CH}_{2} \mathrm{OH}$

Polyethylene terephthalate

Cutinase: Leaf-branch compost cutinase (LCC) variant ICCG, $3 \mathrm{mg} / \mathrm{g} / 20 \%$ suspension of amorphized and micronized PET, $\mathrm{pH} 8,70^{\circ} \mathrm{C}, 24 \mathrm{~h}$ / $90 \%$ hydrolysis based on $\mathrm{NaOH}$ consumption, ethylene glycol and terephthalic acid produced

Cutinase: Humicola insolens (HiC), $10 \mu \mathrm{M} / 7 \%$ crystallinity PET-Gf film, $\mathrm{pH} 8,70^{\circ} \mathrm{C}, 96 \mathrm{~h} / 97 \%$ hydrolysis based on $\mathrm{NaOH}$ consumption, ethylene glycol and terephthalic acid detected by HPLC

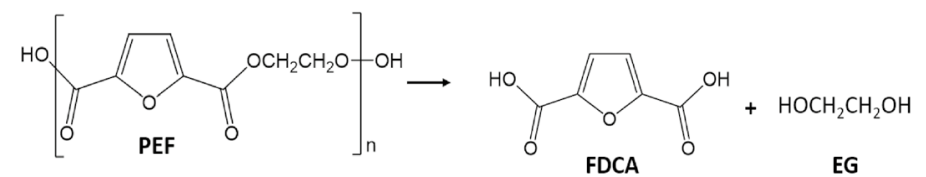

EG
Cutinase: Humicola insolens cutinase (HiC), 5 $\mu \mathrm{M} / 0.5 \mathrm{~cm}^{2}$ amorphous PEF film, $\mathrm{pH} 8,65^{\circ} \mathrm{C}, 96$ $\mathrm{h} / 100 \%$ weight loss and $>95 \%$ degraded to monomers 


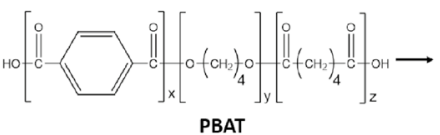

Poly(1,4-butylene adipate-co-terephthalate)

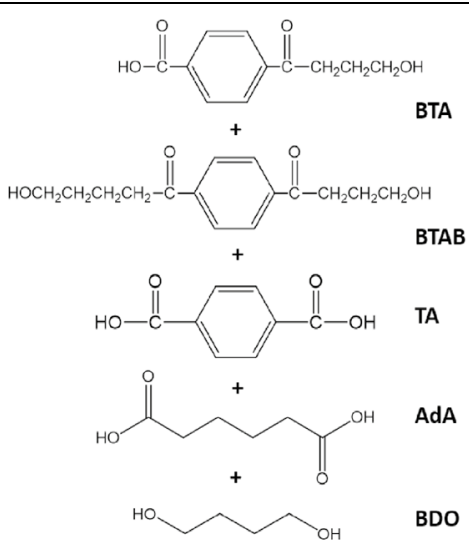

BDO
Lipase: Pelosinus fermentans DSM 17108 lipase (PfL1) $0.6 \mu \mathrm{M} / 10 \mathrm{mg}$ milled PBAT film, $\mathrm{pH} 7.5$, $50^{\circ} \mathrm{C}, 100 \mathrm{rpm}, 72 \mathrm{~h} / \sim 120 \mathrm{~mol}$ total products $/ \mathrm{mol}$ $\mathrm{PfL} 1$, products detected were $\mathrm{BTA}>\mathrm{BTAB}>\mathrm{TA}$<smiles>CC(C)OCCCCOC(=O)CCC(=O)O</smiles><smiles>O=C(O)CCC(=O)O</smiles>

SA

Polybutylene succinate

$$
\text { HOH BDO }
$$<smiles>CC(C)OC(C)C(=O)O</smiles>

PLA<smiles>CC(O)C(=O)O</smiles>

LA

Polylactic acid

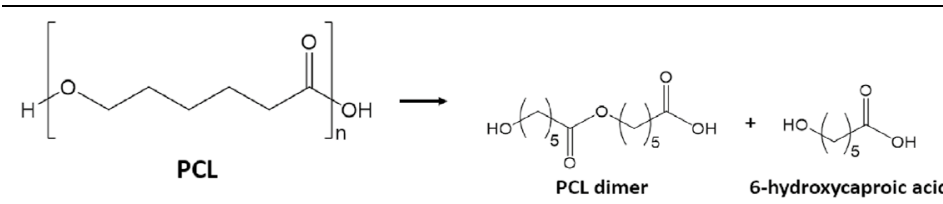

Fusarium sp. FS1301 strain $/ 3 \mathrm{~cm}^{2}$ PBS film, 100 rpm, $\mathrm{pH} 7,30^{\circ} \mathrm{C}, 24$ days $/ 80 \%$ weight loss and detected SA, SA-BDO, SA-BDO-SA and SABDO-SA-BDO from PBS emulsion after $30 \mathrm{~min}$ at $50^{\circ} \mathrm{C}$ with purified enzyme

Protease: Tritirachium album Proteinase K, 1 $\mathrm{U} / \mathrm{mg} / 0.5 \mathrm{~cm}^{2}$ poly(D,L-LA) film, $\mathrm{pH} 8,37^{\circ} \mathrm{C}$, $200 \mathrm{~h} / 80 \%$ weight loss (PCNR)

Protease: Proteinase K, $0.2 \mathrm{mg} / \mathrm{mL} / \sim 20 \mathrm{mg}$ PLA type $2003 \mathrm{D}$ film, $\mathrm{pH} 8,37^{\circ} \mathrm{C}, 56$ days $/ 42 \%$ weight loss (PCNR)

Protease: Bacillus subtilis protease (Pro-1') 2 g/L / $100 \mathrm{~cm}^{2}$ PLA woven fabric, $\mathrm{pH} 7,35^{\circ} \mathrm{C}, 7$ days / $20 \%$ weight loss (PCNR)

Cutinase: Humicola insolens cutinase (HiC) 8.8 $\mu \mathrm{M} / \sim 30 \mathrm{mg}$ PCL film, $\mathrm{pH} 8,40^{\circ} \mathrm{C}, 200 \mathrm{rpm}, 3 \mathrm{~h} /$ $100 \%$ weight loss (PCNR)

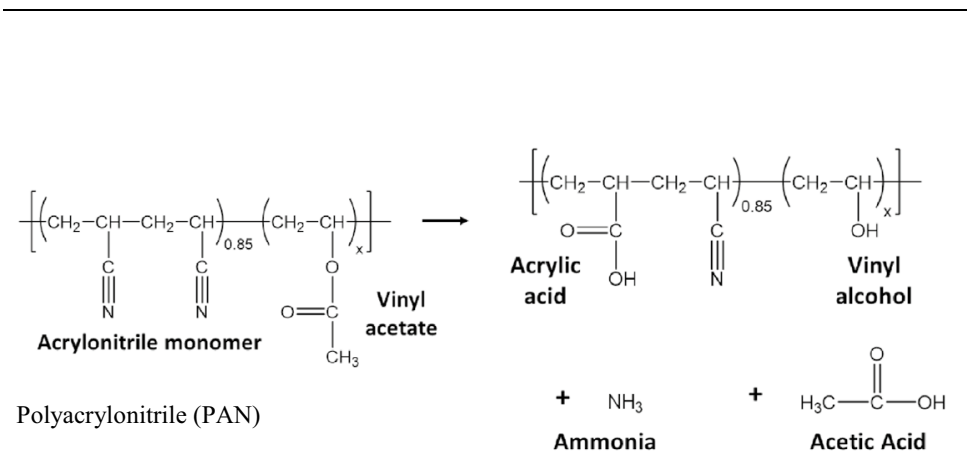

Esterases: Fusarium solani pisi cutinase, 9 Units or Texazym PES esterase, 3.4 Units / 1.6 or $3 \mathrm{~g}$ acrylic taffeta fabric comprising $7 \%$ vinyl acetate, $\mathrm{pH} 8,30^{\circ} \mathrm{C}, 20 \mathrm{rpm}, 3 \mathrm{~h}$, plus additives / no weight loss, some increased reactive dye uptake

Nitrile hydrolyzing enzymes: Membrane bound enzyme isolated from Micrococcus luteus strain BST20, 11 nkat units / $\mathrm{pH} \mathrm{7,2 \%} \mathrm{Triton} \mathrm{X}, 30^{\circ} \mathrm{C}$, $70 \mathrm{rpm}, 24 \mathrm{~h} /$ microscopic evidence of fiber damage, $5 \%$ ammonia release, stained with Methylene blue

Nitrilase: Commercial Cyanovacta Lyase, 412 U/g fabric / $2 \mathrm{~g}$ acrylic taffeta comprising $7 \%$ vinyl acetate, $\mathrm{pH} 7.8,40^{\circ} \mathrm{C}, 20 \mathrm{rpm} /$ detected ammonia release, stained with Basic Blue 9 dye

a) CellOH: cellulose; Glc: glucose; CellOAc: cellulose acetate; GlcAc: glucose acetate; HOAc: acetic acid; a-AA: alpha-amino acid; Ala: alanine; Ser: serine; PA: polyamide; AdA: adipic acid; HMDA: hexamethylenediamine; PET: polyethylene terephthalate; TA: terephthalic acid; EG: ethylene glycol; PLA: polylactic acid; LA: lactic acid; PCL: polycaprolactone; PBS: polybutylene succinate; PBAT: poly(1, 4-butylene adipate-coterephthalate) (PBAT); BTA: 1,4-hydroxybutylene terephthalate; BTAB: bis-1,4-hydroxybutylene terephthalate; BDO: butanediol; PEF: polyethylene furanoate; FDAC: furandicarboxylic acid; SA: 1,4-succinic acid; b) D.S.: degree of substitution; PCNR: Product Compounds Not Reported 
Fig. 10 Comparison of fibers with desirable apparel properties versus desirable biodegradability properties

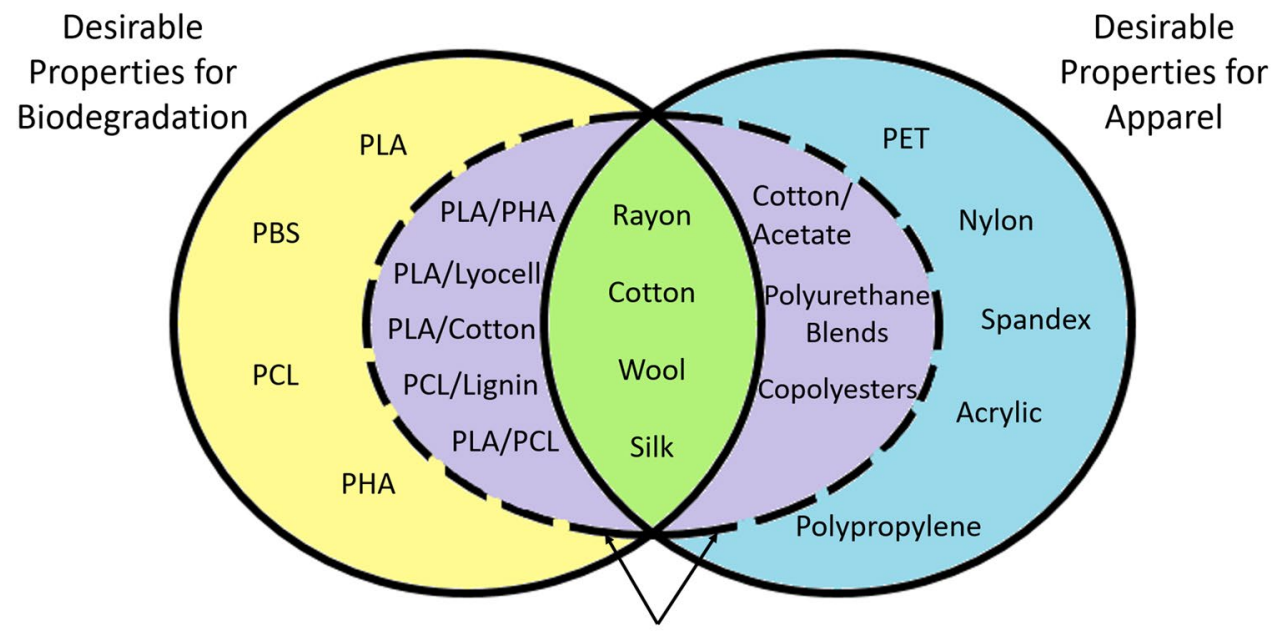

New Composites/Copolymers long range molecular motion even while the material remains solid. While microorganisms generally cannot survive at temperatures as high as the melting temperatures of textile polymers, some microbial environments, e.g. composting and anaerobic digestion, reach the $\mathrm{Tg}$ of polymers like PLA $\left(\sim 50-60^{\circ} \mathrm{C}[121]\right)$, and industrial process reactors can be elevated to the $\mathrm{Tg}$ of other polymers like PET ( $\left.70^{\circ} \mathrm{C}[122]\right)$ to accelerate hydrolysis reactions.

Figure 10 compares different polymer/fiber properties according to their suitability for use in apparel and their biodegradability characteristics. Natural fibers, shown in the green part of Fig. 10, exhibit both the chemical requirements for biodegradation and meet the physical requirements for apparel textiles. Polymers in the yellow-shaded area meet the biodegradability criteria for certain test methods and can be melt-processed to form fibers, but their physical properties can be inadequate for conventional handling of textile apparel. Polymers in the blueshaded area are conventional synthetic apparel textile polymers that do not biodegrade within standard test method timeframes. Materials in the purple-shaded area are polymer blends and composite fibers that have the potential to meet both apparel property requirements and biodegradability criteria.

\section{Basic biochemical degradation mechanisms}

Because fibers and the polymers they contain are too large to pass across cell membranes, microorganisms release enzymes onto these substrates to catalyze polymer bond cleavage. This reduces the molecular weight to small soluble products that can be consumed. Chemical functionality along the polymer chain provides sites for bond cleavage. Table 2 illustrates polymer chemical structures for common apparel fibers and several different types of polyesters. The expected depolymerization products are represented in the table by monomer residues, though the products can actually be a mixture of monomers, dimers, and oligomers. Comparison of polymer and corresponding monomer structures shows that depolymerization occurs at glycosidic ( $\mathrm{R}^{\prime} \mathrm{O}-\mathrm{CH}(\mathrm{R})-\mathrm{OR}^{\prime \prime}$ : cellulose), amide (R-C(O)NH-R': silk, wool, nylon) and ester (R-COO-R': PET, PEF, PBAT, PBS, PLA, PCL) bonds. Side group modifications can also occur.

After the polymer molecular weight is reduced, monomer/oligomer fragments are transported across microbial cell membranes to provide energy to cells, generate biomass, and release by-products, such as $\mathrm{CO}_{2}$ and water through metabolic cycles. For some polymers, like PLA, the degradation process is enhanced by non-enzymatic hydrolytic mechanisms when exposed to heat and moisture [54]. For some fibers, like cotton, the mode of microbial attack depends on the organism. In the presence of bacteria, cotton biodegradation proceeds from the surface towards the center of the fiber whereas in the presence of fungi, the microorganism penetrates into the lumen where it multiplies and eventually breaks down the fiber from the inside-out [123]. Microorganisms associated with the biodegradation of apparel polymers have been reviewed by Gusakov (2011) [124] for cellulosic materials; Puls et al. (2011) [125] for cellulose acetate; Carr et al. (2020) [126] for PET; Tokiwa et al. (2009) [127] for PBAT, PBS, PCL, PLA and silk; Cardamone (2001) [128] for wool; Sudhakar et al. (2007) [129] for nylon 6,6 and 6; and, Gaytán et al. (2021) [130] for acrylic. Enzymes participating in apparel polymer degradation have been reviewed by Gusakov (2011) [124] for cellulosic materials; Wei and Zimmermann (2017) [131], Biundo et al. (2018) [132], Carr et al. (2020) [126], Leitão and Enguita (2021) [133], and Kawai (2021) [134] for polyesters; Karamanlioglu et al. (2017) [66] and Zaaba and 
Jaafar (2020) [135] for PLA; Guo et al. (2020) [136] for silk; Qiu et al. (2020) [137] and Fu et al. [138] for wool; Yadav and Hakkarainen (2021) [139] for cellulose acetate; and, Gaytán et al. (2021) [130] for acrylic.

Polymer degradation may occur in discrete steps. For example, the degradation of cellulose acetate involves separate steps of polymer side group modification (deacetylation), which exposes surface hydroxyl groups [140], followed by glycosidic linkage hydrolysis [141]. When the degree of substitution (DS) of acetyl groups on cellulose is $>2$, compost microorganisms are slower at metabolizing the polymer [142] and enzymes have difficulty catalyzing deacetylation, which can explain the low biodegradation rates observed for textile cellulose diacetate (DS 2.4) and triacetate (DS 2.7) fibers [139-141]. Enzyme engineering to improve substrate docking at the active site resulted in improved surface deacetylation for DS 2.0 cellulose acetate films [143]. Park et al. [79] reported that acetate fabric degraded slower than linen, rayon and cotton in soil burial and activated sludge tests (only reaching $8-10 \%$ of theoretical $\mathrm{CO}_{2}$ evolution), especially when the average environmental temperature was low. In contrast, Gartiser et al. [68]. reported $60 \%$ degradation in 46 days of cellulose acetate fibers (DS 2.45) in mesophilic $\left(35^{\circ} \mathrm{C}\right.$ ) anaerobic digestion tests according to ASTM D5210-91, which was attributed to the large surface area of the $10 \mu \mathrm{m}$ diameter Y-shaped filaments tested. Cotton tissue degradation in the same study was $64 \%$, while $24 \mu \mathrm{m}$ PLA film degradation was only $2-11 \%$ due to the low temperature conditions. Cellulose acetate powders (300-400 $\mu \mathrm{m})$ with DS 1.7 and DS 2.5 treated at laboratory-simulated thermophilic composting conditions $\left(53{ }^{\circ} \mathrm{C}, 60 \%\right.$ moisture, $100 \mathrm{~mL} /$ min aeration) generated $72.4 \%$ and $77.6 \%$ of theoretical $\mathrm{CO}_{2}$ by respirometry in 24 and 60 days, respectively [144]. Under these favorable conditions, the weight loss of solution-cast film samples was also significant, $50 \%$ for DS 1.7 in 5 days and 46\% for DS 2.5 in 16 days, illustrating that manipulation of polymer morphology, particle size and biodegradation conditions can all play roles in improving biodegradation outcomes. In the case of textile acrylic fibers (polyacrylonitrile, PAN), which include copolymers of acrylonitrile and vinyl acetate, some limited hydrolysis at fiber surfaces of vinyl acetate $\left(\mathrm{R}-\mathrm{OC}(\mathrm{O}) \mathrm{CH}_{3}\right)$ side groups to vinyl alcohol (R-OH) by esterase enzymes [145] or conversion of nitrile $(\mathrm{R}-\mathrm{CN})$ side groups to amide $\left(\mathrm{R}-\mathrm{C}(\mathrm{O}) \mathrm{NH}_{2}\right)$ and carboxylic acid ( $\mathrm{R}-\mathrm{COOH})$ groups by nitrile hydrolyzing enzymes have been reported [146-148], but the C-C polymer backbone is highly resistant to degradation [130].

Enzymes listed in Table 2 are selected examples of those associated with fiber depolymerization, along with example treatment conditions and results for studies that quantified the level of degradation (typically by weight loss). Studies reporting full compositional analysis of degradation products are rare, and those performing the analyses usually detect mixtures of monomers, dimers and oligomers rather than only the monomer products shown in the table. Such results can indicate insufficient time for the reactions to go to completion, or can indicate substrate selectivity, accessibility limitations, product inhibition or other confounding phenomena. Experiments usually include physical (cutting or grinding), thermal (elevated temperature) and chemical (swelling) pretreatments to make fiber substrates more accessible. Without these pretreatments, enzyme-catalyzed degradation can stall at low levels of conversion. Heat is applied to improve reaction kinetics and ideally bring thermoplastic materials beyond their Tg, allowing chemicals and enzymes better access to hydrolyzable linkages along the polymer chains. The combination of physical, chemical, and thermal pretreatments with biocatalysis, sometimes called "assisted bioremediation" [130], can significantly reduce the time required for materials to degrade while enabling recovery of primary degradation products for value-adding purposes, such as using glucose from cotton for biofuels production [70] or recycling polyester monomers to make new polymer [149]. While some polymers, e.g. $\mathrm{PCL}$, depolymerize rapidly in the presence of enzymes, others, e.g. nylon 6,6 and PAN, are highly resistant to enzymatic degradation.

\section{A Model biodegradable synthetic textile polymer}

Poly(lactic acid) or polylactide (PLA), a semicrystalline aliphatic thermoplastic polyester, is the leading example of biobased, biodegradable and biocompatible polymers used for numerous applications, including textile fibers [150]. Lactic acid monomer is produced at large scale by fermenting sugars obtained from agricultural resources, such as cornstarch, sugarcane and other plant derived feedstocks. Polymerization occurs in subsequent steps by direct condensation or, primarily, by ring-opening polymerization of the cyclic lactide dimer to achieve high molecular weight PLA [151, 152]. Lactic acid is a chiral monomer that can occur in both L- and D-enantiomeric forms, hence the homopolymers are referred to as poly $(\mathrm{L}-$ lactic acid) (PLLA) or poly(D-lactic acid) (PDLA) and are called poly(DL-lactic acid) (PDLLA) when the two enantiomers form a co-polymer. PLA polymer is commercialized, for example under the trade name Ingeo ${ }^{\mathrm{TM}}$ (NatureWorks LLC), and is used for many applications, including packaging, disposable wipes, geotextiles, 3D printer filament, hospital garments, medical devices, absorbent pad liners, personal hygiene products, and agriculture/horticulture products [114, 150, 153, 154]. In addition to apparel [155], PLA has been used in other textile applications such as 
Fig. 11 Stress-strain curves for PLA and other common textile fibers $\left(20^{\circ} \mathrm{C}, 65 \% \mathrm{RH}\right)$ (republished from Farrington et al. [158] with permission of the copyright holder, Elsevier B.V.)

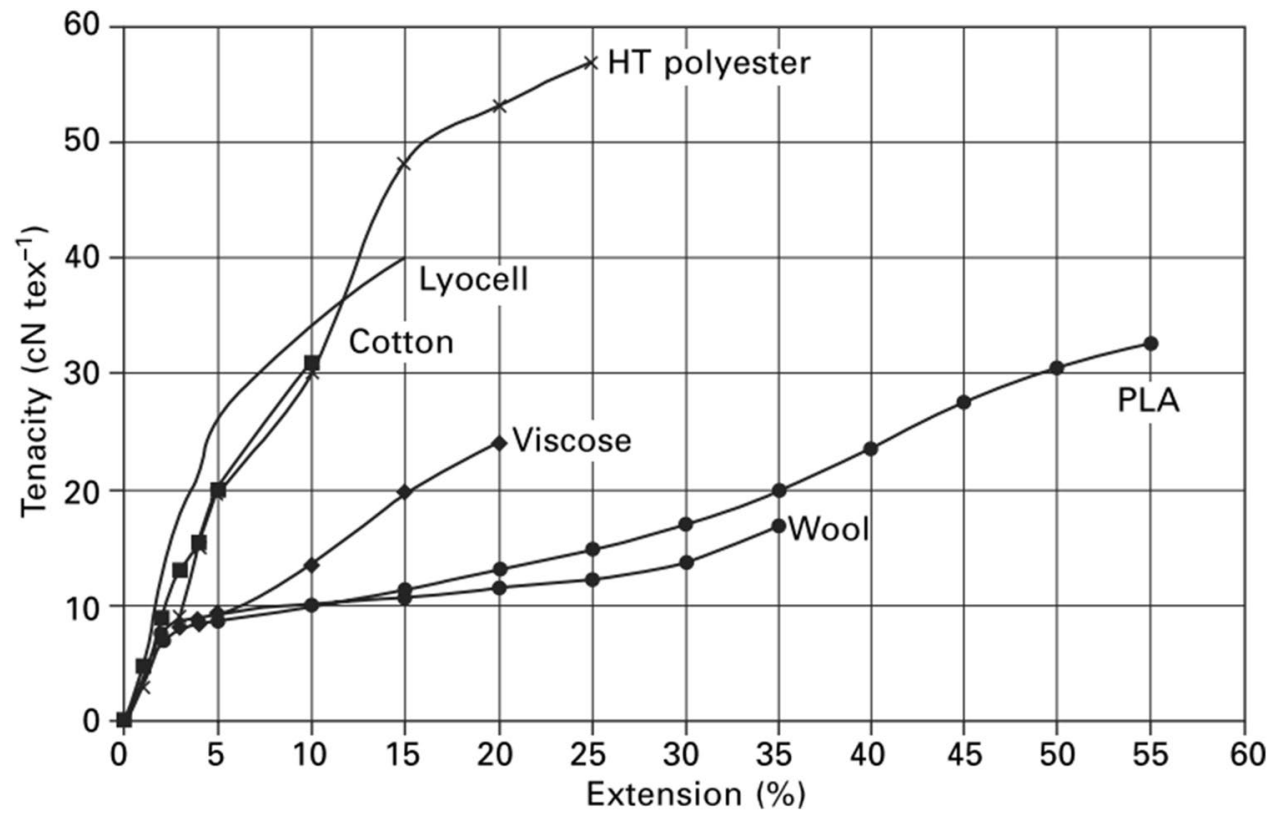

a single-use wipes, tea bags, and automotive carpets or floor mats [156].

\subsection{PLA physical properties}

In the broad realm of aliphatic polyesters, PLA stands out for its attractive mechanical and physical properties that are comparable to common textile fibers (Fig. 11)—high modulus, high strength, and good transparency and barrier properties. PLA also has shortcomings, including low melt strength, slow crystallization rate, temperaturedependent crystal morphology, high brittleness, low toughness, and low service temperature $\left(\mathrm{Tg}=52-67^{\circ} \mathrm{C}\right.$; $\left.\mathrm{T}_{\mathrm{m}}=130-180^{\circ} \mathrm{C}\right)$, which limit its applications [121, 150-152, 156]. Low service temperature can make pure PLA fibers susceptible to deformation during conventional fabric care like hot washing $\left(>50^{\circ} \mathrm{C}\right)$ and ironing $\left(>160^{\circ} \mathrm{C}\right)$ [150]. Notably, the interdigitated helical stereocomplex (sc-PLA) that forms when PLLA and PDLA are physically blended [152] (as opposed to co-polymerized) has significantly higher glass transition $\left(\mathrm{Tg}=65-72^{\circ} \mathrm{C}\right)$ and melting $\left(\mathrm{Tm}=220-230^{\circ} \mathrm{C}\right)$ temperatures [58] compared to each polymer alone. The stereocomplex acts as an efficient nucleating agent for PLLA crystals, and a few percent of stereocomplex are often found in industrial PLLA formulations [152]. From another perspective, the thermal properties of PLA can be an advantage for recycling where conditions of $130^{\circ} \mathrm{C}, \mathrm{pH} 11$, and 150 min treatment time could be used to aid in digestion and recovery of lactic acid from PLA fabrics [157].

\subsection{PLA biodegradability}

Unlike biodegradable polymers that undergo progressive surface degradation by enzymes that are released from microorganisms, the degradation of PLA in a composting environment proceeds by a two-step mechanism in which PLA first disintegrates by moisture-induced chemical bond cleavage in humid environments when the temperature is $\geq 60^{\circ} \mathrm{C}[114,159]$. This lowers the molecular weight to around $10-20 \mathrm{kDa}$, followed by microbial attack on and assimilation of fragmented residues [150]. Carbon dioxide and water are the final metabolic byproducts. Sufficient exposure to heat and moisture is essential for ultimate PLA biodegradation and explains the broad time range observed for PLA degradation at different conditions (Fig. 8). PLA biodegrades completely in a few months at the thermophilic $\left(>50^{\circ} \mathrm{C}\right.$ ) aerobic conditions encountered in industrial compost, whereas only limited biodegradation of PLA occurs in mesophilic or ambient conditions [66, 150]. Amorphous PLA undergoes faster hydrolytic degradation than crystalline PLA. PLA films $(150 \mu \mathrm{m}$ thick) with a relatively high $D$-lactide content $(12 \%)$, leading to amorphous morphology, reached $70 \%$ weight loss in 30 days at $58{ }^{\circ} \mathrm{C}$, while low D-lactide (2\%) film having a $45 \%$ degree of crystallinity required 50 days to reach $60 \%$ weight loss. For a series of rigorously characterized lightweight $(60 \mathrm{~g} /$ $\mathrm{m}^{2}$ ) spunbond PLA nonwoven fabrics with fiber diameters in the range 8-11 $\mu \mathrm{m}$, and the corresponding PLA polymer pellet, $100 \%$ weight loss was achieved after composting in the presence of at least $10^{6} \mathrm{cfu} / \mathrm{cm}^{3}$ microorganisms at $58{ }^{\circ} \mathrm{C}$ and $53 \%$ moisture for 16 weeks [114]. Faster degradation was observed relative to wool and cotton for 

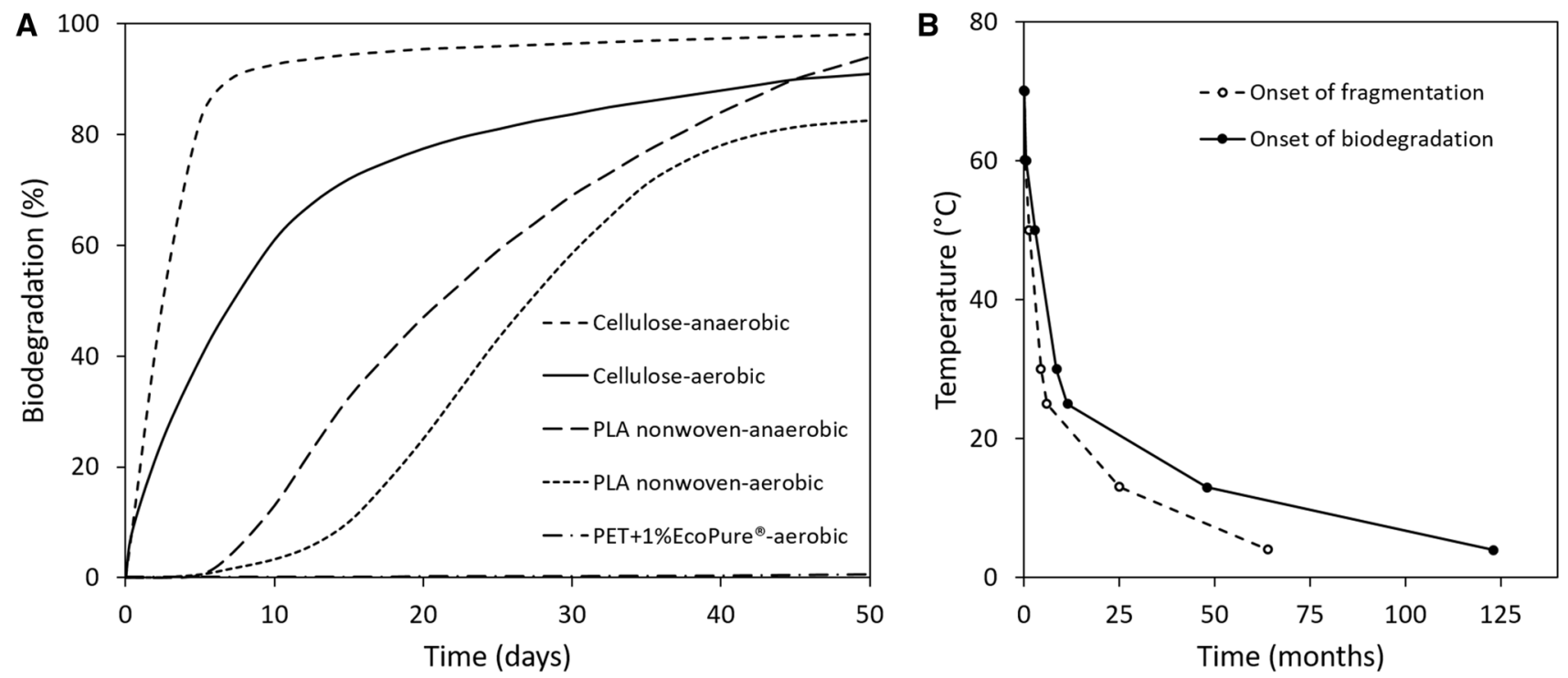

Fig. 12 Compilation of biodegradation behaviors for a thermophilic $\left(58-60{ }^{\circ} \mathrm{C}\right.$ ) anaerobic (ISO 15985) and aerobic (ISO 14855) degradation of cellulose and PLA (adapted from Fig. 29.7 and 29.8 in Mochizuki [152] by permission of John Wiley \& Sons Inc.; permission conveyed through Copyright Clearance Center, Inc.), and for
PET with $1 \%$ EcoPure additive in simulated compost conditions (ASTM D5988-03) (based on Fig. 4 of Gómez and Michel [73]), and b the relationship between temperature and onset of PLA fragmentation and biodegradation in water, based on Table 3 in Lunt [162]

polymers is in the thermal properties. PLA has significantly lower glass transition and melting temperatures compared to PET, as well as higher shrinkage in boiling water. Nevertheless, the molar enthalpy of ester bond hydrolysis for the two polymers is similar and has a larger absolute value compared to the hydrolysis of $\beta$-1,4-glycosidic bonds $(-2.3$ to $-2.6 \mathrm{~kJ} / \mathrm{mol}[161,162])$ found in cellulosic materials. Although PLA has low moisture regain (0.4-0.6\%), similar to PET, PLA has excellent wicking and fast drying properties [158]. During PLA melt spinning, high take-up speed (> $3000 \mathrm{~m} / \mathrm{min}$ ), providing stress-induced crystallization, is needed to generate high strength yarns with low shrinkage [150]. Properties of these materials have been compared to those of conventional yarns including a cotton/PET blend and PET alone [163]. PLA yarns alone exhibit slightly higher moisture regain compared to PET yarns $(0.13 \%$ versus $0.04 \%)$, while the reference cotton/PET blend had $6.34 \%$ moisture regain. Overall, many physical properties of PLA fabric are comparable to a cotton/PET blend of similar fabric construction, including breaking strength, bursting strength and bursting distension. Notably, elongation of PLA yarns is higher than both cotton/ PET and PET [163], resulting in high wear comfort rankings of PLA fabrics [164]. Comparing the tensile properties of materials shown in Table S2 and Fig. 11 to those shown in Table S3 requires mathematical conversions between force per unit linear density and force per unit area. Example calculations are included in the Supplementary Information. microbial properties may be related to low levels of lactic acid release [150]. The most critical difference between the 


\subsection{Laundering properties of PLA}

Two obstacles in broader use of PLA apparel fabrics are the need for special garment care (i.e. low temperature ironing) and avoiding extended exposure to hot, wet conditions during use that could lead to polymer hydrolysis [159] and loss of fabric strength [158]. Domestic textile laundering involves both mechanical abrasion against the machine drum and other fabrics, as well as chemical exposure in water to detergents, bleaching agents, optical brighteners and sequestrants, usually at alkaline conditions, and usually at temperatures that range from $20-43^{\circ} \mathrm{C}[165]$, though hot washing at $60^{\circ} \mathrm{C}$ can occur in some regions [166]. These processes can cause fabric shrinkage, distortion, and deterioration of handle which affect garment shape and size, pilling, and mechanical performance. After 50 laundering cycles, PLA washed with non-phosphate detergent and sodium perborate, a common source of active oxygen in many detergents, responded with an increase in fabric extensibility, from 7.6 to $8.7 \%$ which correlates with an increase in fiber crimping; a decrease in fabric stiffness, which implies decrease in tensile modulus; a decrease in bending stiffness (lower value means a more relaxed fabric); a decrease in bending hysteresis (a low value leads to prevention of fabric bagginess); and, a slight decrease in tensile strength (from $13.6 \mathrm{cN} /$ tex to 12.7 $\mathrm{cN} /$ tex) which is within the acceptable strength loss range [167]. Therefore, machine washing of PLA fabrics should be limited to cold $\left(\leq 35^{\circ} \mathrm{C}\right)$ temperatures, mild laundry detergents with low $\mathrm{pH}(\mathrm{pH} 8)$, and line drying or tumble drying on low heat or permanent press setting $\left(50^{\circ} \mathrm{C}\right)$ [168].

\subsection{PLA fiber blends}

A common way of enhancing apparel fabric benefits while minimizing individual fiber deficits is by blending different fibers. Blending PLA with natural fibers is a way to both tailor properties for use in apparel while maintaining biodegradability characteristics of the fabrics $[97,169$, 170]. Because pure PLA fibers have a higher elongation than cotton, when PLA is added to cotton, the elongation of the blended yarns and fabric increases while the tensile strength remains comparable to industry standards, depending on the percentage of PLA in the blend [169]. PLA fibers blended at 20 to $35 \%$ with cotton and spun into 14.76 tex yarns improved the feel (or "hand") of knitted fabrics, giving better drape and softness compared to $100 \%$ cotton or PET/cotton blends, which is attributed to a finer PLA fiber diameter, smoother PLA surface, lower inter-yarn friction and less hairiness than observed with cotton $[169,171]$. However, at similar fabric basis weight $\left(130-135 \mathrm{~g} / \mathrm{m}^{2}\right)$, the bursting strength of $100 \%$ PLA and PLA blends was somewhat lower than cotton [169]. In comparison to PET/cotton fabrics, increased elongation and better moisture management make PLA/cellulosic fabrics attractive for garments where stretch and perspiration transport are important comfort factors [170]. These blended fabrics are reported to have excellent hand, comfort, and moisture management (wickability) properties [172] that are especially suitable for athletic wear [164]. PLA/cotton blended fabrics are reported to withstand several simulated home laundry washes without creasing, with good appearance and without degradation of PLA polymer [158].

\subsection{Wet processing of PLA}

Due to PLA susceptibility to hydrolysis at low temperatures, when combined in blends with cotton, the wet processing conditions must be adjusted to ensure retention of mechanical and aesthetic properties. Typical cotton fabric wet processing includes cleaning the fibers by alkaline scouring (usually $100^{\circ} \mathrm{C}$ for $1-2 \mathrm{~h}$ ) and bleaching before dyeing and finishing. Although in one evaluation, scouring at up to $100^{\circ} \mathrm{C}$ with alkali for $30 \mathrm{~min}$ did not show significant PLA fabric weight loss, all alkaline scouring processes carried out above $60^{\circ} \mathrm{C}$ showed significant changes in PLA yarn tensile properties, indicating that PLA should not be scoured above $60^{\circ} \mathrm{C}$ [157]. This behavior is attributed to PLA's susceptibility to bulk hydrolysis in water, which can cause loss of molecular weight throughout the structure before any size or mass loss is detected $[173,174]$. To prevent degradation of PLA fibers while sufficiently cleaning the cotton fibers, scouring of PLA/cotton blends should occur at lower temperatures for longer periods of time.

A similar approach is required for bleaching. PLA is severely damaged by the highly alkaline hydrogen peroxide bleaching conditions typically used for cotton, especially in high temperature processes $[157,175]$. Therefore, conventional $\mathrm{NaOH} / \mathrm{H}_{2} \mathrm{O}_{2}$ cotton bleaching treatments cannot be used with PLA/cotton blends. Alternative bleaching approaches, sodium hypochlorite $(\mathrm{NaClO})$ adjusted to $\mathrm{pH} 11$ with sodium carbonate and applied at low $\left(40^{\circ} \mathrm{C}\right)$ temperature, sodium chlorite $\left(\mathrm{NaClO}_{2}\right)$ applied at acidic $\mathrm{pH}(\sim \mathrm{pH} 4)$, or longer-time (24 h) low temperature bleaching with peroxide by cold-pad-batch methods, are better choices for preserving PLA fabric integrity [175]. Among these, bleaching under acidic conditions with sodium chlorite is able to deliver a high level of whiteness while retaining PLA yarn strength even at moderately high $\left(85^{\circ} \mathrm{C}\right)$ temperatures [175], however environmental concerns about use of chlorine-based bleaches [176] could weigh in favor of cold-pad-batch peroxide-based methods.

PLA is moderately dyeable with disperse dyes [177-179]. Due to its lower refractive index, PLA can yield a deeper shade depth than PET when dyed with the same dye 
concentration [175]. However, PLA is limited to lower dyeing temperatures $\left(100-110^{\circ} \mathrm{C}\right)$ than is typical for PET $\left(120^{\circ} \mathrm{C}\right)$ because PLA hydrolysis occurs easily at high temperature and humidity $[150,157]$. Strategies to improve dyeability include PLA knit fabric surface modification by plasma treatment or selection of specific (heterocyclic diazo) disperse dye types that favor interactions with the polymer [178]. For these dyes, $\mathrm{K} / \mathrm{S}$ color strength values, exhaustion, and wet fastness were shown to be comparable to PET fibers dyed with the same class of disperse dyes. Enhancing PLA fiber and fabric dyeability is one aspect of broadening their appeal for textile apparel applications. Under simulated conditions for dyeing cotton with reactive dyes, PLA fabric withstood processing conditions well [157]. Combined, these findings suggests that PLA/cotton blends could be single-bath dyed with alkali-stable disperse dyes and neutrally-applied reactive dyes without damage to PLA fibers.

\section{Other potential biodegradable synthetic textile polymers}

In addition to PLA [156], synthetic fiber-forming polymers considered to have acceptable biodegradability by certain standard methods include the polyesters polycaprolactone $(P C L)[115,117,180,181]$, poly(butylene adipate-co-terephthalate) (PBAT) [182], and polybutylene succinate (PBS) [10]. Polyhydroxyalkanoates (PHAs) are another broad category of biobased polymers, produced by bacteria [183-185], with good biodegradability characteristics [186], however they are primarily considered to be low melting point engineering plastics $[187,188]$. Certain PHAs, e.g. poly(hydroxybutyrate hydroxyhexanoate) (PHBH), can produce fibers by melt spinning, but the crystallization rate is slow and the reported tensile strength (156 $\mathrm{MPa}$ ) and tensile modulus (2.43 GPa) [189] are somewhat lower than is usually acceptable for apparel fibers. The aliphatic-aromatic copolymer PBAT has emerged as a biodegradable replacement for LDPE agricultural films and organic waste bags [190], and can be melt blown into fibers, offering potential for nonwoven textile applications [182]. PBAT fiber mechanical properties are comparable to polypropylene (PP), which is used for rope and in textile apparel linings. As with other semicrystalline thermoplastic polymers, PBAT fiber tensile strength and elongation depend on extrusion take-up speed, which influences fiber orientation and crystallization. At the highest processable take-up speed ( $5 \mathrm{~km} / \mathrm{min}$ ), PBAT exhibited a breaking strength around $210 \mathrm{MPa}$ and elongation at break around $1.5 \%$ [182].

With the exception of PLA, pure fibers made from these alternative polyesters do not have the physical properties needed for apparel, though they are useful in nonwovens and medical textiles. Primarily, these polymers are used commercially to produce films, molded plastic materials and for bio-based components in polyurethanes and elastomers. Given the interest in producing new sustainable textile fibers, efforts have been made to combine alternative polyesters with other polymers/fibers [172], producing blended or composite fiber materials with improved fiber properties. Because it is rare to find single sources that report both a polymer's application performance in fiber form and the biodegradability behavior of those fibers, Table 3 consolidates several studies into groups based on polymer composition to illustrate both the physical form and biodegradation assessments conducted for potentially textile-relevant synthetic materials and their blends.

\section{PET biodegradation challenge}

Poly(ethylene terephthalate) (PET) is chemically inert and highly resistant to biodegradation in anaerobic digestion or composting conditions (Fig. 12.a), even in the presence of additives meant to enhance biodegradation at those conditions [73] or in soil burial [78]. According to an Arrhenius equation-based prediction, the persistence of PET products in moist to wet soil environments at $20^{\circ} \mathrm{C}$ is 25 years or longer, and could exceed 1000 years in dry environments [191, 192]. The presence of the petrochemical-based terephthalic acid (TA) monomer creates obstacles to biodegradability due to the aromatic hydrocarbon ring that imparts polymer chain rigidity and hydrophobicity. Even after alkaline pre-treatment to increase PET surface hydrophilicity, the degradation impact by indigenous microorganisms was only observable microscopically after nine months of natural soil burial [193] and no statistically significant weight loss was observed for $87 \mu \mathrm{m}$ thick PET film after a six month greenhouse compost soil burial test [194].

\subsection{Biological PET degradation}

Unlike aliphatic polyesters, which can occur naturally in plants and bacteria, aromatic polyesters are non-natural substrates that have existed on earth for an evolutionarily short period of time, hence biological mechanisms for their degradation are rare. Remarkably, exploration of PET debris-containing sediments and other environments is uncovering new microbial species and enzymes capable of degrading amorphous PET. Culturing the bacterium Ideonella sakaiensis 201-F6 in the presence of low (1.9\%) crystallinity PET at mesophilic $\left(30^{\circ} \mathrm{C}\right)$ conditions led to identification and isolation of novel recombinant enzymes 
Table 3 Polymers with biodegradability characteristics and potential for textile applications

\begin{tabular}{|c|c|c|c|}
\hline Material & Physical form/application & Biodegradation conditions (test method, if reported) & References \\
\hline \multicolumn{4}{|l|}{ PLA } \\
\hline PLA & Film/food packaging & Compost; Soil Burial & Karamanlioglu et al. [66] \\
\hline PLA & Nonwoven & Compost (PN-EN 14,045; PN-EN 14,806) & Gutowska et al. [114] \\
\hline PLA & Nonwoven & $\begin{array}{l}\text { Thermophilic Aerobic (ASTM 5209) and Anaerobic } \\
\text { (ASTM 5511) Conditions }\end{array}$ & Itävaara et al. [116] \\
\hline PLA & Pellets & Landfill (ASTM 5526) & Kolstad et al. [263] \\
\hline PLA & Fiber & Activated Sludge & Rom et al. [264] \\
\hline PLA & Yarn, fabric & & Sülar et al. [163] \\
\hline \multicolumn{4}{|l|}{ PLA blends } \\
\hline PLA/PCL; PLA; PCL & Powder & Anaerobic Sludge & Yagi et al. [117] \\
\hline PLA/PCL & Pellets & & Simoes et al. [265] \\
\hline PLA/PHB & $80 / 20$ blend nonwoven & Soil Burial & Liu et al. [266] \\
\hline PLA/lyocell & Blended yarns & & Jabbar et al. [170] \\
\hline $\mathrm{PLA} / \mathrm{PHA}$ & Nonwoven & & Szuman et al. [97] \\
\hline PLA/P3HB4HB & Composite fiber & & Chen et al. [267] \\
\hline PLA/cotton & Yarn, fabric & & Guruprasad et al. [169] \\
\hline PLA/PHBV & Yarns & & Huang et al. [171] \\
\hline \multicolumn{4}{|l|}{ PCL } \\
\hline $\mathrm{PCL}$ & Nonwoven & Lab cultured soil filamentous fungi & Ohkawa et al. [268] \\
\hline $\mathrm{PCL}$ & Film & Pond water and seawater & Heimowska et al. [80] \\
\hline $\mathrm{PCL}$ & Film & Embedded lipase enzymes & Huang et al. [82] \\
\hline \multicolumn{4}{|l|}{ PBAT } \\
\hline PBAT & Film & Compost (ASTM D5338) & Kijchavengkul et al. [96] \\
\hline PBAT & Film & Soil Incubation & Zumstein et al. [74] \\
\hline PBAT & Fiber & & Shi et al. [182] \\
\hline \multicolumn{4}{|l|}{ PBAT blends } \\
\hline PBS, PBAT, PBS/PBAT & fiber or copolymer & & Muthuraj et al. [269] \\
\hline \multicolumn{4}{|l|}{ PHBH } \\
\hline $\mathrm{PHBH}$ & Film & Seawater & Morohoshi et al. [270] \\
\hline $\mathrm{PHBH}$ & Powder & Seawater & Sashiwa et al. [112] \\
\hline $\mathrm{PHBH}$ & Powder & Seawater & Nakayama et al. [113] \\
\hline $\mathrm{PHBH}$ & Fiber & & Qin et al. [189] \\
\hline
\end{tabular}

that hydrolyze PET and the reaction intermediate, mono(2hydroxyethyl) terephthalic acid (MHET) [84]. Also, even though the organism producing the enzyme has not yet been identified, another important PET hydrolyzing enzyme, LC-cutinase (LCC), was retrieved by metagenomic methods from DNA extracted from $\sim 70^{\circ} \mathrm{C}$ compost made from leaves and branches at EXPO Park, Japan $[195,196]$. Other cutinase enzymes from the thermophilic actinomycete Thermobifida fusca (TfCut2) and the fungus Humicola insolens $(\mathrm{HiC})$ are also active for sufficiently long times at $70^{\circ} \mathrm{C}\left(\sim \mathrm{T}_{\mathrm{g}}\right.$ of PET) to exhibit hydrolytic activity on low crystallinity PET $[197,198]$.

Based on an analysis of individual chemical conversion steps identified in different organisms, a comprehensive review by Salvador et al. [199] conceptually consolidated the mechanisms required for a hypothetical microorganism to fully metabolize PET. In the compiled scheme (Fig. 13), extracellular enzyme-catalyzed depolymerization is the first essential step for decreasing the large molecular size of PET polymers to oligomer/monomersized compounds that can be transported into microbial cells. For some enzymes, inhibition by the hydrolysis reaction products, MHET and bis-(2-hydroxyethyl) terephthalate (BHET), can occur. This may be overcome naturally by the presence of other endogenous synergistic enzyme activities (such as I. sakaiensis MHETase $[200,201])$, or artificially by applying enzyme mixtures $[202,203]$, by selecting and engineering alternative enzymes [204], or through intentional promotion of the glycolysis reaction [205].

Once depolymerized, monomeric degradation products must undergo further biochemical conversion (Fig. 13). Ethylene glycol is readily metabolized inside cells through 


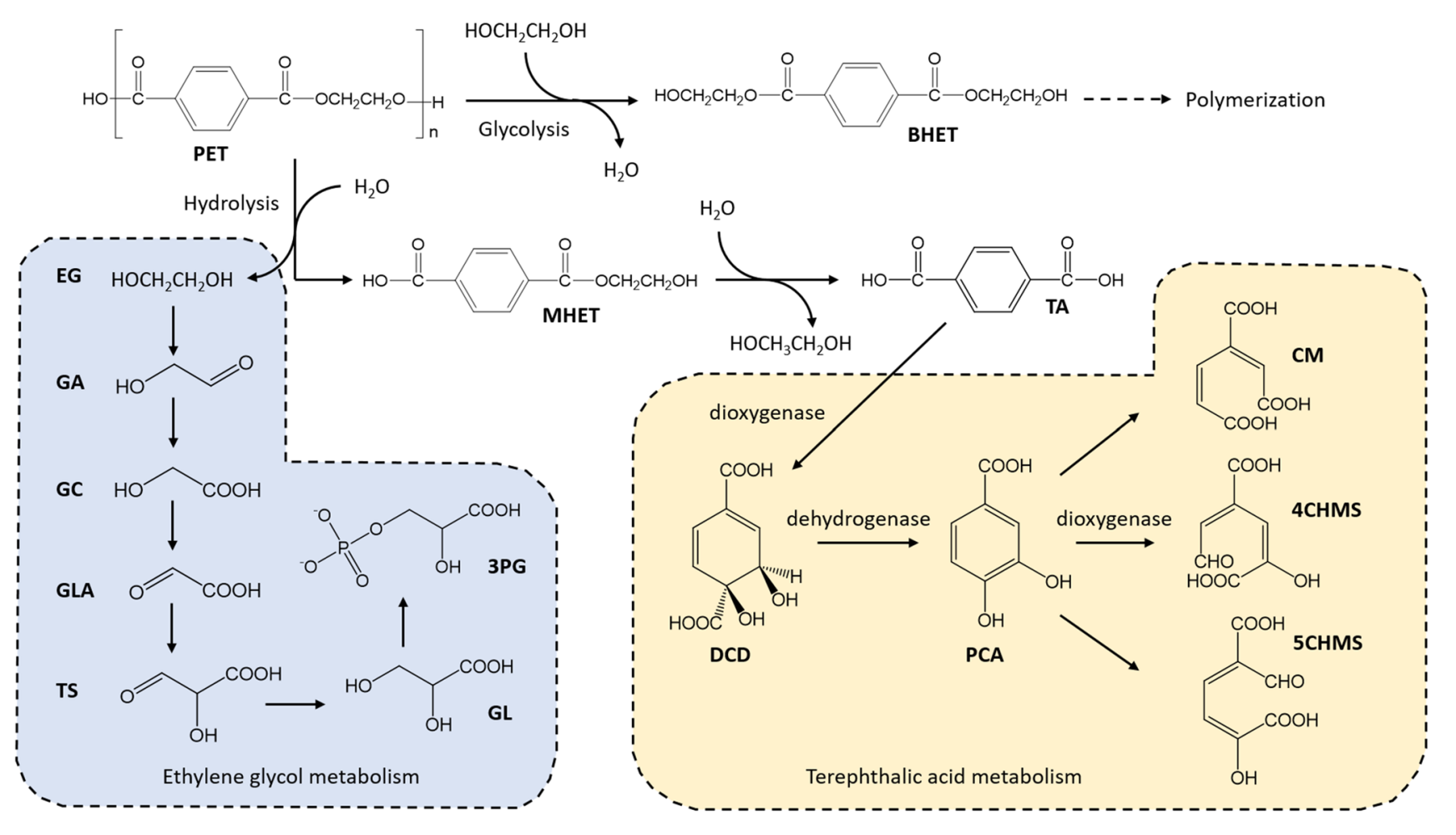

Fig. 13 Chemical pathways for enzyme hydrolysis and glycolysis of PET [205] and potential pathways for metabolic degradation of product compounds based on a consolidation by Salvador et al. [199] of discrete steps observed in bacteria

different pathways depending on the microorganism, e.g. conversion to acetate via acetyl-CoA in acetogen bacteria or conversion to glyoxylate and then to the phosphoglycerate pathway or to the Krebs cycle via isocitrate or malate [199]. In the bacterial 3-phosphoglycerate (3PG) metabolic pathway, ethylene glycol (EG) is first converted to glyoxylate (GLA) through conversions involving glycoladehyde (GA) and glycolate (GC), followed by conversion of GLA to tartronate semialdehyde (TS) and then to glycerate (GL) before conversion to 3PG, which is an essential precursor compound of the central metabolism [199].

The metabolism of terephthalic acid requires transport into the cell via a permease together with an aromatic acid transporter, followed by addition of two hydroxyl groups through the activity of TA dioxygenase, to produce 1,6-dihydroxycyclohexa-2,4-diene-dicarboxylate $(D C D)$, then conversion to protocatechuate (PCA) by the removal of a carbonyl group through the action of a dicarboxylate dehydrogenase. The aromatic ring of PCA is cleaved in a dioxygenolytic step that can follow different paths, depending on the enzyme, to form 3-carboxycis,cis-muconate (CM), 4-carboxy-2-hydroxymuconate semialdehyde (4CHMS), or 5-carboxy-2-hydroxymuconate6-semialdehyde (5CHMS), followed by further degradation inside the cell to molecular fragments that can enter the central metabolism [199].

\subsection{Enzymatic hydrolysis of PET}

Instead of creating new, more biodegradable polymers with similar properties to PET, another approach is to break PET down to its monomer constituents and recycle the monomers to produce new polymer. Both chemical [206] and biochemical approaches are being pursued [207]. Within biochemical approaches, the term "enzymatic recycling" has emerged to describe contained industrial degradation processes that use enzymes (absent microorganisms) to depolymerize polymers to monomers that can be separated, purified, and reused to produce virgin polymer or other materials [202]. Various hydrolytic enzymes, classified as carboxylesterases (EC 3.1.1.1), lipases (EC 3.1.1.3), and cutinases (EC 3.1.1.74), catalyze different extents of PET degradation, depending on many factors [208]. In particular, enzyme hydrolysis is more efficient for amorphous (low crystallinity) PET $[209,210]$ with small particle size [198]. Enzymatic hydrolysis of amorphous PET yields $T A, E G$, and, depending on the enzyme, an enzymeinhibiting dimer (MHET). Enzyme-induced PET glycolysis is reported to be more effective for recycling compared to hydrolysis reactions because glycolysis can yield products (BHET, Fig. 13) that directly enter the polymerization reactor, unlike the monosubstituted (MHET) hydrolysis byproduct [205]. Optimization of glycolysis processes could lead 
to lower cost and energy during PET recycling, however the needed levels of efficiency must be demonstrated.

Recently, a new classification (EC 3.1.1.101) was created for enzymes, like the PET hydrolyzing enzyme from I. sakaiensis, called PET hydrolases, or "PETases" [84, 202]. PETases are capable of causing extensive surface erosion of amorphous (2-7\% crystallinity) PET polymer films, visible by SEM as holes or pores across the film surface, followed by bulk degradation effects $[84,211,212]$. This deep erosion effect distinguishes PET hydrolases from PET surfacemodifying enzymes, which are enzymes that may change superficial PET properties, such as imparting surface hydrophilicity, without causing visible changes in the material structure or substantial weight loss. Investigation of initial catalytic rates $\left(\mathrm{k}_{\mathrm{cat}}\right)$ measured at low extents of PET hydrolysis showed that the PET hydrolytic efficiency of a protein engineered variant (S238F/W159H) of I. sakaiensis PETase (IsP) was explained by its rapid turnover on semicrystalline PET at $50^{\circ} \mathrm{C}$ ( $k_{\text {cat }}$ is $1-2$ orders of magnitude larger) compared to that of two cutinases ( $\mathrm{HiC}$ and TfCut2), rather than substrate affinity, which was similar among the samples [213]. However, at higher temperatures near Tg, where PET polymer chains are more accessible, IsP is unstable, hence cutinases are preferred for those investigations.

Research on modifying the structures of PET hydrolyzing enzymes to improve thermal stability and improve PET hydrolysis rates is progressing rapidly. In one example, thin $(250 \mu \mathrm{m})$ amorphous PET films exhibited up to $95 \%$ weight loss within $48 \mathrm{~h}$ at $\mathrm{pH} 8$ and $70^{\circ} \mathrm{C}$ when treated with a glycosylated leaf and branch compost cutinase (LCC-G) [214]. The corresponding non-glycosylated LCC achieved 31\% depolymerization (calculated on the basis of $\mathrm{NaOH}$ consumption) of bottle grade PET after 3 days at $\mathrm{pH} 8$ and $65^{\circ} \mathrm{C}$ [204]. As reported by Kawai et al., in aqueous solutions, the $\mathrm{Tg}$ of amorphous PET can be as low as $60-65^{\circ} \mathrm{C}$, making this form of PET more accessible to enzymatic attack than the higher crystallinity (30-40\% or more) PET present in bottles and textile fibers at lower temperatures [211].

Subsequently, by implementing several modifications to the LCC enzyme and maintaining the reaction temperature at $72{ }^{\circ} \mathrm{C}$ to minimize PET recrystallization, Tournier et al. [204] reported achieving an impressive $90 \%$ depolymerization within $10 \mathrm{~h}$ (calculated on the basis of $\mathrm{NaOH}$ consumption) of post-consumer colored-flake PET waste that was pretreated at ton scale by extrusion and micronization to "amorphize" the PET and increase its accessible surface. The average degradation efficiency over the course of the reaction, reported as productivity of TA monomer (16.7 $\left.\mathrm{g}_{\mathrm{TA}} \mathrm{L}^{-1} \mathrm{~h}^{-1}\right)$, was significantly higher than the cited values for enzymatic degradation of starch $(4 \mathrm{~g}$ $\left.\mathrm{L}^{-1} \mathrm{~h}^{-1}\right)$ and cotton $\left(0.31 \mathrm{~g} \mathrm{~L}^{-1} \mathrm{~h}^{-1}\right)$. The operational factors underlying this remarkable result show striking differences compared to cellulose hydrolysis, which has been the focus of substantial research in biomass conversion to glucose for production of ethanol and other bioproducts by fermentation [162]. Essentially, it is the combination of three factors, high substrate concentration $(200 \mathrm{~g} / \mathrm{L})$, high extent of conversion (90\%) and short time (10 h), that delivers the high degradation productivity. This high productivity is further driven by a fast initial conversion rate $\left(42.1 \mathrm{~g}_{\mathrm{TA}} \mathrm{L}^{-1} \mathrm{~h}^{-1}\right)$ that is almost three times faster than maximal initial hydrolysis rates $\left(15 \mathrm{~g}_{\text {cellobiose }} \mathrm{L}^{-1} \mathrm{~h}^{-1}\right)$ reported for cellulase catalyzed degradation of $0.78 \mu \mathrm{m}$ cellulose particles [215]. Even when cellulose particle size is reduced to submicron dimensions [216], overall monomer productivity rates reported for different cellulosic materials are similar to each other and lower compared to the PET result (Table 4). To make the monomer productivity rate $\left(\mathrm{g} \mathrm{L}^{-1} \mathrm{~h}^{-1}\right)$ comparisons shown in Table 4, published values for substrate concentration, percent conversion, and reaction time were used in Eq. 1, together with the appropriate mass conversion factor (MCF) (see footnotes of Table 4) to correct for the mass difference between the monomer produced and the repeat units in the polymer. In the cellulose degradation cases, the generally lower substrate concentrations, governed by product inhibition and water absorption that leads to high viscosity [162, 217, 218], and longer reaction times needed to reach high levels of cellulose depolymerization (involving "burst-phase" substrate accessibility behavior [162]) dominate the productivity calculation. Notably, no product inhibition by EG or TA was observed in LCC-ICCG catalyzed PET hydrolysis [204], whereas product inhibition by glucose and cellobiose in cellulase hydrolysis of cellulose is well documented [219]. Recovered TA was purified and repolymerized to bottle-grade PET using conventional methods [204]. Meanwhile, parallel work has already extended the concept towards fully biological upcycling by feeding enzymatically degraded polyester hydrosylates to bacteria in a bioreactor to produce PHA or bio-based poly(amide urethane) products [220]. These significant demonstrations of PET conversion efficiency show that multifaceted strategies-combining biocatalyst improvements through targeted protein engineering that increases substrate affinity and stability while preserving catalytic efficiency, together with thermo-mechanical pretreatments that decrease crystallinity and improve solid substrate accessibility, taking advantage of process conditions that favor depolymerization, and developing integrated bioprocessescan result in step change improvements towards circular reprocessing. Such work should inspire further research into similar strategies for other polymer and fiber types.

Productivity $\left(g L^{-1} h^{-1}\right)=\frac{\left[\text { SubstrateConc. }\left(g L^{-1}\right) \times \text { Conversion }(\%)\right] \times M C F}{[100 \times \operatorname{Time}(h)]}$ 
Table 4 Productivity rates for enzyme hydrolysis of PET and cellulose

\begin{tabular}{|c|c|c|c|c|c|}
\hline Substrate / enzyme & $\begin{array}{l}\text { Substrate } \\
\text { Conc. (g } \\
\left.\mathrm{L}^{-1}\right)\end{array}$ & Time (h) & $\begin{array}{l}\text { Conversion } \\
\text { efficiency } \\
(\%)\end{array}$ & $\begin{array}{l}\text { Monomer } \\
\text { productivity (g } \\
\mathrm{L}^{-1} \mathrm{~h}^{-1} \text { ) }\end{array}$ & Ref. \\
\hline $\begin{array}{l}\text { Micronized and "amorphized" post-consumer PET / Protein engineered } \\
\text { PETase (LCC-ICCG) }\end{array}$ & 200 & 10 & 90 & $16.7^{\mathrm{a}}$ & [204] \\
\hline \multirow{2}{*}{$\begin{array}{l}\text { Phosphoric acid pretreated cotton linters / cellulase AP3 from Aspergillus } \\
\text { niger }\end{array}$} & 20 & 7 & $\sim 82$ & $2.6^{\mathrm{b}}$ & \multirow[t]{2}{*}{217} \\
\hline & 20 & 48 & 91 & $0.42^{b}$ & \\
\hline $\begin{array}{l}\text { Homogenized partially crystalline Avicel } 96 \% \text { cellulose / Celluclast }{ }^{\mathrm{Tm}} \text { cellulase } \\
\text { mixture from Trichoderma reesei plus Novozym } 188^{\circledR} \text { beta glucosidase from } \\
\text { Aspergillus niger }\end{array}$ & $\sim 190$ & 18 & 20 & $2.3^{\mathrm{b}}$ & [162] \\
\hline $\begin{array}{l}\text { Rayon fibers, } 30 \% \text { crystallinity, containing } 20 \% \text { flame-retardant pigment / } \\
\text { Commercial Cellic }{ }^{\circledast} \text { CTec3 cellulase mixture }\end{array}$ & 20 & 8 & 80 & $2.2^{\mathrm{b}}$ & [271] \\
\hline $50 \mu \mathrm{m}$ Avicel PH-101 / multicomponent cellulase from Trichoderma viride & 20 & 8.3 & $\sim 70$ & $1.9^{\mathrm{b}}$ & {$[272]$} \\
\hline Low-crystallinity (7\%) PET film / Cutinase from Humicola insolens ( $\mathrm{HiC})$ & 80 & 96 & 97 & $0.70^{c}$ & {$[210]$} \\
\hline $\begin{array}{l}{ }^{14} \mathrm{C} \text {-Labeled bacterial cellulose from Gluconobacter xylinum / cellulase mix- } \\
\text { ture with AtCel7A }\end{array}$ & 0.25 & 0.5 & 90 & $0.50^{\mathrm{b}}$ & [219] \\
\hline $\begin{array}{l}\mathrm{NaOH} / \text { urea pretreated } 40 / 60 \text { PET-cotton blend milled to }<1 \mathrm{~mm} / \text { Celluclast } \\
1.5 \mathrm{~L} \text { cellulase and Novozym } 188 \beta \text {-glucosidase }\end{array}$ & 30 & 72 & 91 & $0.42^{\mathrm{b}}$ & {$[273]$} \\
\hline Dewaxed cotton / artificial cellulase mixture from C. lucknowense & 25 & 72 & 84 & $0.32^{b}$ & {$[274]$} \\
\hline $\begin{array}{l}\text { 40/60 PET-cotton blend milled to }<1 \mathrm{~mm} \text { / Celluclast } 1.5 \mathrm{~L} \text { cellulase and Novo- } \\
\text { zym } 188 \beta \text {-glucosidase }\end{array}$ & 30 & 72 & 46.3 & $0.21^{\mathrm{b}}$ & [273] \\
\hline $\begin{array}{l}\text { Microcrystalline cotton cellulose milled to } 0.78 \mu \mathrm{m} \text { size with } 25.5 \mathrm{~m}^{2} \mathrm{~g}^{-1} \\
\text { surface area / commercial cellulase from T. reesei }\end{array}$ & 2.5 & 10 & 60 & $0.17^{b}$ & [215] \\
\hline $\begin{array}{l}\text { Highly crystalline (41.1\%) PC-PET / Novozym 51,032 cutinase from Humicola } \\
\text { insolens (HiC) }\end{array}$ & 80.8 & 240 & 23 & $0.07^{c}$ & [202] \\
\hline
\end{tabular}

a) Reported in the citation; b) estimated by Eq. 1 using $M C F=1.11 g_{\text {glucose }}$ per $g_{\text {anhydroglucose; }}$ ) estimated by Eq. 1 using $M C F=0.864 g_{\text {TPA }}$ per gPET

\subsection{PET modifications}

Other strategies to circumvent PET resistance to biodegradation have been developed where "triggering" technologies are incorporated that help the polymer degrade once it is exposed to different environments than during normal use. For example, PET has been modified by incorporating additives, including calcium carbonate $(\sim 1 \%)$ and a combination of different biodegradable polymers like PCL, PHB, PBS, PBAT and PLA ( 60\%) to the PET ( 40\%) melt-spinning dope [221]. The calcium carbonate acts as a nucleation site for degradation, which can propagate through the biodegradable polymer components. Because these components are added in the fiber spinning process, the nucleation sites and degradable regions of the fibers are present throughout the fiber cross section rather than just on the surface, which can be a drawback of biodegradation-enhancing finishes. The dispersion of nucleation sites and degradable regions throughout the fiber enhances accessibility for chemical and biological degradation when the material is exposed to sufficiently active degradation conditions. This PET is described as having good dimensional stability, no pilling, and virtually the same fiber wicking properties as conventional PET [221]. The compounded fiber is claimed to biodegrade by about $60 \%$ (an amount that may correspond to the aliphatic biodegradable polyester content) within about four months, and then degrade more slowly to about $90 \%$ over another three years at simulated anaerobic landfill conditions according to the respirometric method ASTM D5511 [222]. For the technology to reduce waste accumulation, upon disposal, fibers must be exposed to continuous moist environments that eventually allow water to penetrate the fiber and activate the hydrolytic triggering compounds. In view of PET's known biological recalcitrance (Fig. 12), triggering strategies based on material compounding warrant further investigation of the degradation mechanisms, careful accounting of the fate of disintegrated fragments, and establishing frameworks for disposal to occur in properly controlled environments.

\subsection{Replacing monomers in PET}

Already, the ethylene glycol component of PET has been substantially replaced with biobased components from ethanol [223]. Likewise, 1,3-propanediol used 
for poly(trimethylene terephthalate) (PTT)) [224] and 1,4-butanediol used for poly(butylene terephthalate) (PBT) are produced from renewable raw materials to both address sustainability principles and provide new functionality. Such approaches have led to the development of more complex aromatic-aliphatic co-polyesters, where the introduction of aliphatic ester segments makes the polymer hydrolyze more easily [225]. Examples include poly(butylene adipate-co-terephthalate) (PBAT) [96] and poly(butylene succinate-co-terephthalate) (PBST) [226], expanding the realm of new fiber possibilities.

Currently, TA monomer is produced by oxidation of petroleum-derived $p$-xylene. Extensive efforts to identify renewable TA feedstock pathways [223] have led to advances with 5-(chloromethyl)furfural (CMF) as a biobased intermediate to $p$-xylene $[227,228]$. While these approaches address feedstock sustainability, the resulting polymer will be chemically identical to conventional PET, with no change in biodegradability profile. Efforts to replace TA with monomers that could potentially have a better overall sustainability profile without compromising mechanical properties have resulted in development of 2,5-furandicarboxylic acid (FDCA) as a bio-based rigid diacid monomer alternative to $\mathrm{TA}$, with similar physical and chemical properties [229]. FDCA is produced from biobased feedstocks through a process of bioconversion, dehydration, and oxidation [230]. Some advantages of poly(ethylene furanoate) (PEF) - the most common polymer made using FDCA —include improved mechanical and barrier properties and desirable thermal properties like a lower $\mathrm{T}_{\mathrm{m}}$ and higher $\mathrm{T}_{\mathrm{g}}$ compared to PET [226, 229, 231, 232]. PEF disadvantages, relative to $P E T$, include higher cost and lower crystallization rate [226, 231]. Enzyme degradability studies showed that amorphous PEF film could completely degrade within $72 \mathrm{~h}$ at $65^{\circ} \mathrm{C}$ when treated with $\mathrm{HiC}$ cutinase [232] and an isosorbide/FDCA copolyester was able to fulfill the compostability requirements (disintegration within 12 weeks and $\geq 90 \%$ conversion to $\mathrm{CO}_{2}$ within six months) of the EN 13,432 Standard [226]. However, like PET, size reduction and decrystallization strategies would be needed for fiber-quality PEF to be susceptible to biological degradation as part of a waste management approach.

\section{Future directions}

Given the vastness of consumer textile product diversity and complexity-intimate fiber blends, complex polymer morphology, chemical additives, seams, and embellishments - to date there have been relatively few studies that enlist biodegradation as a route to improved sustainability, though interest is increasing [8]. Most studies include cotton as a reference for favorable biodegradation behavior, though not always using standard methods. Absent dyes and chemical finishes, scoured or bleached cotton textiles can meet soil burial and anaerobic digestion biodegradability criteria established for plastics testing, and may meet composting and seawater biodegradability criteria in certain circumstances. However, the presence of dyes and finishes can inhibit biodegradation, and more work is needed to understand the effects. When pure conventional synthetic fibers (e.g. PET, nylon and acrylic) are tested, little to no biodegradability is detected by plastics standard methods, even after more than one year. This is attributed to the highly ordered, relatively hydrophobic structures of synthetic fibers that create physical barriers to bond cleavage by water or microbial enzymes. Even natural fibers present structural obstacles to rapid biodegradation, however, their combination of hydrophilicity and greater chemical reactivity align with biodegradation as an eventual outcome. In laboratory evaluations, degradation rates are increased by grinding substrates into small sizes, implying that mechanical processing would be required for efficient biodegradation of apparel. Additionally, thermal and chemical treatments that disrupt fiber crystallinity are important for increasing degradation efficiency and lead to significant increases in enzyme catalyzed hydrolysis rates, especially for enzymes that have been selected or engineered to act on specific polymer substrates. Such hybrid processes can dramatically improve process efficiency, as is evident in the work where engineered enzymes applied to small amorphous particles of PET plastic at carefully selected reaction conditions catalyzed depolymerization to monomers at productivity rates higher than have yet been observed for other textile fiber types (Table 4). Among the "new" synthetic textile fibers, PLA is the most advanced in terms of combining a sustainable biobased origin with favorable apparel fiber properties that also meet certain standard biodegradability criteria.

The evolution of new synthetic fibers and recycling strategies, motivated by the desire for increased sustainability, requires parallel adaptation of waste management practices and consumer behaviors to support the innovations. For "biodegradable" labeling to have beneficial impact, the material must meet specific test method requirements and accessible options for proper disposal must exist. In the absence of specific standardized test methods for textile biodegradation, surrogate methods developed for other materials (plastics) have become the default reference. While these methods could be helpful in predicting the fate of textile fibers released to the environment, they have not been employed in a focused way to generate alternatives to textile waste accumulation by dumping and landfilling. At minimum, textile waste 
Fig. 14 Future directions for biodegradability research to improve textile sustainability

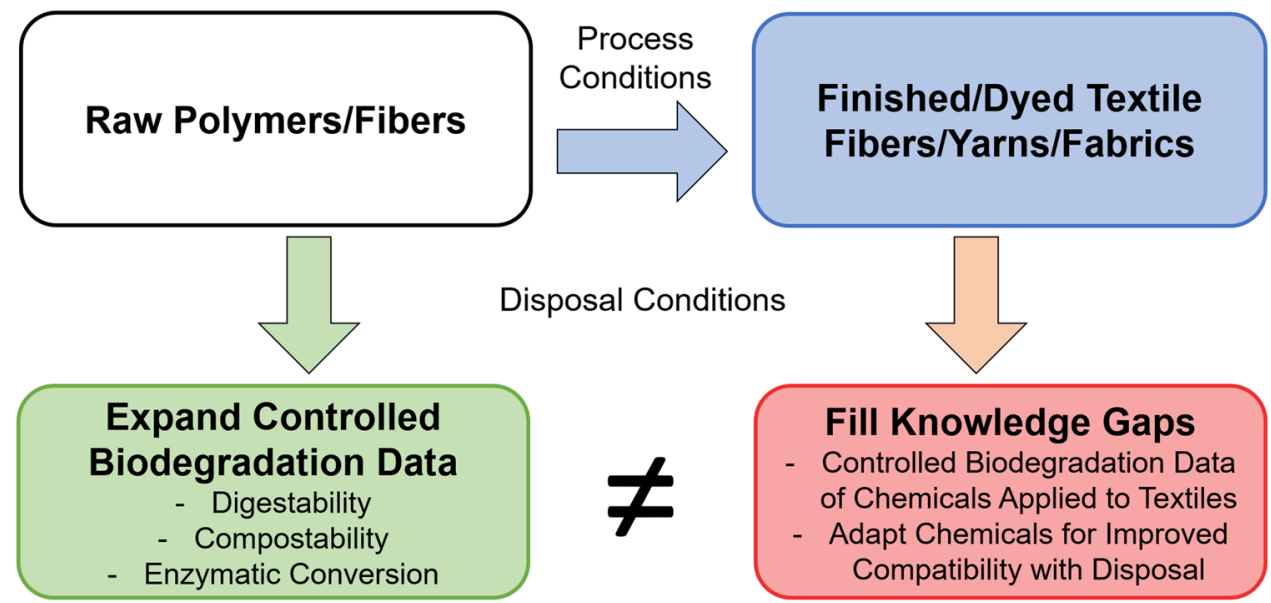

persistence of less than five years (the average textile product lifetime [7]) seems essential to curtail accumulation, and much faster conversion will be necessary for waste minimization and value-generating industrial processes, e.g. composting, digestion or enzymatic recycling. Because textiles need to maintain good physical properties during the product lifetime, waste treatment strategies that apply moderate process intensification conditions not encountered during normal use-combinations of heat, moisture, mixing/shearing, enzymes and microorganisms-will lower the risk for poor product performance while increasing waste conversion efficiency. More rigorous studies with respect to conversion efficiency are needed to expand knowledge on textile fiber digestibility, compostability and enzymatic conversion. Disposal assessments that account for the presence and impact of textile chemical treatments are also urgently needed because this aspect is largely unexplored (Fig. 14).

Continued research across disciplines will improve biodegradation and biorecycling options. This includes development of composite polymer/fiber blends [233-235], production of biosynthetic and microbial fibers [236, 237], re-engineering of natural fibers [238], advances in biodegradable co-polymers [58], introducing biostimulation and bioaugmentation [239, 240], identifying and modifying enzymes for improved depolymerization [132, 204, 241-244], engineering microorganisms to produce polymer degrading enzymes [245-247], adaptively evolving microorganisms to metabolize non-natural substrates [220], combining biological and chemical recycling [206, 248], identifying structure-activity relationships for dye biodegradation [249], establishing biodegradation and recycling pathways for dyes and finishes $[35,42,109,111$, $250,251]$, and even uncovering relationships between the human microbiome and the clothes we wear [252]. Emerging and combined concepts from across these disciplines will reveal new opportunities to merge performance with sustainability and lead to improved textile waste management infrastructure, where circular manufacturing and sustainable handling of disposed materials become the norm.

Acknowledgements The authors appreciate constructive discussions with Dr. Renuka Dhandapani throughout the preparation of this work.

Author's contributions The authors contributed equally to research and preparation of the manuscript. Sonja Salmon conceived of the topic and made final revisions.

Funding This work was made possible by financial support from Cotton Incorporated, Cary, NC [Project 20-697], from Wilson College of Textiles at North Carolina State University, Raleigh, NC and by a scholarship to JE from the Environmental Research and Education Foundation.

\section{Declarations}

Conflict of interest The authors declare no conflict of interest regarding the publication of this manuscript.

Availability of data and material All data analyzed for this work are included in this published article, in the References, or in the associated Supplementary Information.

Open Access This article is licensed under a Creative Commons Attribution 4.0 International License, which permits use, sharing, adaptation, distribution and reproduction in any medium or format, as long as you give appropriate credit to the original author(s) and the source, provide a link to the Creative Commons licence, and indicate if changes were made. The images or other third party material in this article are included in the article's Creative Commons licence, unless indicated otherwise in a credit line to the material. If material is not included in the article's Creative Commons licence and your intended use is not permitted by statutory regulation or exceeds the permitted use, you will need to obtain permission directly from the copyright holder. To view a copy of this licence, visit http://creativecommons. org/licenses/by/4.0/. 


\section{References}

1. Kaza S, Yao L, Bhada-Tata P, Van Woerden F (2018) What a Waste 2.0 - A Global Snapshot of Solid Waste Management to 2050. The World Bank. 1-272. https://doi.org/10.1596/978-1-4648-1329-0

2. United Nations Statistics Division-Environment Statistics Section (2020) Environment Statistics. Waste: Composition of municipal waste (latest year). https://unstats.un.org/ unsd/envstats/qindicators.cshtml. Accessed 17 Jan 2021

3. Chiara Campione (2017) Copenhagen Fashion Summit: How NOT to make the fashion industry more sustainable - Greenpeace International. https://www.greenpeace.org/internatio $\mathrm{nal} /$ story/7575/copenhagen-fashion-summit-how-not-tomake-the-fashion-industry-more-sustainable/. Accessed 25 Jun 2020

4. Bukhari MA, Carrasco-Gallego R, Ponce-Cueto E (2018) Developing a national programme for textiles and clothing recovery. Waste Manag Res 36:321-331. https://doi.org/10.1177/ $0734242 \times 18759190$

5. United States Environmental Protection Agency (2020) Advancing Sustainable Materials Management: 2018 Fact Sheet. https://www.epa.gov/sites/production/files/2020-11/ documents/2018_ff_fact_sheet.pdf

6. Powell JT, Chertow MR (2019) Quantity, components, and value of waste materials landfilled in the United States. J Ind Ecol 23:466-479. https://doi.org/10.1111/jiec.12752

7. Geyer R, Jambeck JR, Law KL (2017) Production, use, and fate of all plastics ever made. Sci Adv 3:1-5. https://doi.org/10. $1126 /$ sciadv. 1700782

8. Jönsson C, Wei R, Biundo A, Landberg J, Schwarz Bour L, Pezzotti F, Toca A, Jacques LM, Bornscheuer UT, Syrén P-O (2021) Biocatalysis in the recycling landscape for synthetic polymers and plastics towards circular textiles. Chemsuschem 14:1-14. https://doi.org/10.1002/cssc.202002666

9. Koller M, Mukherjee A (2020) Polyhydroxyalkanoates-Linking properties applications and end-of-life options. Chem Biochem Eng Q 34:115-129. https://doi.org/10.15255/ CABEQ.2020.1819

10. Zhu Y, Romain C, Williams CK (2016) Sustainable polymers from renewable resources. Nature 540:354-362. https://doi.org/10. 1038/nature21001

11. Wurm FR, Spierling S, Endres HJ, Barner L (2020) Plastics and the environment-current status and challenges in Germany and Australia. Macromol Rapid Commun 41:2000351. https:// doi.org/10.1002/marc.202000351

12. Werpy T, Petersen G (2004) Top Value Added Chemicals from Biomass. https://www.osti.gov/biblio/926125-top-valueadded-chemicals-from-biomass-results-screening-potentialcandidates-from-sugars-synthesis-gas

13. Fitzgerald N, Bailey A (2018) Moving Beyond Drop-In Replacements: Performance-Advantaged Biobased Chemicals: Workshop Summary Report. https://www.energy.gov/sites/prod/ files/2018/06/f53/Performance-Advantaged Biobased Chemicals Workshop Report.pdf

14. Jambeck JR, Geyer R, Wilcox C, Siegler TR, Perryman M, Andrady A, Narayan R, Law KL (2015) Plastic waste inputs from land into the ocean. Science 347:768-771. https://doi.org/10.1126/scien ce.1260352

15. Endres H-J (2019) Bioplastics. In: Wagemann K, Tippkötter N (eds) Biorefineries Advances in Biochemical Engineering/Biotechnology. Springer, Cham., pp 427-468

16. Holmberg AL, Reno KH, Wool RP, Epps TH (2014) Biobased building blocks for the rational design of renewable block polymers. Soft Matter 10:7405-7424. https://doi.org/10.1039/ c4sm01220h
17. Emadian SM, Onay TT, Demirel B (2017) Biodegradation of bioplastics in natural environments. Waste Manag 59:526-536. https://doi.org/10.1016/j.wasman.2016.10.006

18. Lamberti FM, Román-Ramírez LA, Wood J (2020) Recycling of Bioplastics: routes and Benefits. J Polym Environ 28:2551-2571. https://doi.org/10.1007/s10924-020-01795-8

19. Goel V, Luthra P, Kapur GS, Ramakumar S (2021) Biodegradable/ Bio-plastics: Myths and Realities. J Polym Environ 29:30793104. https://doi.org/10.1007/s10924-021-02099-1

20. Shruti VC, Kutralam-Muniasamy G (2019) Bioplastics: missing link in the era of microplastics. Sci Total Environ 697:134139. https://doi.org/10.1016/j.scitotenv.2019.134139

21. Bhagwat G, Gray K, Wilson SP, Muniyasamy S, Vincent SGT, Bush $R$, Palanisami T (2020) Benchmarking bioplastics: a natural step towards a sustainable future. J Polym Environ 28:3055-3075. https://doi.org/10.1007/s10924-020-01830-8

22. McDonald JE, Houghton JNI, Rooks DJ, Allison HE, Mccarthy AJ (2012) The microbial ecology of anaerobic cellulose degradation in municipal waste landfill sites: evidence of a role for fibrobacters. Environ Microbiol 14:1077-1087. https://doi.org/ 10.1111/j.1462-2920.2011.02688.x

23. Ansari IA, East GC, Johnson DJ (2003) Structure-property relationships in natural cellulosic fibres: part IV: biodegradability of textile fibres. J Text Inst 94:16-36. https://doi.org/10.1080/ 00405000308630591

24. Textile Exchange (2020) Preferred Fiber \& Materials Market Report 2020. https://textileexchange.org/wp-content/uploa ds/2020/06/Textile-Exchange_Preferred-Fiber-Material-Market-Report_2020.pdf

25. Carney Almroth BM, Åström L, Roslund S, Petersson H, Johansson M, Persson NK (2018) Quantifying shedding of synthetic fibers from textiles; a source of microplastics released into the environment. Environ Sci Pollut Res 25:1191-1199. https://doi. org/10.1007/s11356-017-0528-7

26. Re V (2019) Shedding light on the invisible: addressing the potential for groundwater contamination by plastic microfibers. Hydrogeol J 27:2719-2727. https://doi.org/10.1007/ s10040-019-01998-x

27. Bruce N, Hartline N, Karba S, Ruff B, Sonar S (2017) Microfiber Pollution and the Apparel Industry Bren School of Environmental Science \& Management. Santa Barbara, CA

28. Suaria G, Achtypi A, Perold V, Lee JR, Pierucci A, Bornman TG, Aliani S, Ryan PG (2020) Microfibers in oceanic surface waters: a global characterization. Sci Adv 6:1-8. https://doi.org/10.1126/ sciadv.aay8493

29. Zambrano MC, Pawlak JJ, Daystar J, Ankeny M, Cheng JJ, Venditti RA (2019) Microfibers generated from the laundering of cotton, rayon and polyester based fabrics and their aquatic biodegradation. Mar Pollut Bull 142:394-407. https://doi.org/ 10.1016/j.marpolbul.2019.02.062

30. Cesa FS, Turra A, Checon HH, Leonardi B, Baruque-Ramos J (2020) Laundering and textile parameters influence fibers release in household washings. Environ Pollut. https://doi.org/ 10.1016/j.envpol.2019.113553

31. Peters G, Li M, Lenzen M (2021) The need to decelerate fast fashion in a hot climate-A global sustainability perspective on the garment industry. J Clean Prod 295:126390. https://doi. org/10.1016/j.jclepro.2021.126390

32. Hole G, Hole AS (2019) Recycling as the way to greener production: a mini review. J Clean Prod 212:910-915. https://doi.org/ 10.1016/j.jclepro.2018.12.080

33. Vaverková MD (2019) Landfill impacts on the environment-review. Geosci 9:431. https://doi.org/10.3390/geosc iences9100431

34. Ellen McArthur Foundation (2017) A new textiles economy: Redesigning fashion's future. https://www.ellenmacarthurf 
oundation.org/publications/a-new-textiles-economy-redes igning-fashions-future

35. Pensupa N, Leu SY, Hu Y, Du C, Liu H, Jing H, Wang H, Lin CSK (2017) Recent trends in sustainable textile waste recycling methods: current situation and future prospects. Top Curr Chem. https://doi.org/10.1007/s41061-017-0165-0

36. Banwell E, Schuknect M, Rattner B, Hulst N, Dougherty B (2020) The Nature of Fashion. Biomimicry Institute. https:// biomimicry.org/thenatureoffashion/

37. Luckachan GE, Pillai CKS (2011) Biodegradable polymersa review on recent trends and emerging perspectives. J Polym Environ 19:637-676. https://doi.org/10.1007/ s10924-011-0317-1

38. Gloy Y-S, Gulich B, Hofmann M (2021) Textile Waste Management and Processing. In: Matthes A, Beyer K, Cebulla $H$, Arnold MG, Schumann A (eds) Sustainable Textile and Fashion Value Chains. Springer Nature, Switzerland, AG, pp 185-204

39. Wanassi B, Azzouz B, Ben HM (2016) Value-added waste cotton yarn: optimization of recycling process and spinning of reclaimed fibers. Ind Crops Prod 87:27-32. https://doi.org/ 10.1016/j.indcrop.2016.04.020

40. Johnson S, Echeverria D, Venditti R, Jameel H, Yao Y (2020) Supply chain of waste cotton recycling and reuse: A review. AATCC J Res 7:19-31. https://doi.org/10.14504/ajr.7.S1.3

41. Gan L, Guo H, Xiao Z, Jia Z, Yang H, Sheng D, Pan H, Xu W, Wang $Y$ (2019) Dyeing and characterization of cellulose powder developed from waste cotton. Polymers (Basel) 11:1982. https://doi.org/10.3390/polym11121982

42. Smith S, Ozturk M, Frey M (2021) Soil biodegradation of cotton fabrics treated with common finishes. Cellulose 28:4485-4494. https://doi.org/10.1007/s10570-020-03666-w

43. Solazzo C, Dyer JM, Clerens S, Plowman J, Peacock EE, Collins MJ (2013) Proteomic evaluation of the biodegradation of wool fabrics in experimental burials. Int Biodeterior Biodegrad 80:48-59. https://doi.org/10.1016/j.ibiod.2012.11.013

44. Payne A (2015) Open-and closed-loop recycling of textile and apparel products. In: Muthu SS (ed) Handbook of Life Cycle Assessment (LCA) of Textiles and Clothing. Woodhead Publishing, Amsterdam, pp 103-123

45. Koo HJ, Chang GS, Kim SH, Hahm WG, Park SY (2013) Effects of recycling processes on physical, mechanical and degradation properties of PET yarns. Fibers Polym 14:2083-2087. https:// doi.org/10.1007/s12221-013-2083-2

46. Sadeghi B, Marfavi Y, AliAkbari R, Kowsari E, Borbor Ajdari F, Ramakrishna S (2021) Recent Studies on Recycled PET Fibers: production and applications: a review. Mater Circ Econ. https:// doi.org/10.1007/s42824-020-00014-y

47. Shen L, Worrell E, Patel MK (2012) Comparing life cycle energy and GHG emissions of bio-based PET, recycled PET, PLA, and man-made cellulosics. Biofuels, Bioprod Biorefin 6:625-639. https://doi.org/10.1002/bbb.1368

48. Haule LV, Carr CM, Rigout M (2016) Preparation and physical properties of regenerated cellulose fibres from cotton waste garments. J Clean Prod 112:4445-4451. https://doi.org/10. 1016/j.jclepro.2015.08.086

49. Björquist S, Aronsson J, Henriksson G, Persson A (2018) Textile qualities of regenerated cellulose fibers from cotton waste pulp. Text Res J 88:2485-2492. https://doi.org/10.1177/00405 17517723021

50. Horrocks AR (2013) Textile flammability research since 1980Personal challenges and partial solutions. Polym Degrad Stab 98:2813-2824. https://doi.org/10.1016/j.polymdegradstab. 2013.10.004

51. Sørensen L, Groven AS, Hovsbakken IA, Del Puerto O, Krause DF, Sarno A, Booth AM (2021) UV degradation of natural and synthetic microfibers causes fragmentation and release of polymer degradation products and chemical additives. Sci Total Environ 755:143170. https://doi.org/10.1016/j.scitotenv.2020. 143170

52. Rajabinejad H, Zoccola M, Patrucco A, Montarsolo A, Rovero G, Tonin C (2018) Physicochemical properties of keratin extracted from wool by various methods. Text Res J 88:2415-2424. https://doi.org/10.1177/0040517517723028

53. Lucas N, Bienaime C, Belloy C, Queneudec M, Silvestre F, NavaSaucedo JE (2008) Polymer biodegradation: mechanisms and estimation techniques-A review. Chemosphere 73:429-442. https://doi.org/10.1016/j.chemosphere.2008.06.064

54. Samami H, Pan J (2016) A constitutive law for degrading bioresorbable polymers. J Mech Behav Biomed Mater 59:430-445. https://doi.org/10.1016/j.jmbbm.2016.02.026

55. Hutmacher D, Hürzeler MB, Schliephake H (1996) A review of material properties of biodegradable and bioresorbable polymers and devices for GTR and GBR applications. Int J Oral Maxillofac Implants 11:667-678

56. Dhandayuthapani B, Yoshida Y, Maekawa T, Kumar DS (2011) Polymeric scaffolds in tissue engineering application: a review. Int J Polym Sci 2011:290602. https://doi.org/10.1155/2011/ 290602

57. Low YJ, Andriyana A, Ang BC, Zainal Abidin NI (2020) Bioresorbable and degradable behaviors of PGA: current state and future prospects. Polym Eng Sci 60:2657-2675

58. Larrañaga A, Lizundia E (2019) A review on the thermomechanical properties and biodegradation behaviour of polyesters. Eur Polym J 121:1-31. https://doi.org/10.1016/j.eurpolymj.2019. 109296

59. Laycock B, Nikolić M, Colwell JM, Gauthier E, Halley P, Bottle S, George $G$ (2017) Lifetime prediction of biodegradable polymers. Prog Polym Sci 71:144-189. https://doi.org/10.1016/j. progpolymsci.2017.02.004

60. Kirk O, Borchert TV, Fuglsang CC (2002) Industrial enzyme applications. Curr Opin Biotechnol 13:345-351. https://doi.org/10. 1016/S0958-1669(02)00328-2

61. Guebitz GM, Cavaco-Paulo A (2008) Enzymes go big: surface hydrolysis and functionalisation of synthetic polymers. Trends Biotechnol 26:32-38. https://doi.org/10.1016/j.tibtech.2007.10. 003

62. Araújo R, Casal M, Cavaco-Paulo A (2008) Application of enzymes for textile fibres processing. Biocatal Biotransformation 26:332-349. https://doi.org/10.1080/10242420802390457

63. Nielsen PH, Kuilderd H, Zhou W, Lu X (2009) Enzyme biotechnology for sustainable textiles. Sustainable Textiles: life Cycle and Environmental Impact, 98th edn. Woodhead Publishing, Cambridge, pp 113-138

64. Jegannathan KR, Nielsen PH (2013) Environmental assessment of enzyme use in industrial production-a literature review. J Clean Prod 42:228-240. https://doi.org/10.1016/j.jclepro.2012. 11.005

65. Al-Ghanayem AA, Joseph $B$ (2020) Current prospective in using cold-active enzymes as eco-friendly detergent additive. Appl Microbiol Biotechnol 104:2871-2882. https://doi.org/10.1007/ s00253-020-10429-x

66. Karamanlioglu M, Preziosi R, Robson GD (2017) Abiotic and biotic environmental degradation of the bioplastic polymer poly(lactic acid): A review. Polym Degrad Stab 137:122-130. https://doi.org/10.1016/j.polymdegradstab.2017.01.009

67. Bátori V, Åkesson D, Zamani A, Taherzadeh MJ, Horváth IS (2018) Anaerobic degradation of bioplastics: a review. Waste Manag 80:406-413. https://doi.org/10.1016/j.wasman.2018.09. 040

68. Gartiser S, Wallrabenstein M, Stiene G (1998) Assessment of several test methods for the determination of the anaerobic 
biodegradability of polymers. J Environ Polym Degrad 6:159173. https://doi.org/10.1023/A:1021869530253

69. Wang YS, Byrd CS, Barlaz MA (1994) Anaerobic biodegradability of cellulose and hemicellulose in excavated refuse samples using a biochemical methane potential assay. J Ind Microbiol 13:147-153. https://doi.org/10.1007/BF01583999

70. Hasanzadeh E, Mirmohamadsadeghi S, Karimi K (2018) Enhancing energy production from waste textile by hydrolysis of synthetic parts. Fuel 218:41-48. https://doi.org/10. 1016/j.fuel.2018.01.035

71. Plastics Industry Association Bioplastics Division (2018) Position Paper on Degradable Additives. https://www.plasticsin dustry.org/sites/default/files/2018 PLASTICS-Position Paper on Degradable Additives.pdf. Accessed 13 Mar 2021

72. Castro-Aguirre E, Auras R, Selke S, Rubino M, Marsh T (2017) Insights on the aerobic biodegradation of polymers by analysis of evolved carbon dioxide in simulated composting conditions. Polym Degrad Stab 137:251-271. https://doi.org/10. 1016/j.polymdegradstab.2017.01.017

73. Gómez EF, Michel FC (2013) Biodegradability of conventional and bio-based plastics and natural fiber composites during composting, anaerobic digestion and long-term soil incubation. Polym Degrad Stab 98:2583-2591. https://doi.org/10. 1016/j.polymdegradstab.2013.09.018

74. Zumstein MT, Schintlmeister A, Nelson TF, Baumgartner R, Woebken D, Wagner M, Kohler HPE, McNeill K, Sander M (2018) Biodegradation of synthetic polymers in soils: tracking carbon into $\mathrm{CO}_{2}$ and microbial biomass. Sci Adv. https://doi.org/10. 1126/sciadv.aas9024

75. Zambrano MC, Pawlak JJ, Daystar J, Ankeny M, Goller CC, Venditti RA (2020) Aerobic biodegradation in freshwater and marine environments of textile microfibers generated in clothes laundering: effects of cellulose and polyester-based microfibers on the microbiome. Mar Pollut Bull. https://doi. org/10.1016/j.marpolbul.2019.110826

76. Sülar V, Devrim G (2019) Biodegradation behaviour of different textile fibres: visual, morphological, structural properties and soil analyses. Fibres Text East Eur 27:100-111. https://doi.org/ 10.5604/01.3001.0012.7751

77. Warnock M, Davis K, Wolf D, Gbur E (2011) Soil burial effects on biodegradation and properties of three cellulosic fabrics. AATCC Rev 11:53-57

78. Li L, Frey M, Browning KJ (2010) Biodegradability study on cotton and polyester fabrics. J Eng Fiber Fabr 5:42-53. https://doi. org/10.1177/155892501000500406

79. Park CH, Kang YK, Im SS (2004) Biodegradability of cellulose fabrics. J Appl Polym Sci 94:248-253. https://doi.org/10.1002/ app.20879

80. Heimowska A, Morawska M, Bocho-Janiszewska A (2017) Biodegradation of poly ( $\epsilon$-caprolactone) in natural water environments. Polish J Chem Technol 19:120-126. https://doi.org/10. 1515/pjct-2017-0017

81. Gleadall A, Pan J, Atkinson H (2012) A simplified theory of crystallisation induced by polymer chain scissions for biodegradable polyesters. Polym Degrad Stab 97:1616-1620. https://doi. org/10.1016/j.polymdegradstab.2012.06.023

82. Huang Q, Kimura S, Iwata T (2021) Development of self-degradable aliphatic polyesters by embedding lipases via melt extrusion. Polym Degrad Stab 190:109647. https://doi.org/10.1016/j. polymdegradstab.2021.109647

83. Shi K, Bai Z, Su T, Wang Z (2019) Selective enzymatic degradation and porous morphology of poly(butylene succinate)/ poly(lactic acid) blends. Int J Biol Macromol 126:436-442. https://doi.org/10.1016/j.ijbiomac.2018.12.168

84. Yoshida S, Hiraga K, Takehana T, Taniguchi I, Yamaji H, Maeda Y, Toyohara K, Miyamoto K, Kimura Y, Oda K (2016) A bacterium that degrades and assimilates poly (ethylene terephthalate). Science 351:1196-1199. https://doi.org/10.1126/science.aad63 59

85. Li M, Ogiso M, Minoura N (2003) Enzymatic degradation behavior of porous silk fibroin sheets. Biomaterials 24:357-365. https://doi.org/10.1016/S0142-9612(02)00326-5

86. Weir NA, Buchanan FJ, Orr JF, Dickson GR (2004) Degradation of poly-L-lactide. Part 1: In vitro and in vivo physiological temperature degradation. Proc Inst Mech Eng Part H J Eng Med 218:307-319. https://doi.org/10.1243/0954411041932782

87. Weir NA, Buchanan FJ, Orr JF, Farrar DF, Dickson GR (2004) Degradation of poly-L-lactide. Part 2: increased temperature accelerated degradation. Proc Inst Mech Eng Part H J Eng Med 218:321-330. https://doi.org/10.1243/0954411041932809

88. DelRe C, Jiang Y, Kang P, Kwon J, Hall A, Jayapurna I, Ruan Z, Ma L, Zolkin K, Li T, Scown CD, Ritchie RO, Russell TP, Xu T (2021) Near-complete depolymerization of polyesters with nanodispersed enzymes. Nature 592:558-563. https://doi.org/10. 1038/s41586-021-03408-3

89. Salmon S (2019) Designed for degradability —a fashionable fabric fate. In: SMART Regional Meeting. Raleigh, NC

90. Singh J, Sung K, Cooper T, West K, Mont O (2019) Challenges and opportunities for scaling up upcycling businesses-The case of textile and wood upcycling businesses in the UK. Resour Conserv Recycl 150:104439. https://doi.org/10.1016/j. resconrec.2019.104439

91. Sandin G, Peters GM (2018) Environmental impact of textile reuse and recycling-A review. J. Clean. Prod. 184

92. Hawley JM (2009) Understanding and improving textile recycling: a systems perspective. In: Blackburn RS (ed) Sustainable Textiles: Life Cycle and Environmental Impact. Woodhead Publishing, pp 179-199

93. Ransom-Jones E, McCarthy AJ, Haldenby S, Doonan J, McDonald JE (2017) Lignocellulose-degrading microbial communities in landfill sites represent a repository of unexplored biomassdegrading diversity. Appl Environ Sci 2:1-13. https://doi.org/ 10.1128/msphere.00300-17

94. Degenstein LM, McQueen RH, Krogman NT (2021) 'What goes where'? Characterizing Edmonton's municipal clothing waste stream and consumer clothing disposal. J Clean Prod 296:126516. https://doi.org/10.1016/j.jclepro.2021.126516

95. Saveyn H, Eder P (2014) Final report on end-of-waste criteria for biodegradable waste subjected to biological treatment (compost \& digestate): Technical proposals. JRC Scientific and Policy Reports European Commission 1-312. https://asset-pdf.scina pse.io/prod/1589332136/1589332136.pdf

96. Kijchavengkul T, Auras R, Rubino M, Selke S, Ngouajio M, Fernandez RT (2010) Biodegradation and hydrolysis rate of aliphatic aromatic polyester. Polym Degrad Stab 95:2641-2647. https://doi.org/10.1016/j.polymdegradstab.2010.07.018

97. Szuman K, Krucińska I, Boguń M, Draczyński Z (2016) PLA / PHABiodegradable Blends for Pneumothermic Fabrication of Nonwovens. AUTEX Res J. https://doi.org/10.1515/aut-2015-0047

98. De Wilde B, Boelens J (1998) Prerequisites for biodegradable plastic materials for acceptance in real-life composting plants and technical aspects. Polym Degrad Stab 59:7-12. https://doi. org/10.1016/s0141-3910(97)00159-6

99. Suh H, Duckett K, Bhat G (1996) Biodegradable and tensile properties of cotton/cellulose acetate nonwovens. Text Res J 66:230-237. https://doi.org/10.1177/004051759606600408

100. Kopeć M, Gondek K, Baran A (2013) Assessment of respiration activity and ecotoxicity of composts containing biopolymers. Ecotoxicol Environ Saf 89:137-142. https://doi.org/10.1016/j. ecoenv.2012.11.021

101. Mao C, Feng Y, Wang X, Ren G (2015) Review on research achievements of biogas from anaerobic digestion. Renew 
Sustain Energy Rev 45:540-555. https://doi.org/10.1016/j.rser. 2015.02.032

102. Jeihanipour A, Aslanzadeh S, Rajendran K, Balasubramanian $G$, Taherzadeh MJ (2013) High-rate biogas production from waste textiles using a two-stage process. Renew Energy 52:128-135. https://doi.org/10.1016/j.renene.2012.10.042

103. Quecholac-Piña X, Hernández-Berriel MDC, Mañón-Salas MDC, Espinosa-Valdemar RM, Vázquez-Morillas A (2020) Degradation of plastics under anaerobic conditions: a short review. Polymers (Basel) 12:109. https://doi.org/10.3390/polym12010109

104. Peters GM, Sandin G, Spak B (2019) Environmental prospects for mixed textile recycling in Sweden. ACS Sustain Chem Eng 7:11682-11690. https://doi.org/10.1021/acssuschemeng. $9 \mathrm{~b} 01742$

105. Broadbent AD (2001) Basic principles of textile coloration. Society of Dyers and Colourists, West Yorkshire, England

106. Chiellini E, Corti A, D'Antone S, Billingham NC (2007) Microbial biomass yield and turnover in soil biodegradation tests: carbon substrate effects. J Polym Environ 15:169-178. https://doi.org/ 10.1007/s10924-007-0057-4

107. Stuart BH, Ueland M (2017) Degradation of clothing in depositional environments. In: Schotsmans EMJ, Márquez-Grant N, Forbes SL (eds) Taphonomy of human remains: Forensic analysis of the dead and the depositional environment. John Wiley \& Sons, Ltd, Chichester, UK, pp 120-133

108. Morais DS, Guedes RM, Lopes MA (2016) Antimicrobial approaches for textiles: from research to market. Mater (Basel) 9:1-21. https://doi.org/10.3390/ma9060498

109. Feng C, Sui $X$, Ankeny MA, Vinueza NR (2021) Identification and quantification of $\mathrm{Cl}$ Reactive Blue 19 dye degradation product in soil. Color Technol 137:251-258. https://doi.org/10.1111/ cote. 12527

110. Zambrano MC, Pawlak JJ, Daystar J, Ankeny M, Venditti RA (2021) Impact of dyes and finishes on the aquatic biodegradability of cotton textile fibers and microfibers released on laundering clothes: correlations between enzyme adsorption and activity and biodegradation rates (submitted for review). Mar Pollut Bull 165:112030. https://doi.org/10.1016/j.marpo Ibul.2021.112030

111. Ali H (2010) Biodegradation of synthetic dyes-A review. Water Air Soil Pollut 213:251-273. https://doi.org/10.1007/ s11270-010-0382-4

112. Sashiwa H, Fukuda R, Okura T, Sato S, Nakayama A (2018) Microbial degradation behavior in seawater of polyester blends containing poly(3-hydroxybutyrate-co-3-hydroxyhexanoate) (PHBHHx). Mar Drugs 16:1-11. https://doi.org/10.3390/md160 10034

113. Nakayama A, Yamano N, Kawasaki N (2019) Biodegradation in seawater of aliphatic polyesters. Polym Degrad Stab 166:290299. https://doi.org/10.1016/j.polymdegradstab.2019.06.006

114. Gutowska A, Jóźwicka J, Sobczak S, Tomaszewski W, Sulak K, Miros P, Owczarek M, Szalczyńska M, Ciechańska D, Krucińska I (2014) In-compost biodegradation of PLA nonwovens. Fibres Text East Eur 22:99-106

115. Kunioka M, Ninomiya F, Funabashi M (2007) Novel evaluation method of biodegradabilities for oil-based polycaprolactone by naturally occurring radiocarbon- 14 concentration using accelerator mass spectrometry based on ISO 14855-2 in controlled compost. Polym Degrad Stab 92:1279-1288. https://doi. org/10.1016/j.polymdegradstab.2007.03.028

116. Itävaara M, Karjomaa S, Selin JF (2002) Biodegradation of polylactide in aerobic and anaerobic thermophilic conditions. Chemosphere 46:879-885. https://doi.org/10.1016/S00456535(01)00163-1

117. Yagi H, Ninomiya F, Funabashi M, Kunioka M (2009) Anaerobic biodegradation tests of poly(lactic acid) and polycaprolactone using new evaluation system for methane fermentation in anaerobic sludge. Polym Degrad Stab 94:1397-1404. https:// doi.org/10.1016/j.polymdegradstab.2009.05.012

118. Zhang $X$ (2014) Fundamentals of fiber science. DEStech Publications, Lancaster, PA, USA

119. Morton WE, Hearle JWS (2001) Physical properties of textile fibres, Fourth. Woodhead Publishing, Philadelphia

120. Warner S (1995) Fiber science. Prentice Hall, Englewood Cliffs, NJ

121. Agrawal AK (2010) Spinning of poly(lactic acid) fibers. In: Auras R, Selke S, Lim L-T, Tsuji H (eds) Poly(lactic acid): synthesis, structures, properties, processing, and applications, vol 1. John Wiley \& Sons Inc, pp 323-341

122. Militký J (2018) Tensile failure of polyester fibers. In: Bunsell AR (ed) Handbook of Properties of Textile and Technical Fibres, Second. Elsevier Ltd, pp 421-514

123. Arshad K, Skrifvars M, Vivod V, Al E (2014) Biodegradation of Natural Textile Materials in Soil. Tekstilec 57:118-132. https:// doi.org/10.14502/Tekstilec2014.57.118

124. Gusakov AV (2011) Alternatives to Trichoderma reesei in biofuel production. Trends Biotechnol 29:419-425. https://doi. org/10.1016/j.tibtech.2011.04.004

125. Puls J, Wilson SA, Hölter D (2011) Degradation of cellulose acetate-based materials: a review. J Polym Environ 19:152165. https://doi.org/10.1007/s10924-010-0258-0

126. Carr CM, Clarke DJ, Dobson ADW (2020) Microbial polyethylene terephthalate hydrolases: current and future perspectives. Front Microbiol 11:1-23. https://doi.org/10.3389/fmicb. 2020.571265

127. Tokiwa Y, Calabia BP, Ugwu CU, Aiba S (2009) Biodegradability of plastics. Int J Mol Sci 10:3722-3742

128. Cardamone JM (2001) Biodeterioration of Wool by Microorganisms and Insects. ACS Symp Ser 792:263-298. https://doi. org/10.1021/bk-2001-0792.ch016

129. Sudhakar M, Priyadarshini C, Doble M, Sriyutha Murthy $P$, Venkatesan R (2007) Marine bacteria mediated degradation of nylon 66 and 6. Int Biodeterior Biodegrad 60:144-151. https://doi.org/10.1016/j.ibiod.2007.02.002

130. Gaytán I, Burelo M, Loza-Tavera H (2021) Current status on the biodegradability of acrylic polymers: microorganisms, enzymes and metabolic pathways involved. Appl Microbiol Biotechnol 105:991-1006. https://doi.org/10.1007/ s00253-020-11073-1

131. Wei R, Zimmermann W (2017) Microbial enzymes for the recycling of recalcitrant petroleum-based plastics: how far are we? Microb Biotechnol 10:1308-1322. https://doi.org/10. 1111/1751-7915.12710

132. Biundo A, Ribitsch D, Guebitz GM (2018) Surface engineering of polyester-degrading enzymes to improve efficiency and tune specificity. Appl Microbiol Biotechnol 102:3551-3559. https://doi.org/10.1007/s00253-018-8850-7

133. Leitão AL, Enguita FJ (2021) Structural insights into carboxylic polyester-degrading enzymes and their functional depolymerizing neighbors. Int J Mol Sci 22:1-14. https://doi.org/10.3390/ ijms22052332

134. Kawai F (2021) The current state of research on PET hydrolyzing enzymes available for biorecycling. Catalysts 11:1-10. https:// doi.org/10.3390/catal11020206

135. Zaaba NF, Jaafar M (2020) A review on degradation mechanisms of polylactic acid: Hydrolytic, photodegradative, microbial, and enzymatic degradation. Polym Eng Sci 60:2061-2075. https://doi.org/10.1002/pen.25511

136. Guo C, Li C, Kaplan DL (2020) Enzymatic degradation of bombyx mori silk materials: a review. Biomacromol 21:1678-1686. https://doi.org/10.1021/acs.biomac.0c00090 
137. Qiu J, Wilkens C, Barrett K, Meyer AS (2020) Microbial enzymes catalyzing keratin degradation: classification, structure, function. Biotechnol Adv. https://doi.org/10.1016/j.biotechadv. 2020.107607

138. Fu J, Su J, Wang P, Yu Y, Wang Q, Cavaco-Paulo A (2015) Enzymatic processing of protein-based fibers. Appl Microbiol Biotechnol 99:10387-10397. https://doi.org/10.1007/ s00253-015-6970-x

139. Yadav N, Hakkarainen M (2020) Degradable or not? Cellulose acetate as a model for complicated interplay between structure, environment and degradation. Chemosphere. https://doi. org/10.1016/j.chemosphere.2020.128731

140. Matamá T, Araújo R, Gübitz GM, Casal M, Cavaco-Paulo A (2010) Functionalization of cellulose acetate fibers with engineered cutinases. Biotechnol Prog 26:636-643. https://doi.org/10. 1002/btpr.364

141. Haske-Cornelius O, Pellis A, Tegl G, Wurz S, Saake B, Ludwig R, Sebastian A, Nyanhongo GS, Guebitz GM (2017) Enzymatic systems for cellulose acetate degradation. Catalysts 7:1-15. https://doi.org/10.3390/catal7100287

142. Gardner RM, Buchanan CM, Komarek R, Dorschel D, Boggs $C$, White AW (1994) Compostability of cellulose acetate films. J Appl Polym Sci 52:1477-1488. https://doi.org/10.1002/app. 1994.070521012

143. Shirke AN, Butterfoss GL, Saikia R, Basu A, de Maria L, Svendsen A, Gross RA (2017) Engineered Humicola insolens cutinase for efficient cellulose acetate deacetylation. Biotechnol J 12:1700188. https://doi.org/10.1002/biot.201700188

144. Gu JD, Eberiel D, McCarthy SP, Gross RA (1993) Degradation and mineralization of cellulose acetate in simulated thermophilic compost environments. J Environ Polym Degrad 1:281-291. https://doi.org/10.1007/BF01458295

145. Matamá T, Vaz F, Gübitz GM, Cavaco-Paulo A (2006) The effect of additives and mechanical agitation in surface modification of acrylic fibres by cutinase and esterase. Biotechnol J 1:842-849. https://doi.org/10.1002/biot.200600034

146. Fischer-Colbrie G, Matama T, Heumann S, Martinkova L, Cavaco Paulo A, Guebitz G (2007) Surface hydrolysis of polyacrylonitrile with nitrile hydrolysing enzymes from Micrococcus luteus BST20. J Biotechnol 129:62-68. https://doi.org/10.1016/j.jbiot ec.2006.11.018

147. Matamá T, Carneiro F, Caparrós C, Gübitz GM, Cavaco-Paulo A (2007) Using a nitrilase for the surface modification of acrylic fibres. Biotechnol J 2:353-360. https://doi.org/10.1002/biot. 200600068

148. Akkaya A, Ozseker EE (2019) Modification of polyacrylonitrile fabric for antibacterial application by tetracycline immobilization. Polym Test 78:105959. https://doi.org/10.1016/j.polym ertesting.2019.105959

149. de Castro AM, Carniel A, Sirelli L, Dias ML, de Menezes SMC, Chinelatto Junior LS, de Angeli Honorato H (2018) Enzymecatalyzed simultaneous hydrolysis-glycolysis reactions reveals tunability on PET depolymerization products. Biochem Eng J 137:239-246. https://doi.org/10.1016/j.bej.2018.06.007

150. Mochizuki M (2010) Textile Applications. In: Auras RA, Selke SE, Lim L-T, Tsuji H (eds) Poly(lactic acid): synthesis, structures, properties, processing, and applications, vol 1. John Wiley \& Sons Inc, pp 469-476

151. Nofar M, Sacligil D, Carreau PJ, Kamal MR, Heuzey MC (2019) Poly (lactic acid) blends: processing, properties and applications. Int J Biol Macromol 125:307-360. https://doi.org/10. 1016/j.ijbiomac.2018.12.002

152. Di Lorenzo ML, Androsch R (2019) Influence of $a^{\prime}$-/a-crystal polymorphism on properties of poly(I-lactic acid). Polym Int 68:320-334. https://doi.org/10.1002/pi.5707
153. Singhvi MS, Zinjarde SS, Gokhale DV (2019) Polylactic acid: synthesis and biomedical applications. J Appl Microbiol 127:16121626. https://doi.org/10.1111/jam.14290

154. Farah S, Anderson DG, Langer R (2016) Physical and mechanical properties of PLA, and their functions in widespread applications-A comprehensive review. Adv Drug Deliv Rev 107:367392. https://doi.org/10.1016/j.addr.2016.06.012

155. Gupta B, Revagade N, Hilborn J (2007) Poly(lactic acid) fiber: an overview. Prog Polym Sci 32:455-482. https://doi.org/10. 1016/j.progpolymsci.2007.01.005

156. Qi X, Ren Y, Wang X (2017) New advances in the biodegradation of Poly(lactic) acid. Int Biodeterior Biodegrad 117:215-223. https://doi.org/10.1016/j.ibiod.2017.01.010

157. Baig GA (2013) Hydrolytic stability of PLA yarns during textile wet processing. Fibers Polym 14:1912-1918. https://doi.org/ 10.1007/s12221-013-1912-7

158. Farrington D, Lunt J, Davies S, Blackburn R (2005) Poly(lactic acid) fibers. In: Blackburn R (ed) Biodegradable and sustainable fibres. CRC Press, Boca Raton, pp 191-220

159. Gorrasi G, Pantani R (2013) Effect of PLA grades and morphologies on hydrolytic degradation at composting temperature: assessment of structural modification and kinetic parameters. Polym Degrad Stab 98:1006-1014. https://doi.org/10.1016/j. polymdegradstab.2013.02.005

160. Lunt J (1998) Large-scale production, properties and commercial applications of poly lactic acid polymers. Polym Degrad Stab 59:145-152. https://doi.org/10.1016/s0141-3910(97) 00148-1

161. Tafoukt D, Soric A, Sigoillot JC, Ferrasse JH (2017) Determination of kinetics and heat of hydrolysis for non-homogenous substrate by isothermal calorimetry. Bioprocess Biosyst Eng 40:643-650. https://doi.org/10.1007/s00449-016-1728-0

162. Olsen SN, Lumby E, McFarland K, Borch K, Westh P (2011) Kinetics of enzymatic high-solid hydrolysis of lignocellulosic biomass studied by calorimetry. Appl Biochem Biotechnol 163:626-635. https://doi.org/10.1007/s12010-010-9068-z

163. Sülar V, Oner E, Devrim G, Aslan M, Eser B (2016) A comparative study on performance properties of yarns and knitted fabrics made of biodegradable and conventional fibers. Fibers Polym 17:2085-2094. https://doi.org/10.1007/s12221-016-6808-x

164. Hohenstein Institute (2005) Fabrics Containing Ingeo Fibers Outperform Polyester and Cotton Fabrics in Sporting Applications. Technical Bulletin 260904

165. Laitala K, Klepp IG, Kettlewell R, Wiedemann S (2020) Laundry care regimes: Do the practices of keeping clothes clean have different environmental impacts based on the fibre content? Sustain. https://doi.org/10.3390/su12187537

166. Kim J, Park Y, Yun C, Park CH (2015) Comparison of environmental and economic impacts caused by the washing machine operation of various regions. Energy Effic 8:905-918. https:// doi.org/10.1007/s12053-015-9333-7

167. Baig GA, Carr CM (2015) Kawabata evaluation of PLA-knitted fabric washed with various laundering formulations. J Text Inst 106:111-118. https://doi.org/10.1080/00405000.2014.960249

168. Karst D, Hain M, Yang $Y$ (2009) Care of PLA textiles. Res J Text Appar 13:69-74. https://doi.org/10.1108/ RJTA-13-04-2009-B008

169. Guruprasad R, Prasad GK, Prabu GTV, Raj S, Patil PG (2018) Lowstress mechanical properties and fabric hand of cotton and polylactic acid fibre blended knitted fabrics. Indian J Fibre Text Res 43:381-384

170. Jabbar A, Tausif M, Riaz Tahir H, Basit A, Rehan Asghar Bhatti M, Abbas G (2019) Polylactic acid/lyocell fibre as an eco-friendly alternative to polyethylene terephthalate/cotton fibre blended yarns and knitted fabrics. J Text Inst 111:129-138. https://doi. org/10.1080/00405000.2019.1624070 
171. Huang XX, Tao XM, Zhang ZH, Chen $P$ (2017) Properties and performances of fabrics made from bio-based and degradable polylactide acid / poly ( hydroxybutyrate-co-hydroxyvalerate) (PLA/PHBV) filament yarns. Text Res J 87:2464-2474. https:// doi.org/10.1177/0040517516671128

172. Castro-Aguirre E, Iñiguez-Franco F, Samsudin H, Fang X, Auras $\mathrm{R}$ (2016) Poly(lactic acid)—Mass production, processing, industrial applications, and end of life. Adv Drug Deliv Rev 107:333366. https://doi.org/10.1016/j.addr.2016.03.010

173. Gonzalez MF, Ruseckaite RA, Cuadrado TR (1999) Structural Changes of Polylactic-Acid (PLA) Microspheres under Hydrolytic Degradation. J Appl Polym Sci 71:1223-1230. https://doi. org/10.1002/(SICI)1097-4628(19990222)71:8\%3c1223::AIDAPP2\%3e3.0.CO;2-I

174. Musioł M, Sikorska W, Adamus G, Janeczek H, Richert J, Malinowski R, Jiang G, Kowalczuk M (2016) Forensic engineering of advanced polymeric materials. Part III-Biodegradation of thermoformed rigid PLA packaging under industrial composting conditions. Waste Manag 52:69-76. https://doi.org/10. 1016/j.wasman.2016.04.016

175. Baig GA, Carr CM (2014) A study on damage to PLA knitted fabrics during scouring and bleaching. Polish J Chem Technol 16:45-50. https://doi.org/10.2478/pjct-2014-0049

176. Walters, A., Santillo, D., \& Johnston P (2005) An overview of textiles processing and related environmental concerns. Greenpeace Res Lab Dep Biol Sci Univ Exet UK 1-31

177. Wang C-C, Lin L-H, Chen C-W, Lo Y-C (2017) Surface modification of poly(lactic acid) fabrics with plasma pretreatment and chitosan/siloxane polyesters coating for color strength improvement. Polymers (Basel). https://doi.org/10.3390/polym 9080371

178. Avinc O, Bakan E, Demirçalı A, Gedik G, Karcı F (2020) Dyeing of poly(lactic acid) fibres with synthesised novel heterocyclic disazo disperse dyes. Color Technol 136:356-369. https://doi. org/10.1111/cote. 12472

179. Avinc O, Khoddami A (2010) Overview of Poly(lactic acid) (PLA) fibre: Part ii: wet processing; pretreatment, dyeing, clearing, finishing, and washing properties of Poly(lactic acid) Fibres. Fibre Chem 42:68-78. https://doi.org/10.1007/s10692-010-9226-7

180. Al Hosni AS, Pittman JK, Robson GD (2019) Microbial degradation of four biodegradable polymers in soil and compost demonstrating polycaprolactone as an ideal compostable plastic. Waste Manag 97:105-114. https://doi.org/10.1016/j.wasman. 2019.07.042

181. Funabashi M, Ninomiya F, Kunioka M (2007) Biodegradation of polycaprolactone powders proposed as reference test materials for international standard of biodegradation evaluation method. J Polym Environ 15:7-17. https://doi.org/10.1007/ s10924-006-0041-4

182. Shi $X Q$, Ito $H$, Kikutani $T$ (2005) Characterization on mixedcrystal structure and properties of poly (butylene adipateco-terephthalate) biodegradable fibers. Polymer (Guildf) 46:11442-11450. https://doi.org/10.1016/j.polymer.2005.10. 065

183. Verlinden RAJ, Hill DJ, Kenward MA, Williams CD, Radecka I (2007) Bacterial synthesis of biodegradable polyhydroxyalkanoates. J Appl Microbiol 102:1437-1449. https://doi.org/10. 1111/j.1365-2672.2007.03335.x

184. Prajapati K, Nayak R, Shukla A, Parmar P, Goswami D, Saraf M (2021) Polyhydroxyalkanoates: an exotic gleam in the gloomy tale of plastics. J Polym Environ 29:2013-2032. https://doi.org/ 10.1007/s10924-020-02025-x

185. Muneer F, Rasul I, Azeem F, Siddique MH, Zubair M, Nadeem H (2020) Microbial polyhydroxyalkanoates (PHAs): efficient replacement of synthetic polymers. J Polym Environ 28:23012323. https://doi.org/10.1007/s10924-020-01772-1
186. Meereboer KW, Misra M, Mohanty AK (2020) Review of recent advances in the biodegradability of polyhydroxyalkanoate (PHA) bioplastics and their composites. Green Chem 22:55195558. https://doi.org/10.1039/d0gc01647k

187. Corre YM, Bruzaud S, Audic JL, Grohens Y (2012) Morphology and functional properties of commercial polyhydroxyalkanoates: a comprehensive and comparative study. Polym Test 31:226-235. https://doi.org/10.1016/j.polymertesting.2011.11. 002

188. Srubar WV, Wright ZC, Tsui A, Michel AT, Billington SL, Frank CW (2012) Characterizing the effects of ambient aging on the mechanical and physical properties of two commercially available bacterial thermoplastics. Polym Degrad Stab 97:19221929. https://doi.org/10.1016/j.polymdegradstab.2012.04.011

189. Qin Q, Takarada W, Kikutani T (2017) Fiber structure development of PHBH through stress-induced crystallization in highspeed melt spinning process. J Fiber Sci Technol 73:49-60. https://doi.org/10.2115/fiberst.2017-0007

190. Nelson TF, Remke SC, Kohler H-PE, Mcneill K, Sander M (2020) Quantification of synthetic polyesters from biodegradable mulch films in soils. Environ Sci Technol 54:266-275. https:// doi.org/10.1021/acs.est.9b05863

191. Sang T, Wallis CJ, Hill G, Britovsek GJP (2020) Polyethylene terephthalate degradation under natural and accelerated weathering conditions. Eur Polym J. https://doi.org/10.1016/j.eurpo lymj.2020.109873

192. Edge $M$, Hayes $M$, Mohammadian M, Allen NS, Jewitt TS, Brems K, Jones K (1991) Aspects of poly(ethylene terephthalate) degradation for archival life and environmental degradation. Polym Degrad Stab 32:131-153. https://doi.org/10.1016/01413910(91)90047-U

193. Hirota Y, Naya M, Tada M, Shikyo Y, Kawanishi T, Takiguchi N (2021) Analysis of soil fungal community structure on the surface of buried polyethylene terephthalate. J Polym Environ 29:1227-1239. https://doi.org/10.1007/s10924-020-01960-z

194. Janczak K, Hrynkiewicz K, Znajewska Z, Dąbrowska G (2018) Use of rhizosphere microorganisms in the biodegradation of PLA and PET polymers in compost soil. Int Biodeterior Biodegrad 130:65-75. https://doi.org/10.1016/j.ibiod.2018.03.017

195. Sulaiman S, Yamato S, Kanaya E, Kim J-J, Koga Y, Takano K, Kanaya S (2012) Isolation of a novel cutinase homolog with polyethylene terephthalate-degrading activity from leafbranch compost by using a metagenomic approach. Appl Environ Microbiol 78:1556-1562. https://doi.org/10.1128/AEM. 06725-11

196. Sulaiman S, You DJ, Kanaya E, Koga Y, Kanaya S (2014) Crystal structure and thermodynamic and kinetic stability of metagenome-derived LC-cutinase. Biochemistry 53:1858-1869. https:// doi.org/10.1021/bi401561p

197. de Castro AM, Carniel A, Nicomedes Junior J, da Conceição GA, Valoni É (2017) Screening of commercial enzymes for poly(ethylene terephthalate) (PET) hydrolysis and synergy studies on different substrate sources. J Ind Microbiol Biotechnol 44:835-844. https://doi.org/10.1007/s10295-017-1942-z

198. de Castro AM, Carniel A, Stahelin D, Chinelatto Junior LS, de Angeli Honorato $\mathrm{H}$, de Menezes SMC (2019) High-fold improvement of assorted post-consumer poly(ethylene terephthalate) (PET) packages hydrolysis using Humicola insolens cutinase as a single biocatalyst. Process Biochem 81:85-91. https://doi.org/ 10.1016/j.procbio.2019.03.006

199. Salvador M, Abdulmutalib U, Gonzalez J, Kim J, Smith AA, Faulon JL, Wei R, Zimmermann W, Jimenez JI (2019) Microbial genes for a circular and sustainable bio-PET economy. Genes (Basel). https://doi.org/10.3390/genes10050373

200. Knott BC, Erickson E, Allen MD, Gado JE, Graham R, Kearns FL, Pardo I, Topuzlu E, Anderson JJ, Austin HP, Dominick G, Johnson 
CW, Rorrer NA, Szostkiewicz CJ, Copié V, Payne CM, Woodcock HL, Donohoe BS, Beckham GT, McGeehan JE (2020) Characterization and engineering of a two-enzyme system for plastics depolymerization. Proc Natl Acad Sci U S A 117:25476-25485. https://doi.org/10.1073/pnas.2006753117

201. Palm GJ, Reisky L, Böttcher D, Müller H, Michels EAP, Walczak MC, Berndt L, Weiss MS, Bornscheuer UT, Weber G (2019) Structure of the plastic-degrading Ideonella sakaiensis MHETase bound to a substrate. Nat Commun. https://doi.org/10.1038/ s41467-019-09326-3

202. Carniel A, da Conceição Gomes A, Coelho MAZ, de Castro AM (2021) Process strategies to improve biocatalytic depolymerization of post-consumer PET packages in bioreactors, and investigation on consumables cost reduction. Bioprocess Biosyst Eng 44:507-516. https://doi.org/10.1007/s00449-020-02461-y

203. Barth $M$, Honak $A$, Oeser $T$, Wei R, Belisário-Ferrari MR, Then J, Schmidt J, Zimmermann W (2016) A dual enzyme system composed of a polyester hydrolase and a carboxylesterase enhances the biocatalytic degradation of polyethylene terephthalate films. Biotechnol J 11:1082-1087. https://doi.org/10. 1002/biot.201600008

204. Tournier V, Topham CM, Gilles A, David B, Folgoas C, MoyaLeclair E, Kamionka E, Desrousseaux ML, Texier H, Gavalda $S$, Cot M, Guémard E, Dalibey M, Nomme J, Cioci G, Barbe S, Chateau M, André I, Duquesne S, Marty A (2020) An engineered PET depolymerase to break down and recycle plastic bottles. Nature 580:216-219. https://doi.org/10.1038/ s41586-020-2149-4

205. de Castro AM, Carniel A (2017) A novel process for poly(ethylene terephthalate) depolymerization via enzymecatalyzed glycolysis. Biochem Eng J 124:64-68. https://doi.org/ 10.1016/j.bej.2017.04.011

206. Palme A, Peterson A, de la Motte $H$, Theliander $H$, Brelid H (2017) Development of an efficient route for combined recycling of PET and cotton from mixed fabrics. Text Cloth Sustain 3:4. https://doi.org/10.1186/s40689-017-0026-9

207. Koshti R, Mehta L, Samarth N (2018) Biological recycling of polyethylene terephthalate: a mini-review. J Polym Environ. https://doi.org/10.1007/s10924-018-1214-7

208. Herrero Acero E, Ribitsch D, Steinkellner G, Gruber K, Greimel K, Eiteljoerg I, Trotscha E, Wei R, Zimmermann W, Zinn M, CavacoPaulo A, Freddi G, Schwab H, Guebitz G (2011) Enzymatic surface hydrolysis of PET: effect of structural diversity on kinetic properties of cutinases from Thermobifida. Macromolecules 44:4632-4640. https://doi.org/10.1021/ma200949p

209. Wei R, Oeser T, Barth $M$, Weigl N, Lübs $A$, Schulz-Siegmund $M$, Hacker MC, Zimmermann W (2014) Turbidimetric analysis of the enzymatic hydrolysis of polyethylene terephthalate nanoparticles. J Mol Catal B Enzym 103:72-78. https://doi.org/10. 1016/j.molcatb.2013.08.010

210. Ronkvist ÅM, Xie W, Lu W, Gross RA (2009) Cutinase-Catalyzed hydrolysis of poly(ethylene terephthalate). Macromolecules 42:5128-5138. https://doi.org/10.1021/ma9005318

211. Kawai F, Kawabata T, Oda M (2019) Current knowledge on enzymatic PET degradation and its possible application to waste stream management and other fields. Appl Microbiol Biotechnol 103:4253-4268. https://doi.org/10.1007/ s00253-019-09717-y

212. Austin HP, Allen MD, Donohoe BS, Rorrer NA, Kearns FL, Silveira RL, Pollard BC, Dominick G, Duman R, El OK, Mykhaylyk V, Wagner A, Michener WE, Amore A, Skaf MS, Crowley MF, Thorne AW, Johnson CW, Lee Woodcock H, McGeehan JE, Beckham GT (2018) Characterization and engineering of a plastic-degrading aromatic polyesterase. Proc Natl Acad Sci U S A 115:E4350E4357. https://doi.org/10.1073/pnas.1718804115
213. Bååth JA, Borch $K$, Jensen $K$, Brask J, Westh $P$ (2021) Comparative Biochemistry of Four Polyester (PET) Hydrolases. ChemBioChem 22:1627-1637. https://doi.org/10.1002/cbic.202000793

214. Shirke AN, White $C$, Englaender JA, Zwarycz A, Butterfoss GL, Linhardt RJ, Gross RA (2018) Stabilizing Leaf and Branch Compost Cutinase (LCC) with Glycosylation: mechanism and Effect on PET Hydrolysis. Biochemistry 57:1190-1200. https://doi.org/ 10.1021/acs.biochem.7b01189

215. Yeh Al, Huang YC, Chen SH (2010) Effect of particle size on the rate of enzymatic hydrolysis of cellulose. Carbohydr Polym 79:192-199. https://doi.org/10.1016/j.carbpol.2009.07.049

216. Gaikwad A (2019) Effect of particle size on the kinetics of enzymatic hydrolysis of microcrystalline cotton cellulose: a modeling and simulation study. Appl Biochem Biotechnol 187:800-816. https://doi.org/10.1007/s12010-018-2856-6

217. Kuo C-H, Lin $P-J$, Wu Y-Q, Ye L-Y, Yang D-J, Shieh C-J, Lee C-K (2014) Simultaneous Saccharification and Fermentation of Waste Textiles for Ethanol Production. BioResources 9:28662875. https://doi.org/10.15376/biores.9.2.2866-2875

218. Hsieh CWC, Cannella D, Jørgensen H, Felby C, Thygesen LG (2014) Cellulase inhibition by high concentrations of monosaccharides. J Agric Food Chem 62:3800-3805. https://doi.org/ 10.1021/jf5012962

219. Teugjas $H$, Väljamäe $P$ (2013) Product inhibition of cellulases studied with ${ }^{14} \mathrm{C}$-labeled cellulose substrates. Biotechnol Biofuels 6:1-14. https://doi.org/10.1186/1754-6834-6-104

220. Tiso T, Narancic T, Wei R, Pollet E, Beagan N, Schröder K, Honak A, Jiang $M$, Kenny ST, Wierckx N, Perrin R, Avérous L, Zimmermann W, O'Connor K, Blank LM (2021) Towards bio-upcycling of polyethylene terephthalate. Metab Eng 66:167-178. https:// doi.org/10.1016/j.ymben.2021.03.011

221. Ferris A, McIntosh A, Rao S, Usher Jr. RA (2019) Biodegradable Textiles, Masterbatches, and Method of Making Biodegradable Fibers. AU 2019203686 B2. Aust. Pat. Off.

222. Intrinsic Advanced Materials LLC (2020) The Technology - CiCLO Additive Textile Technology. https://www.ciclotextiles.com/ ciclo-technology1. Accessed $10 \mathrm{Jul} 2020$

223. Zheng M, Zhang T, Pang J, Sun R, Wang A, Wang X (2016) Synthesis of ethylene glycol and terephthalic acid from biomass for producing PET. Green Chem 18:342-359. https://doi.org/ 10.1039/c5gc01771h

224. Kurian JV (2005) A new polymer platform for the future Sorona ${ }^{\circledast}$ from corn derived 1,3-propanediol. J Polym Environ 13:159-167. https://doi.org/10.1007/s10924-005-2947-7

225. Shah AA, Kato S, Shintani N, Kamini NR, Nakajima-Kambe T (2014) Microbial degradation of aliphatic and aliphatic-aromatic co-polyesters. Appl Microbiol Biotechnol 98:3437-3447. https://doi.org/10.1007/s00253-014-5558-1

226. Jacquel N, Saint-Loup R, Pascault JP, Rousseau A, Fenouillot F (2015) Bio-based alternatives in the synthesis of aliphatic-aromatic polyesters dedicated to biodegradable film applications. Polymer (Guildf) 59:234-242. https://doi.org/10.1016/j.polym er.2014.12.021

227. Mascal M (2019) 5-(Chloromethyl)furfural (CMF): a platform for transforming cellulose into commercial products. ACS Sustain Chem Eng 7:5588-5601. https://doi.org/10.1021/acssuschem eng.8b06553

228. Masuno MN, Smith PB, Hucul DA, Brune K, Smith RL, Bissell JAl, Hirsch-Weil D, Stark EJ (2018) Methods of producing paraxylene and terephthalic acid US 10,125,060

229. Yu HY, Qin ZY, Liu L, Yang XG, Zhou Y, Yao JM (2013) Comparison of the reinforcing effects for cellulose nanocrystals obtained by sulfuric and hydrochloric acid hydrolysis on the mechanical and thermal properties of bacterial polyester. Compos Sci Technol 87:22-28. https://doi.org/10.1016/j.compscitech.2013. 07.024 
230. Jia Z, Wang J, Sun L, Zhu J, Liu X (2018) Fully bio-based polyesters derived from 2,5-furandicarboxylic acid (2,5-FDCA) and dodecanedioic acid (DDCA): from semicrystalline thermoplastic to amorphous elastomer. J Appl Polym Sci 135:1-11. https:// doi.org/10.1002/app.46076

231. Burgess SK, Leisen JE, Kraftschik BE, Mubarak CR, Kriegel RM, Koros WJ (2014) Chain mobility, thermal, and mechanical properties of poly(ethylene furanoate) compared to poly(ethylene terephthalate). Macromolecules 47:1383-1391. https://doi.org/ 10.1021/ma5000199

232. Weinberger S, Canadell J, Quartinello F, Yeniad B, Arias A, Pellis A, Guebitz GM (2017) Enzymatic degradation of poly(Ethylene 2,5-furanoate) powders and amorphous films. Catalysts 7:1-12. https://doi.org/10.3390/catal7110318

233. Araújo RS, Ferreira LC, Rezende CC, Marques MFV, Errico ME, Avolio R, Avella M, Gentile G, Russo P (2018) Poly(lactic acid)/ cellulose composites obtained from modified cotton fibers by successive acid hydrolysis. J Polym Environ 26:3149-3158. https://doi.org/10.1007/s10924-018-1198-3

234. Perin D, Rigotti D, Fredi G, Papageorgiou GZ, Bikiaris DN, Dorigato A (2021) Innovative bio-based poly(lactic acid)/ poly(alkylene furanoate)s fiber blends for sustainable textile applications. J Polym Environ. https://doi.org/10.1007/ s10924-021-02161-y

235. Eichelter J, Wilhelm H, Mautner A, Fahrngruber B, Schafler E, Eder A, Kozich M, Bismarck A (2021) High-velocity stretching of renewable polymer blends. J Polym Environ. https://doi.org/ 10.1007/s10924-021-02072-y

236. Arcidiacono S, Mello CM, Butler M, Welsh E, Soares JW, Allen A, Ziegler D, Laue T, Chase $S$ (2002) Aqueous processing and fiber spinning of recombinant spider silks. Macromolecules 35:1262-1266. https://doi.org/10.1021/ma011471o

237. Cottet C, Ramirez-Tapias YA, Delgado JF, la Osa O, De SAG, Peltzer MA (2020) Biobased materials from microbial biomass and its derivatives. Mater (Basel) 13:1-26. https://doi.org/10.3390/ ma13061263

238. Graupner N, Albrecht K, Hegemann D, Müssig J (2013) Plasma modification of man-made cellulose fibers (Lyocell) for improved fiber/matrix adhesion in poly(lactic acid) composites. J Appl Polym Sci 128:4378-4386. https://doi.org/10.1002/app. 38663

239. Nzila A, Razzak SA, Zhu J (2016) Bioaugmentation: An emerging strategy of industrial wastewater treatment for reuse and discharge. Int J Environ Res Public Health. https://doi.org/10. 3390/ijerph13090846

240. Thompson AA, Samuelson MB, Kadoma I, Soto-Cantu E, Drijber $\mathrm{R}$, Wortman SE (2019) Degradation rate of bio-based agricultural mulch is influenced by mulch composition and biostimulant application. J Polym Environ 27:498-509. https://doi.org/ 10.1007/s10924-019-01371-9

241. Cui Y, Chen Y, Liu X, Dong S, Tian Y, Qiao Y, Mitra R, Han J, Li C, Han X, Liu W, Chen Q, Wei W, Wang X, Du W, Tang S, Xiang H, Liu $\mathrm{H}$, Liang Y, Houk KN, Wu B (2021) Computational redesign of a PETase for plastic biodegradation under ambient condition by the GRAPE strategy. ACS Catal 11:1340-1350. https://doi.org/ 10.1021/acscatal.0c05126

242. Kitadokoro K, Kakara M, Matsui S, Osokoshi R, Thumarat U, Kawai F, Kamitani S (2019) Structural insights into the unique polylactate-degrading mechanism of Thermobifida alba cutinase. FEBS J 286:2087-2098. https://doi.org/10.1111/febs. 14781

243. Taniguchi I, Yoshida S, Hiraga K, Miyamoto K, Kimura Y, Oda K (2019) Biodegradation of PET: current Status and Application Aspects. ACS Catal 9:4089-4105. https://doi.org/10.1021/acsca tal.8b05171
244. Dai L, Qu Y, Huang J-W, Hu Y, Hu H, Li S, Chen C-C, Guo R-T (2021) Enhancing PET hydrolytic enzyme activity by fusion of the cellulose-binding domain of cellobiohydrolase I from Trichoderma reesei. J Biotechnol 334:47-50. https://doi.org/ 10.1016/j.jbiotec.2021.05.006

245. Yan Z-F, Wang L, Xia W, Liu Z-Z, Gu L-T, Wu J (2021) Synergistic biodegradation of poly(ethylene terephthalate) using Microbacterium oleivorans and Thermobifida fusca cutinase. Appl Microbiol Biotechnol 105:4551-4560. https://doi.org/10.1007/ s00253-020-11067-z

246. Moeis MR, Maulana MF (2021) Improving plastic degradation by increasing the thermostability of a whole cell biocatalyst with LC-cutinase activity. In: Journal of Physics: Conference Series. IOP Publishing, p 12029

247. Yan F, Wei R, Cui Q, Bornscheuer UT, Liu YJ (2021) Thermophilic whole-cell degradation of polyethylene terephthalate using engineered Clostridium thermocellum. Microb Biotechnol 14:374-385. https://doi.org/10.1111/1751-7915.13580

248. Quartinello F, Vajnhandl S, Volmajer Valh J, Farmer TJ, Vončina B, Lobnik A, Herrero Acero E, Pellis A, Guebitz GM (2017) Synergistic chemo-enzymatic hydrolysis of poly(ethylene terephthalate) from textile waste. Microb Biotechnol 10:1376-1383. https://doi.org/10.1111/1751-7915.12734

249. Li Y, Xi D (2007) Quantitative structure-activity relationship study on the biodegradation of acid dyestuffs. J Environ Sci 19:800-804. https://doi.org/10.1016/S1001-0742(07)60134-X

250. Deraniyagala H (2017) Textile colour waste and sustainability. In: Best J (ed) Colour design: Theories and applications: Second Edition. Elsevier Inc., pp 653-669

251. Wedin $H$, Niit $E$, Mansoor ZA, Kristinsdottir AR, de la Motte $H_{\text {, }}$ Jönsson C, Östlund $\AA$, Lindgren C (2018) Preparation of viscose fibres stripped of reactive dyes and wrinkle-free crosslinked cotton textile finish. J Polym Environ 26:3603-3612. https:// doi.org/10.1007/s10924-018-1239-y

252. Sanders D, Grunden A, Dunn RR (2021) A review of clothing microbiology: the history of clothing and the role of microbes in textiles: a review of clothing microbiology. Biol Lett. https:// doi.org/10.1098/rsbl.2020.0700rsbl20200700

253. Quartinello F, Vecchiato S, Weinberger S, Kremenser K, Skopek L, Pellis A, Guebitz GM (2018) Highly selective enzymatic recovery of building blocks from wool-cotton-polyester textile waste blends. Polymers (Basel). https://doi.org/10.3390/polym10101 107

254. Navone L, Moffitt K, Hansen KA, Blinco J, Payne A, Speight R (2020) Closing the textile loop: enzymatic fibre separation and recycling of wool/polyester fabric blends. Waste Manag 102:149-160. https://doi.org/10.1016/j.wasman.2019.10.026

255. Nagai K, lida K, Shimizu K, Kinugasa R, Izumi M, Kato DI, Takeo M, Mochiji K, Negoro S (2014) Enzymatic hydrolysis of nylons: quantification of the reaction rate of nylon hydrolase for thinlayered nylons. Appl Microbiol Biotechnol 98:8751-8761. https://doi.org/10.1007/s00253-014-5885-2

256. Gashti MP, Assefipour R, Kiumarsi A, Gashti MP (2013) Enzymatic surface hydrolysis of polyamide 6,6 with mixtures of proteolytic and lipolytic enzymes. Prep Biochem Biotechnol 43:798-814. https://doi.org/10.1080/10826068.2013.805623

257. Biundo A, Hromic A, Pavkov-Keller T, Gruber K, Quartinello F, Haernvall K, Perz V, Arrell MS, Zinn M, Ribitsch D, Guebitz GM (2016) Characterization of a poly(butylene adipate-coterephthalate)-hydrolyzing lipase from Pelosinus fermentans. Appl Microbiol Biotechnol 100:1753-1764. https://doi.org/10. 1007/s00253-015-7031-1

258. Mao H, Liu H, Gao Z, Su T, Wang Z (2015) Biodegradation of poly(butylene succinate) by Fusarium sp. FS1301 and purification and characterization of poly(butylene succinate) 
depolymerase. Polym Degrad Stab 114:1-7. https://doi.org/ 10.1016/j.polymdegradstab.2015.01.025

259. Shirahama H, Mizuma K, Umemoto K, Yasuda H (2001) Synthesis of poly(lactide-ran-MOHEL) and its biodegradation with proteinase K. J Polym Sci Part A Polym Chem 39:1374-1381. https://doi.org/10.1002/pola.1114

260. Richert A, Olewnik-Kruszkowska E, Adamska E, Tarach I (2019) Enzymatic degradation of bacteriostatic polylactide composites. Int Biodeterior Biodegrad 142:103-108. https://doi.org/10. 1016/j.ibiod.2019.04.010

261. Sawada K, Urakawa H, Ueda M (2007) Modification of polylactic acid fiber with enzymatic treatment. Text Res J 77:901-905. https://doi.org/10.1177/0040517507082331

262. Baker PJ, Poultney C, Liu Z, Gross R, Montclare JK (2012) Identification and comparison of cutinases for synthetic polyester degradation. Appl Microbiol Biotechnol 93:229-240. https:// doi.org/10.1007/s00253-011-3402-4

263. Kolstad JJ, Vink ETH, De Wilde B, Debeer L (2012) Assessment of anaerobic degradation of Ingeo ${ }^{\mathrm{TM}}$ polylactides under accelerated landfill conditions. Polym Degrad Stab 97:1131-1141. https://doi.org/10.1016/j.polymdegradstab.2012.04.003

264. Rom M, Fabia J, Grübel K, Sarna E, Graczyk T (2017) Study of the biodegradability of polylactide fibers in wastewater treatment processes. Polimery 62:834-840

265. Simoes CL, Viana JC, Cunha AM (2009) Mechanical Properties of poly(e-caprolactone) and Poly(lactic acid) Blends. J Appl Polym Sci 112:345-352. https://doi.org/10.1002/app

266. Liu Y, Zhan Z, Ye H, Lin X (2019) Accelerated biodegradation of PLA / PHB-blended nonwovens by a microbial community. RSC Adv 9:10386-10394. https://doi.org/10.1039/c8ra10591j

267. Chen Z, Zhao Z, Hong J, Pan Z (2020) Novel bioresourcebased poly(3-Hydroxybutyrate-co-4-Hydroxybutyrate)/ poly(LacticAcid) blend fibers with high strength and toughness via melt-spinning. J Appl Polym Sci 137:17-20. https://doi.org/ 10.1002/app.48956
268. Ohkawa K, Kim H, Lee K (2004) Biodegradation of electrospun poly-(E-caprolactone) non-woven fabrics by pure-cultured soil filamentous fungi. J Polym Environ 12:211-218. https://doi.org/ 10.1007/s10924-004-8148-y

269. Muthuraj R, Misra M, Mohanty AK (2015) Hydrolytic degradation of biodegradable polyesters under simulated environmental conditions. J Appl Polym Sci 132:1-13. https://doi.org/10. 1002/app.42189

270. Morohoshi T, Ogata K, Okura T, Sato S (2018) Molecular characterization of the bacterial community in biofilms for degradation of poly(3-hydroxybutyrate-co-3-hydroxyhexanoate) films in seawater. Microbes Environ 33:19-25. https://doi.org/ 10.1264/jsme2.ME17052

271. Vecchiato S, Skopek L, Jankova S, Pellis A, Ipsmiller W, Aldrian A, Mueller B, Herrero Acero E, Guebitz GM (2018) Enzymatic recycling of high-value phosphor flame-retardant pigment and glucose from rayon fibers. ACS Sustain Chem Eng 6:2386-2394. https://doi.org/10.1021/acssuschemeng.7b03840

272. Gaikwad A, Chakraborty S (2013) Mixing effects on the kinetics of enzymatic hydrolysis of Avicel for batch production of cellulosic ethanol. Ind Eng Chem Res 52:3988-3999. https://doi. org/10.1021/ie301234b

273. Gholamzad E, Karimi K, Masoomi M (2014) Effective conversion of waste polyester-cotton textile to ethanol and recovery of polyester by alkaline pretreatment. Chem Eng J 253:40-45. https://doi.org/10.1016/j.cej.2014.04.109

274. Gusakov AV, Salanovich TN, Antonov Al, Ustinov BB, Okunev ON, Burlingame R, Emalfarb M, Baez M, Sinitsyn AP (2007) Design of highly efficient cellulase mixtures for enzymatic hydrolysis of cellulose. Biotechnol Bioeng 97:1028-1038. https://doi.org/10.1002/bit.21329

Publisher's Note Springer Nature remains neutral with regard to jurisdictional claims in published maps and institutional affiliations. 